\title{
DYNAMICS OF THE JAROSITE COINVERSION PROCESS
}

\author{
A THESIS \\ by \\ GILLIAN L. HOLCROFT \\ Department of Chemical Engineering \\ McGill University, Montréal
}

March 1994

A Thesis submitted to the Faculty of Graduate Studies and Research in partial fulfilment of the requirements of the degree of Master of Engineering

(c) Gillian Holcroft 1994 


\section{Abstract}

Canadian Electrolytic Zınc in Valleyfield, Québec utilizes the conventional RoastLeach-Electrowin process to produce zinc metal. Iron removal is carried out in the jarosite conversion circuit which consists of ten continuous stirred tank reactors in series.

In this study, the first five tanks of the jarosite conversion circuit were piloted and process identification experiments were carried out. Step changes in the flows of the raw acid, spent acid, jarosite slurry and zinc ferrite slurry streams were performed. The goal of these experiments was to collect transient response data which could be used to validate a dynamic conversion circuit model. The process was found to be most sensitive to changes in the flow of the raw acid stream.

The zinc ferrite dissolution rate constant calculated from the experimental data agrees with literature values. Using a jarosite precipitation rate expression from the literature, it was found that jarosite precipitation is negligible in the first reactor but cannot be ignored in the second tank.

The dynamic model provides a good representation of the first two tanks of the jarosite conversion circuit and can be used for both process control and optimization studies on a full-scale facility. 


\section{Résumé}

Zinc Électrolytique du Canada (Valleyfield, Québec) utilise le procédé conventionnel: Grillage-Lixiviation-Électrolyse pour produire du zinc. L'enlèvement de fer dans le circuit de conversion avec jarosite est effectué dans un régime de dix réservoirs continus agités en série.

Dans cette étude, les cinq premiers réservoirs du circuit de conversion avec jarosite ont été étudiés à l'échelle pılote et des expériences permettant l'identification des paramètres du procédé onl été effectuées. Des changements de type échelon ont été appliqués sur les débits de: acide brut, éléctrolyte, pulpe de jarosite, et pulpe des farrites de zinc. Ces expériences avaient pour but d'obtenir cles données en régime transitoire et ensulie de permettre la validation d'un modèle dynamıque du circuit de conversion. Les changements de débit sur le courant d'acide brut ont eu le plus grand effet sur le procédé.

Le taux de dissolution de la ferrite de zinc calculé à partir des données expérimentales est en accord avec les données disponibles dans la littérature. L'utilisation d'un taux de précipitation de la jarosite tiré de la littérature a permis de montrer que la précipitation de la jarosite est négligeable dans le premier réservoir mais significative dans le second.

Le modèle dynamique obtenu a permis d'obtenir une indication fiable du comportement des deux premiers réservoirs du circuit de conversion avec jarosite. Ce modèle sera utilisé pour étudier les stratégies de contrôle et d'optimisation du procédé existant. 


\section{Acknowledgements}

I would like to thank the Noranda Technology Centre for supporting this work, and more specifically Lucy Rosato for her technical guidance throughout this project and for helping put together its original concept. Without her ability for making people challenge themselves, this project would never have been initiated. I would also like to thank Robert Stanley who authorized Noranda's support for this study.

This work was performed with the financial assistance received from an NSERC scholarship for employed scientists and engineers.

Invaluable guidance was received from my supervisor Dr. Dimitrios Berk, especially with the detailed chemical reaction engineering aspects of this work. Dr. Michel Perrier, who co-supervised this thesis, provided direction during the project's conception and with the process control portion of this study.

I was fortunate to get assistance with the pilot experiments from a very bright and energetic student from Sherbrooke University, Chantal Goyette. The large amount of data that was generated after each experiment was put into an understandable format and plotted with the help of my sister, Carolyn, and I thank her very much.

Finally, I would like to thanh my husband, Paul for his continual support as well as the rest of my family for their understanding during my studies. 


\section{Table of Contents}

Page

\section{Chapter 1 General Introduction}

1.1 Jarosite Conversion Process $\ldots \ldots \ldots \ldots \ldots \ldots \ldots \ldots \ldots 1$

1.2 Canadian Electrolytic Zinc's Conversion Process . . . . . . . . 3

1.3 Process Control Modelling Approaches . . . . . . . . . . . . . 5

1.4 Thesis Objectives $\ldots \ldots \ldots \ldots \ldots \ldots \ldots \ldots \ldots \ldots$

1.5 Thesis Outıne . . . . . . . . . . . . . . . . 7

\section{Chapter 2 Literature Review}

2.1 Process Control \& Automation of a Zinc Leaching Circuit ..... 9

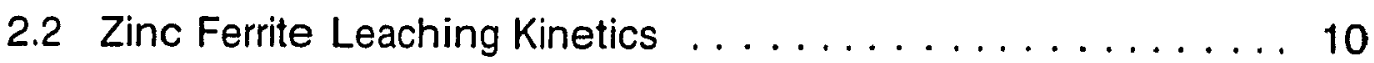

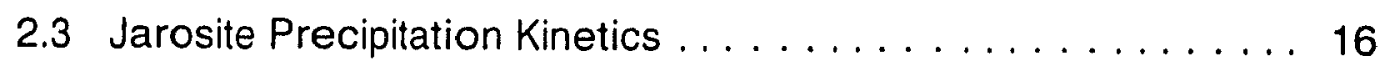

\section{Chapter 3 Experimental Methods}

3.1 Overview ........................ 21

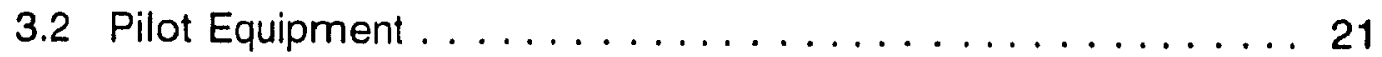

3.3 Operating Procedure $\ldots \ldots \ldots \ldots \ldots \ldots \ldots \ldots \ldots \ldots$

3.4 Error Analysis . . . . . . . . . . . . . . . . . . . . 33

\section{Chapter 4 Experimental Results}

4.1 Parameters Investigated $\ldots \ldots \ldots \ldots \ldots \ldots \ldots$

4.2 Mass Ealances for First Reactor . . . . . . . . . . . . . . 42

4.3 Statistical Analysis . . . . . . . . . . . . . . . . . . . 51

4.4 Determination of Rate Constant . . . . . . . . . . . . . . 55

4.5 Process Identification from Step Responses . . . . . . . . 57

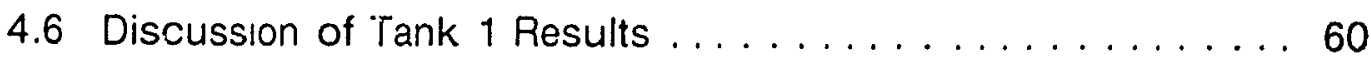


Chapter 5 Dynamic Model

5.1 Determinıstic Dynamic Model . . . . . . . . . . . . . . . 62

5.1 .1 Incorporation of the Rate Equations . . . . . . . 65

5.1.2 Tank 1 Transient Model ................ 67

5.2 Process Simulation Results

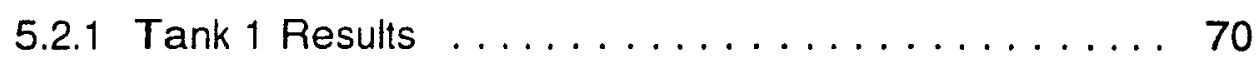

5.2.2 Tank 1 Jarosite Rate Constant Stability . . . . . . . 76

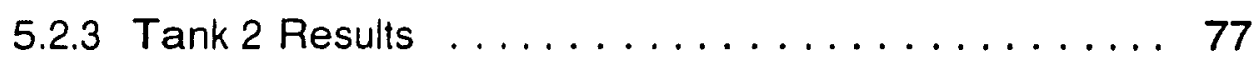

5.4 Process Control Strategy $\ldots \ldots \ldots \ldots \ldots \ldots \ldots \ldots \ldots . \ldots 2$

\section{Chapter 6 Conclusion}

6.1 Conclusion ....................... 84

6.2 Proposal for Future Studies $\ldots \ldots \ldots \ldots \ldots \ldots \ldots \ldots .65$

Chapter $7 \quad$ References $\ldots \ldots \ldots \ldots \ldots \ldots \ldots \ldots$ 


\title{
Appendices
}

\author{
APPENDIX I Nomenclature \\ APPENDIX II Calibration Curves for Rotameters \\ APPENDIX III Tank Characterisatıon and Tracer Selection Study \\ APPENDIX IV Zinc Ferrite and Jarosite Solids \\ APPENDIX V Acid Titration Method \\ APPENDIX VI Test for Comparing the Means of Two Variables \\ APPENDIX VII Calculation of the lonic Strength in Tank 1 \\ APPENDIX VIII TANK 1 Assays: Tests B,C,D and E
}




\title{
List of Figures
}

\author{
Chapter 1
}

Figure 1-1 R.L.E. Process

Figure 1-2 CEZınc Zinc Refinıng Process

Figure 1-3 CEZinc Leaching Crrcuit

\section{Chapter 3}

Figure 3-1 Actual Jarosite Pilot Circuit

Figure 3-2 Actual Jarosite Pllot Circuit: View of First Tank

Figure 3-3 Pilot Scale Jarosite Circuit

Figure 3-4 Reactor Construction

Figure 3-5 Pilot Plant Instrumentation

\section{Chapter 4}

Figure 4-1 Grouping of Data Into Process States

Figure 4-2 Jarosite Tank 1

Figure 4-3 Process Gaın and Tıme Constant Estimation

\section{Chapter 5}

Figure 5-1 Jarosite Tank 1

Figure 5-2 TEST B Sulphuric Acid Concentration Changes

Figure 5-3 TEST D Sulphuric Acid Concentration Changes

Figure 5-4 TEST E Sulphuric Acid Concentration Changes

Figure 5-5 TEST B Ferric Iron Concentration Changes

Figure 5-6 TEST C Ferric Iron Concentration Changes

Figure 5-7 TEST D Zinc Concentration Changes

Figure 5-8 TEST B Mass Fraction of ZInc in Solids Changes

Figure 5-9 TEST C Mass Fraction of Zinc in Solids Changes 


$$
\text { Chapter } 5 \text { (continued) }
$$

Figure 5-10

Figure 5-11

Figure 5-12

Figure 5-13

Figure 5-14

Figure 5-15

Figure 5-16

Figure 5-17

Figure 5-18

Figure 5-19

Figure 5-20
TEST D Miass Fraction of Zinc in Solids Changes TEST 5: Mass Fraction of Zinc in Solids Changes TEST E Effect of Jarosite Precipitation TEST B Tank 2: Sulphuric Acid Concentration Changes TEST D Tank 2: Sulphuric Acid Coricentration Changes TEST B Tank 2. Ferric Iron Concentration Changes TEST C Tank 2. Ferric Iron Concentration Changes TEST D Tank 2: Zinc Concentration Changes TEST C Tank 2: Mass Fraction of Zinc in Solids Changes TEST D Tank 2: Mass Fraction of Zinc in Solids Changes TESTE Tank 2: Mass Fraction of Zinc in Solids Changes

\section{Chapter 6}

Figure 6-1 Possible Controi Strategy 


\section{List of Tables}

Chapter 3

Table III-1

Table III-2

Table III-3

Table III-4

Table III-5

Table IV-1

Table IV-2

Table IV-3

Table IV-4

Table IV-5

Table IV-6a

Table IV-6b

Table IV-7a

Table IV-7b

Table IV-8a

Table IV-8b

Table IV-9

Table IV-10
Feed Stream Flows

Comparison of Industrial and Elemental Solid Compositions Feed Solution Compositions and Densities

Error in 1.C.P. Analysis

Error in Flow Measurements

\section{Chapter 4}

Step Change Flows

TEST B - Tank 1: Exit Flow

TEST B - Tank 1: Acid Consumption

TEST B - Tank 1: Zinc Mass Balance

Tank 1: Acid Consumed and Solids Leached

Tank 1: Mass Balances for Zinc, Iron, and Lead

Tank 2: Mass Balances for Zinc, Iron, and Lead

Comparison of Initial and Step Change Steady State Acid Concentrations for Tank 1

Comparison of Initial and Step Change Steady State Iron Concentrations for Tank 1

Comparison of Initial and Step Change Steady State Iron in Solids for Tank 1

Comparison of Initial and Step Change Steady State Zinc in Solids for Tank 1

Reaction Extents and Rate Constants

Process Gains and Time Constants 


\section{Chapter 1}

\section{INTRODUCTION}

\subsection{Jarosite Conversion Process}

Over $75 \%$ of commercial zinc is produced via the Roast-Leach-Electrowin (R.L.E.) process. The general flow-sheet of this process is shown in Figure 1-1. In the roasting section of this process, the concentrate, which is composed of zinc and iron sulfides, is oxidized at $930^{\circ} \mathrm{C}$ to produce a calcine of mainly zinc oxides $(\mathrm{ZnO})$ and zinc ferrites $\left(\mathrm{ZnO} . \mathrm{Fe}_{2} \mathrm{O}_{3}\right)$. Spent electrolyte, which is high in sulphuric acid, leaches the calcine under atmospheric conditions to produce a zinc sulphate solution. This solution is then electrowinned in the cell-house to produce pure zinc cathodes. The differences amongst R.L.E. plants lies mainly in the method used to remove iron from the zinc sulphate leach solutions. Iron removal is an essential step in electrowinning flow-sheets since iron interferes with the purification process and causes problems with the electro-deposition of zinc in the cell house.

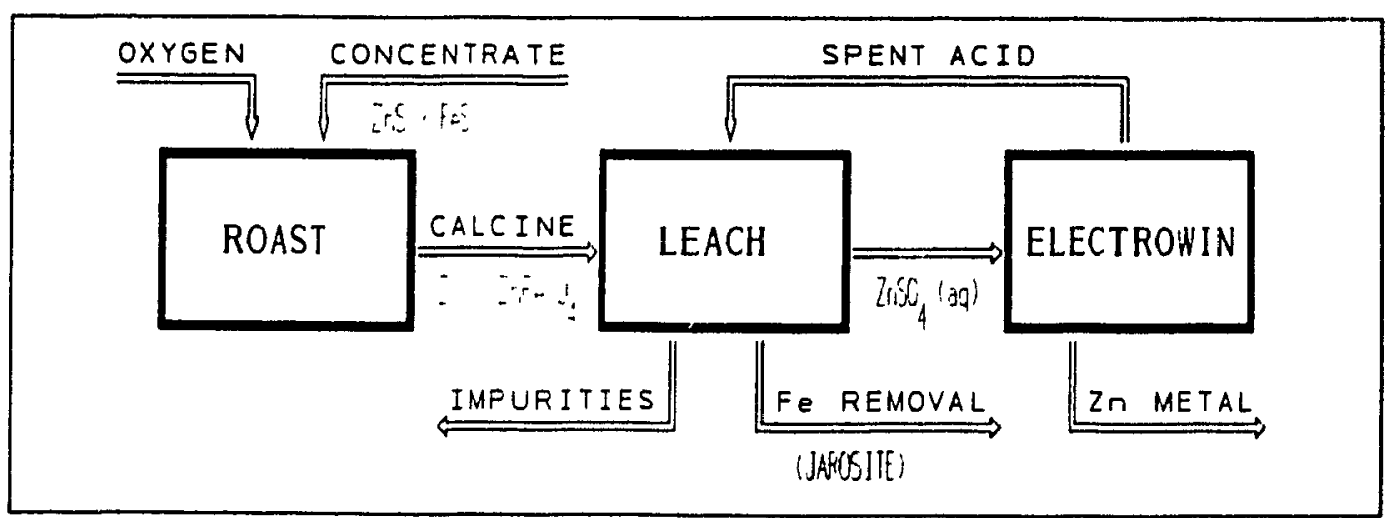

Figure 1-1 R.L.E. Process

The majority of zinc concentrates contain approximately $50 \%$ zinc and between $5 \%$ to $12 \%$ iron, in which a large portion of the iron is converted to zinc ferrite in the roaster. The three main methods of iron removal are named after the mineral that they generate, namely the Hematite, Goethiie and the Jarosite process. 
The Jarosite process was developed independently in Europe and Australia in the '60's. The advent of this process, which has many variations (eg. pre neutralization, multistage leaching...), resulted in the ability to separate readily the dissolved iron from the zinc solution. Normally the temperature is maintained between 95 to $100^{\circ} \mathrm{C}$, a source of alkali is added, and jarosite seed is recycled to provide nucleation sites for jarosite crystal growth. One of the drawbacks of this process stems from the nature of its relatively high temperature and corrosive operating conditions. As a result, the selection of appropriate construction materials is essential. There is also an environmental drawback of this process due to the large quantity of jarosite that must be disposed of. As an example, a typical 100000 tons per year plant will produce 40000 tons per year jarosite solids (approximately 73000 tons per year jarosite slurry) which are normally sent to tailings ponds. A study is currently under-way at the Noranda Technology Centre to examine alternative options for iron disposal.

The difference between the conventional jarosite process and the jarosite conversion process is in the addition of calcine in the former for acidity control. The conversion process results in the simultaneous hot acid leaching of zinc ferrites and in the precipitation of jarosite solids in the same process stage. This process offers significant capital cost savings but at the expense of any possible recovery of silver and lead values. This process can achieve both high overall zinc extractions and zinc recoveries. Although many electrolytic zinc plants have adopted the jarosite process, only Canadian Electrolytic Zinc (CEZinc) in Valleyfield, Québec and Outokumpu in Kokkola, Finland employ the jarosite conversion process.

According to Dutrizac (1), the major control parameters for the conversion process are acid concentration, which is the key variable, temperature, and the molar ratio of acid to iron. If the acid concentration is low, iron will readily precipitate; however, high acid concentrations are advantageous for leaching of zinc ferrites. 
Consequently, the optimization of the conversion process requires the determination of the most suitable acid level in each stage.

\subsection{Canadian Electrolytic Zinc's Conversion Process}

Tr.a CEZinc plant produces 230000 tons per year of electrowinned zinc. As seen in Figure 1-2, the plant is divided into five main areas: roasting, leaching, purification, electrolysis and casting. The jarosite conversion circuit is in the leaching section of the plant. This circuit consists of ten continuous stirred tank reactors in series as shown in Figure 1-3.

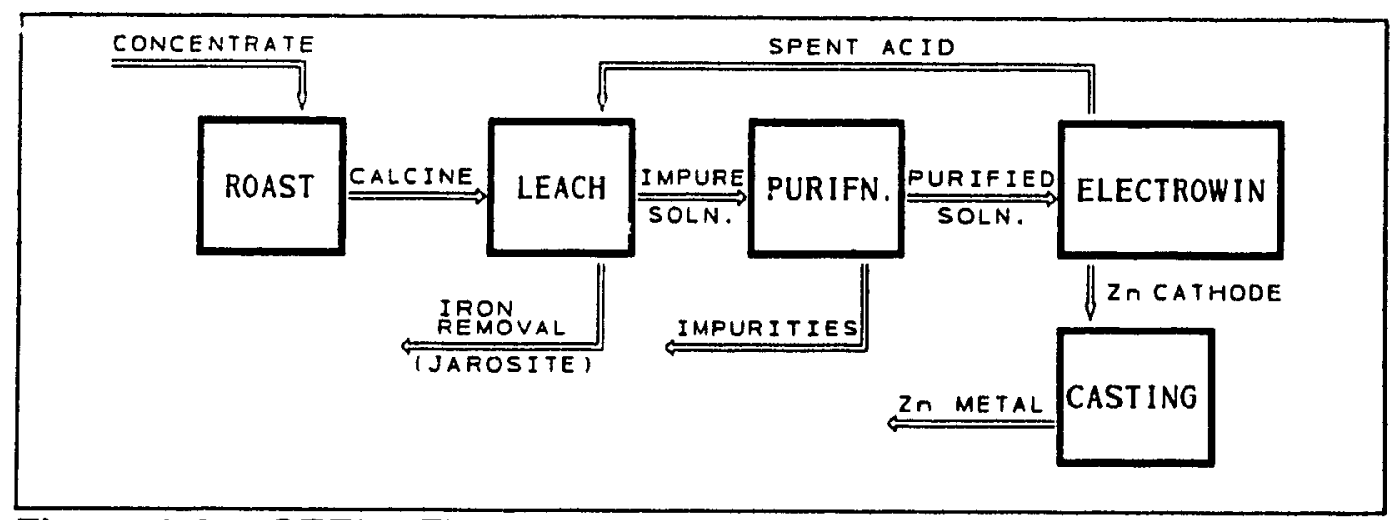

Figure 1-2 CEZinc Zinc Refining Process

The following are the two main reactions occurring in the conversion circuit:

Zinc Ferrite leaching:

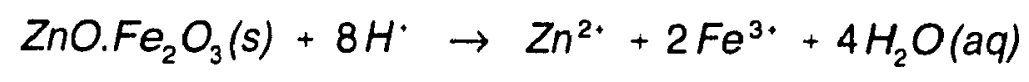

Ammonium Jarosite Precipitation:

$$
3 \mathrm{Fe}^{3 \cdot}+\mathrm{NH}_{4}+2 \mathrm{SO}_{4}^{2 \cdot}+6 \mathrm{H}_{2} \mathrm{O}(\mathrm{aq}) \rightarrow \mathrm{NH}_{4}\left[\mathrm{Fe}_{3}\left(\mathrm{SO}_{4}\right)_{2}\left(\mathrm{OH}_{6}\right](\mathrm{s})+6 \mathrm{H}^{\prime}(1\right.
$$

The purpose of the jarosite conversion circuit is to extract the zinc from the zinc ferrite solids and to dispose of the iron as insoluble ammonium jarosite. In the conversion circuit, zinc ferrites are leached with concentrated acid and spent electrolyte which bring both the iron and zinc into solution. Ammonia is added to 
the reactors, further down the train, to precipitate the soluble iron as ammonium jarosite. It is critical to control the exiting iron concentration from this circuit since high iron in solution is deleterious to other areas of the process. The principal objective of this circuit is to maximize the zinc ferrite extraction and to minimize the iron concentration in the liquid product. Figure 1-3 is a schematic diagram of the Leaching Circuit at CEZinc.

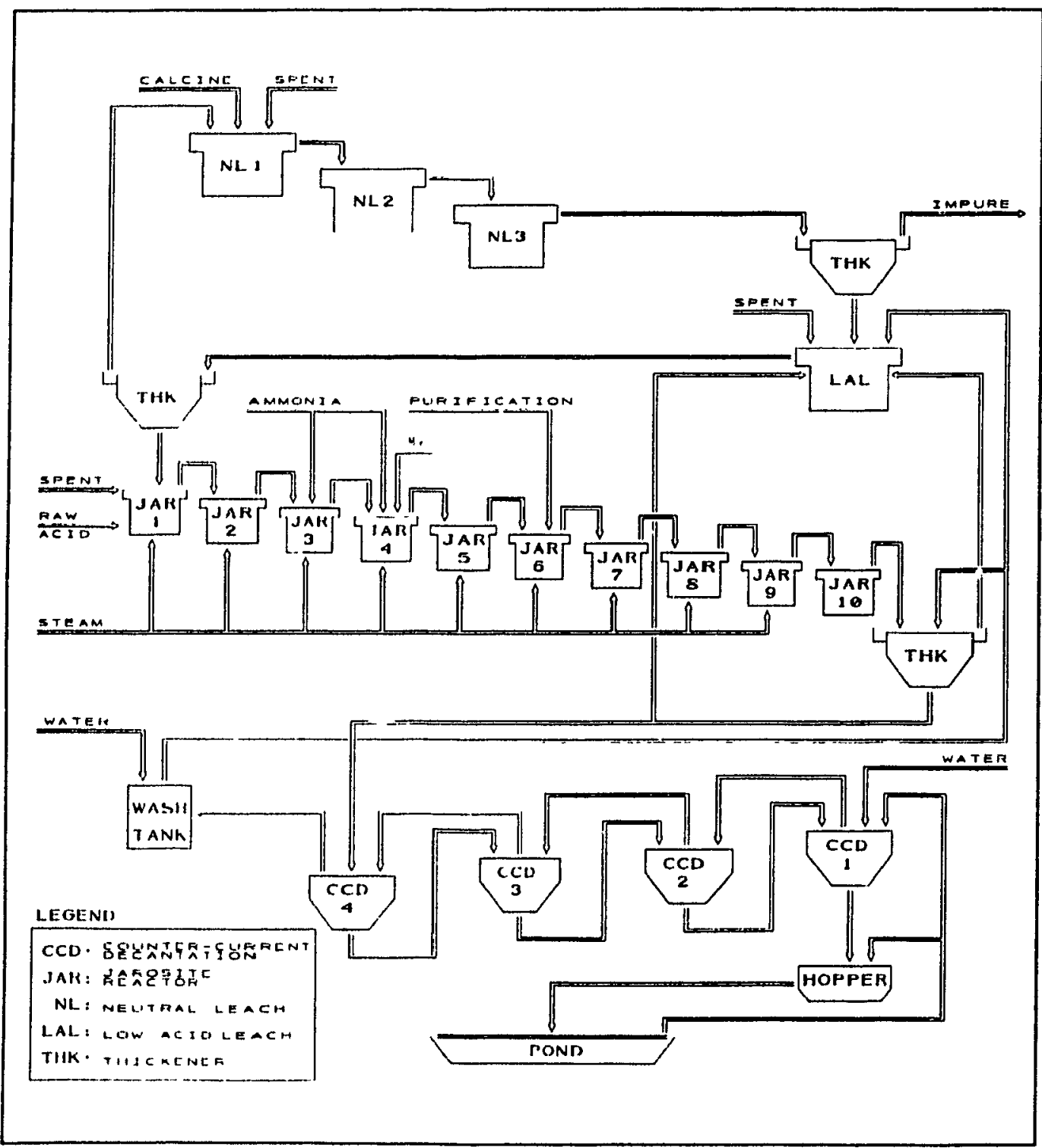

Figure 1-3 CEZınc Leaching Circuit 
In this flow-sheet calcine, which consists of zinc oxide, some zinc ferrite, and some insoluble gangue material is leached with spent electrolyte in the Neutral Leach (NL) section.

Since the conditions in the neutral leach (NL) circuit are not severe enough to leach all of the zinc oxide $\left(\mathrm{pH}=3\right.$ to $4, T=70^{\circ} \mathrm{C}$ ), the remaining zinc oxide is dissolved under slightly more acidic conditions in the Low Acid Leach (LAL) vessel. The zinc ferrites are leached in the Jarosite circuit (JAR), which follows the Low Acid Leach stage, since it is operated at much higher acidities $\left(\mathrm{pH}=1, T=98^{\circ} \mathrm{C}\right)$. The iron which also dissolves is then simultaneously precipitated and removed from the circuit in the form of ammonium jarosite solids. A four stage CCD (Counter-Current Decantation) circuit washes the jarosite residue before it is disposed of in the tailings ponds. Washing the residue helps to maximize zinc recoveries by reducing the amount of zinc lost to the ponds. The large number of recycle streams employed also helps to increase zinc recoveries.

\subsection{Process Control Modelling Approaches}

The need for improved process control can arise from a variety of sources. For example, the incentive may be either to increase production, improve process safety or to meet more stringent environmental regulations. Quite often, better control will increase profitability as well as safety since the aim of closed-loop control is to reduce process variability.

Control strategy formulation begins by defining the control objectives. In the case of the Jarosite conversion circuit, the objective is to consistently maximize zinc extractions and minimize iron in solution.

Normally, the next steps would involve the installation of the appropriate hardware such as sensors and control valves. Once the electrical connoctions of all the field instrumentation to the distributed control system (D.C.S.) has been completed, a 
trial and error or field tuning of the PI (Proportional-Integral) controller settings on the D.C.S. will commence. If this "simplified" approach is used for complex processes, such as the jarosite conversion circuit, then the closed-loop controller will most probably result in poor performance. The reduction in controller performance occurs because it was tuned under one set of operating conditions without any regard for process non-linearities. Consequently, as the controller goes from one operating point to another the tuning parameters may result in suboptimal controller performance. In the industry, it is often found that improperly tuned controllers can have a destabilizing effect on a process.

An alternative approach, once the control objective has been identified, is to develop a model for the complex processes. This model-based approached is worth the effort for a variety of reasons. For example, the process model can be used as a basis for classical controller design. If more advanced techniques are being considered, the model can be incorporated directly into the control algorithm. Finally, a process model can be part of a computer simulation for testing alternative control strategies.

Once it has been decided to pursue the development of a dynamic model, the next step involves the formation of a control strategy which will take into account all of the process constraints. Classical control strategies include feedback, feedfonward, and ratio control. More advanced techniques involve adaptive control, inferential control, model predictive control etc... Most advanced control techniques will initially be tested by computer simulation before the strategy is proposed to the operation. If the strategy is acceptable, the control system is installed on-site and then minor adjustments to the controller paramelers are made.

\subsection{Thesis Objectives}

The first objective of this thesis was to simulate, on a pilot scale, the operating conditions of the first five tanks of the jarosite circuit and to study the dynamic 
effects of manipulating the main feed streams. Since the analysis of the experimental results proved to be a formidable task, the scope of the thesis was limited to the study of the first jarosite tank results. The second objective was to develop a dynamic model of the first jarosite reactor.

This thesis was an applied project as opposed to a fundamental study on jarosite production. The experimental work was supported by the Noranda Technology Centre and the pilot plant experiments were carried out at their facility. Although this work involves mainly pilot scale experiments, in the future, residence time distribution tests will be carried out at the plant site and these results will be incorporated into the developed model so that it can be used as a basis for evaluating various proposed control strategies at CEZinc. The success of this study will provide the basis for closed-loop control for the plant's Jarosite circuit and will also provide insight into dynamic modelling for other zinc producers.

\subsection{Thesis Outline}

Since one of the aims of this project is to develop a tool which will eventually be used towards on-going process automation work in the zinc industry, a summary of important work to date in this area was examined in the Literature Review chapter. Through the evaluation of past studies on metallurgical process automation, much insight was gained into the problems associated with this type of work. It was found that the major obstacles which arise are due to the lack of on-line process sensors which can handle the harsh conditions in hydrometallurgical flow-sheets. The essence of this work was to develop a deterministic model of the jarosite circuit using available kinetic information. Consequently, it was important to review all of the available kinetic literature on the main reactions which are occurring in the jarosite circuit. Two sections are provided which discuss the kinetics of zinc ferrite leaching and jarosite precipitation. 
Chapter 3 begins by giving a general overview of the process identification experiments which were carried out. The pilot equipment along with the operating procedure is then discussed. The following chapter begins by giving a detailed description of the parameters which were investigated so that the reader is able to get an understanding of the purpose of each experiment. A section is devoted to the analysis of the experımental results from the first tank through mass balance calculations, statistical analyses and calculations of reaction extents, reaction rate constants and process time constants.

Chapter 5 begins with the approach taken during the development of the dynamic conversion circuit model. Following this section, the simulation results are used to compare the model's predictions with the actual experimental data from the first two reactors. This chapter closes with a discussion on the development of a process control strategy in this circuit. The final chapter provides overall conclusions from thesis work and closes with a proposal for future studies in this area. 


\section{Chapter 2}

\section{LITERATURE REVIEW}

\subsection{Process Control \& Automation of a Zinc Leaching Circuit}

Most hydrometallurgical plants lag behind other industries such as petroleum and mineral beneficiation operations in regards to the degree of process control and automation present in their circuits. Recently there has been a trend to increase automation in this industry because it has been realized that substantial operating improvements such as reduced operating costs, increased production, and higher quality control can be achieved through automation.

One of the main reasons for the delay in automation of hydrometallurgical circuits is the lack of reliable on-line sensors. The nature of most hydrometallurgical flowsheets is such that the "key" streams to be measured are usually abrasive slurries which are extremely corrosive due to the high acidities normally present. Consequently sensor development is quite a challenge.

Nevertheless there has been some work on automation in this area and new online sensors are continually being developed. CEZinc has recently installed on-line self cleaning $\mathrm{pH}$ probes in their Neutral Leaching (NL) stage which has enabled them to automatically control $\mathrm{pH}$ in these reactors. Automatic on-line acid and iron titrators are being commissioned in the Jarosite circuit (JAR) and at the exit of the Low acid Leach tank (LAL). Following the installation of these autornatic titrators, closed-loop control in this area of the plant will eventually be possible.

Work was initiated in $1987(2,3)$ to develop an expert system which would aid the operators at CEZinc to better utilize the available process information thus allowing them to make sound operating decisions. The first component of the system involved the collection of data which was to be used for the generation of concise 
reports, and for the analysis of process trends. The second component involved the collection of knowledge from the process experts which was to be used in the expert system to help guide the operators. In 1988 a major upgrade in the process control system was carried out at the plant (a Rosemount D.C.S. was installed) which resulted in a drastic change in the amount and nature of the information that was available to the developed expert system. As a consequence, the work on this expert system was interrupted (5) before it was ever tested.

\subsection{Zinc Ferrite Leaching Kinetics}

For a continuous stirred tank reactor (CSTR) with a homogeneous reaction, the following relationship expresses the change in the number of moles of component i, $N_{1}$, with time:

$$
\frac{d N_{1}}{d t}=\sum_{n=1}^{m} F_{l_{k E E U}}-\sum_{n=1}^{p} F_{l_{E \times T r}}+\sum_{J=1}^{k} v_{J J} r_{J} V
$$

where: $\quad F_{1}:$ molar flow rate of component $i$, mol/time

$v_{w}:$ stoichiometric coeff. of component $i$ in the $J^{\text {th }}$ reaction

$r_{\lrcorner}:$global rate of reaction \#J, mol/(time)(vol)

$\checkmark$ : reactor volume

For a heterogeneous reaction, such as zinc ferrite dissolution, the global rate for the reaction is a function of the bulk concentration and temperature with the reaction rate constants (of all the reactions involving species $i$ ), mass transfer coefficient, and effective diffusivity as parameters:

$$
r_{p}=f\left[\left(C_{1}\right)_{b}, T\right]
$$

where: $\quad r_{p}: \quad$ global reaction rate per particle surface area, mol/(time)(area)

$\left(C_{1}\right)_{b}$ : bulk concentration of reagent $i$ in the fluid stream, mol/vol.

Many fluid-solid non-catalytic reactions are modelled using the shrinking core 
model assumptions. This model assumes that the reaction is first order, the solid has a non-porous core and that the reaction occurs at the surface boundary. When the bulk fluid reactant concentration is assumed to remain constant in the reactor, we can develop analytical relationships between conversion and time using the shrinking core model. Using this approach, different expressions can be generated for the cases when the rate is controlled by external mass transfer, internal diffusion or by reaction kinetics. In the case of zinc ferrite dissolution, there is no solid product to provide internal diffusion resistance since the zinc sulphate product dissolves away. Consequently, the reaction cannot be controlled by internal diffusion. In the absence of external mass transfer resistances, the integrated shrinking core model is given by (4):

$$
1-\left(1-x_{B}\right)^{\frac{1}{3}}=\frac{v_{B} M_{B} k}{\rho_{B} r_{s}}\left(C_{A}\right)_{D} t
$$

where: $\quad x_{B}: \quad$ conversion of solid reactant $B$

$r_{s}: \quad$ radius of the solid particle, (length)

$\rho_{\mathrm{B}}:$ density of solid reactant, mass solid/volume

$M_{B}$ : molecular weight of solid reactant $B$

A. recent study be Elgersma (6) has shown that zinc ferrite dissolution can be represented by a modification of the surface reaction controlled shrinking core model for up to $70 \%$ conversion. In his study, he used the following equations to represent the shrinking core mode!:

$$
\begin{gathered}
1-(1-x)^{1 / 3}=K t \\
K=r_{p} \cdot \frac{S_{0}}{3}
\end{gathered}
$$

where: $\quad \mathrm{K}: \quad$ apparent rate, time ${ }^{-1}$ 
$r_{p}:$ global reaction rate per particle surface area, mass/(time)(area)

$S_{0}: \quad$ initial specific surface area of particle, erea/mass

$x$ : conversion

The apparent rate was calculated by plotting the left hand side of equation 2.4 against time giving a slope equal to " $\mathrm{K}$ ".

Upon using the above relationship for conversion and time, Elgersma showed that the global reaction rate for zinc ferrite dissolution depends on the hydrogen ion activity and the ferric ion concentration. In his thesis, however, he writes the relationship as the ratio of two activities, as shown in equation 2.6 , instead of using the iron concentration.

$$
r_{p}^{\cdot}=k \sqrt{\frac{\hat{a}_{H^{*}}}{\hat{a}_{\mathrm{Fe}^{*} \cdot}}} \quad\left(\frac{\text { mass }}{\text { lime area }}\right)
$$

where: $\quad \hat{a}_{1}$ is the activity of component $i$ in the bulk

As seen by this equation, Elgersma used a modified form of the shrinking core model since he did not assume a first order reaction mechanism.

In order to simplify equation 2.6, the ionic activity can be written as the product of its activity coefficient and the ion molality. For electrolytes, the molality is assumed to be equivalent to the molar concentration; therefore the ionic activity can be expressed as: $\hat{a}_{1}=\gamma C_{1}$. If we rewrite equation 2.6 by substituting the iron concentration for its activity and by writing the hydrogen activity in terms of its activity coefficient and molar concentration, we obtain the following expression for zinc ferrite dissolution: 


$$
r_{p}^{\cdot}=k_{\sqrt{\gamma_{H}}} \sqrt{\frac{\left[H^{+}\right]}{\left[F e^{\left.\dot{s}^{+}\right]}\right.}} \quad\left(\frac{\text { mass }}{\text { tune area }}\right)
$$

where the species concentratıons are given as $\mathrm{mol} / \mathrm{L}$.

In order to use the above expression, it is necessary to calculate the hydrogen ion activity coefficient. Unfortunately, expressions for calculating ionic activities are only valid under dilute solution concentrations. For example, equation 2.8 below is an extension of the Debye-Hückel limiting law for calculating the activity coefficients for ionic strengths greater than 0.01 and less than 0.1 .

$$
\log \gamma_{ \pm}=05091 Z . Z \frac{\sqrt{\mu}}{1+\sqrt{\mu}}
$$

where $\mu$ is the ionic strength which is defined as:

$$
\mu \equiv \frac{1}{2} \sum_{1} C_{1} z_{1}^{2}
$$

with, $\quad \mathrm{Z}$ : ionic charge $\left(\mathrm{Z}_{+}=1\right.$ and $\mathrm{Z}=-2$ for $\left.\mathrm{H}_{2} \mathrm{SO}_{4}\right)$

Using equation 2.9, the ionic strength of the solution in the first jarosite tank was estimated to be close to 12.3. Details of this calculation are provided in Appendix VII. Although the ionic strength is well above the limits of equation 2.8, if we use this as an approxımation for the hydrogen ion activity coefficient, we calculate a value of: $\gamma_{H_{+}}=0.16$. If we assume that the ionic strength of the solution is essentially constant in the first tank, then the activity coefficient can be incorporated into the rate expression by defining a new rate constant:

$$
k^{\prime}=k \times\left(\gamma_{H_{+}}\right)^{1 / 2}=k \times(0.16)^{1 / 2}
$$

Elgersma found that the rate constant, $k$, at $95^{\circ} \mathrm{C}$, using synthetic zinc ferrite, was 
in the order of $1.74 \times 10^{-2} \mathrm{~g} /\left(\min . \mathrm{m}^{2}\right)$. However further tests, by this researcher, using industrial zinc ferrite, had shown that the rate constant was half of the above value $\left(8.70 \times 10^{-3} \mathrm{~g} / \mathrm{min} . \mathrm{m}^{2}\right)$.

Nii and Hisamatsu (14) similarly found that the dissolution of synthetic zinc ferrite follows the shrinking core model up to $80 \%$ dissolution. Rate constants in the order of $5 \times 10^{-3} \mathrm{~g} / \mathrm{min} . \mathrm{m}^{2}$ or $4.0 \times 10^{-3} \mathrm{~mol} / \mathrm{L} \cdot \min$ (as calculated above) were reported. Other conclusions from this work noted a significant drop in the dissolution rate in the presence of $50 \mathrm{~g} / \mathrm{L}$ zinc in the aqueous phase.

Rastas (7) also found that synthetic zinc ferrite reacted according to the shrinking core model (equation 2.3). The difference in Rastas approach is in the definition of the global rate expression which he found to be a function of the $\mathrm{H}_{2} \mathrm{SO}_{4}$ concentration and of temperature. In 1980, Rastas was employed by CEZinc to study their industrial zinc ferrites. In this work he found that the global rate expression took the following form:

$$
r_{p}^{\cdot}=a_{1}\left[H_{2} S O_{4}\right]+a_{2} \quad\left(\frac{\text { mass }}{\text { lime area }}\right)
$$

where: $\quad a_{1}$ and $a_{2}$ are constants

The applicability of this equation is questionable since it implies that zinc ferrite will dissolve in the absence of sulphuric acid.

Ismay (8), in a review paper, reports that extensive leaching studies have determined that natural zinc ferrite dissolves uniformly in sulphuric acid solutions with a rate that is proportional to the ferrite surface area. Higher temperatures enhance the reaction while zinc in solution reduces the dissolution rate. In his review he found that most researchers have reported that the reaction rate has an activation energy between 14 to $15 \mathrm{kcal} / \mathrm{mol}$ (59 to $63 \mathrm{~kJ} / \mathrm{mol}$ ). 
Filippou (9) recently studied the leaching kinetics of industrial zinc ferrite (provided by CEZinc) and found the dissolution process was best represented using the "grain model" whose characteristic equation is given by:

$$
1-(1-x)^{\frac{1}{F_{p}}}=\frac{r_{p}}{\rho}\left(\frac{S_{g}}{F_{g} V_{g}}\right) t
$$

where: $\quad S_{g}$ and $V_{g}$ : grain surface area and volume respectively $F_{g}$ : $\quad$ shape factor (for spherical grains $F_{g}=3$ )

With a shape factor of 3 , the "grain" model is similar to the characteristic "shrinking core model" (equation 2.3). His results agree with those of Elgersma and Rastas in that the surface reaction, and not diffusion, was found to be the rate controlling step. This is not surprising since the zinc sulphate product dissolves in the fluid.

Filippou also proposed that the following equation described the kinetics for the dissolution of industrial zinc ferrite in the presence of a $\mathrm{H}_{2} \mathrm{SO}_{4}-\mathrm{ZnSO}_{4}-\mathrm{Fe}_{2}\left(\mathrm{SO}_{4}\right)_{3}$ system:

$$
r=k a_{H \cdot}^{0.54} \quad\left(\frac{\text { mol }}{\text { IIme.volume }}\right)
$$

with $k$ dependent on temperature according to the Arrhenius expression:

$$
k=3.8 \times 10^{3} \exp \left(\frac{-64.8 \mathrm{~kJ} / \mathrm{mol}}{R T}\right)
$$

Equation (2.12) takes a similar form to equation (2.6) with the exception that the $\mathrm{H}^{+}$activity has a 0.54 order dependency on the rate instead of 0.50 , and the $\mathrm{Fe}^{3+}$ activity does not appear in the equation. At $98^{\circ} \mathrm{C}(371.15 \mathrm{~K})$, which was the operating temperature of the jarosite pilot circuit, the rate constant for the above kinetic expression is equal to: $\quad k\left(98^{\circ} \mathrm{C}\right)=2.88 \times 10^{-6}\left(\mathrm{~mol}^{0.46} \cdot \mathrm{L}^{054} / \mathrm{m}^{2} \cdot \mathrm{min}\right.$ ) 
Filippou's calculated activation energy of $64.8 \mathrm{~kJ} / \mathrm{mol}(15.5 \mathrm{kcal} / \mathrm{mol})$ lies close to the range which was reported by Ismay. In equation 2.12 , the activity of hydrogen is employed. This feature allows this rate expression to account for the negative effects that high zinc and iron concentrations in solution have on the dissolution rate. It was postulated that the piesence of other electrolytes would result in a decrease in the activity of the hydrogen ion. The half order dependency on the hydrogen ion activity was calculated by plotting the log of the derivative of the conversion with time (dx/dt) against the log of the acid concentration. This method results in a straight line with a slope equal to the order of the reaction. This method is acceptable if it is valid to assume that the particle surface area is constant for a given conversion. It was also found, as expected, that temperature resulted in an increased dissolution rate but that agitation speed had no significant effect. These results confirm that the reaction is not diffusion controlled since mass transfer is not affecting the rate.

\subsection{Jarosite Precipitation Kinetics}

Jarosite precipitation is a nucleation reaction in which the reagents react to form jarosite nuclei and then these nuclei subsequently grow to produce jarosite crystals. For ammonium jarosite precipitation the reaction is as follows:

$$
3 \mathrm{Fe}^{3+}+\mathrm{NH}_{4}^{+}+2 \mathrm{SO}_{4}^{2-}+6 \mathrm{H}_{2} \mathrm{O}(\mathrm{aq}) \rightarrow \mathrm{NH}_{4}\left[\mathrm{Fe}_{3}\left(\mathrm{SO}_{4}\right)_{2}\left(\mathrm{OH}_{6}\right](\mathrm{s})+6 \mathrm{H}^{+}(1.2)\right.
$$

Following the literature survey, it was found that there is a general agreement amongst the various researchers as to the effects of the main variables on Jarosite precipitation. This section will begin by discussing the parameters which effect Jarosite precipitation. Following this review, various jarosite kinetic expressions found in the literature will be outlined.

\section{Induction Period and Jarosite Seeding Effects}

An induction period was first observed by Steintveit (10) and was found to disappear through the addition of jarosite seeds. Ismay (8) reports that since 
jarosite precipitation involves hydrolysis and crystallization, this induction period is due to the slow formation of a sufficient number of nuclei. Although jarosite seeding does not change the final equilibrium iron concentration, it does drastically shorten the time required for jarosite precipitation (11).

Qian-kun (12) found that jarosite seeding increased the jarosite precipitation rate and thus the rate of iron removal from solution. Through the addition of 25 to 190 $\mathrm{g} / \mathrm{L}$ seed the time required for precipitation in their tests was reduced by several hours (over $75 \%$ ).

Limpo (13) reports that the rate is dependent on the surface area of seed crystals and that since the velocity of growth of jarosite crystals is greater than the rate of nucleation he concludes that the number of nuclei controls the rate of precipitation, which is in agreement with Ismay.

\section{Effect of Reactant and Product Concentrations}

The jarosite precipitation reaction stoichiometry, given by Equation 1.2, shows that ferric iron, and ammonium in solution are reactants and acid is a product. The literature review confirms that increased concentration of these reactants increases the jarosite precipitation kinetics. Similarly the rate of precipitation is reduced when high concentrations of acid are present. For example, several researchers $(1,8,12)$ found that higher than stoichiometric proportions of alkali (ammonium ion) increased the rate of jarosite precipitation.

It was found $(12,13)$ that although high initial ferric iron concentrations would increase the rate of Jarosite precipitation, the final iron concentration was always higher than the case where lower initial concentrations were examined. An expression for Jarosite precipitation developed by Rastas (7) showed that the rate of iron precipitation depended strongly on the ferric sulphate concentration. This expression will be shown in the next section. 
Since acid is produced during jarosite precipitation, a high acidity was found to reduce the amount of iron removal (this follows the reaction stoichiometry). It is apparent that although high initial acid concentrations are found to increase zinc ferrite leaching, a compromise is necessary for the optimum operation of the jarosite conversion circuit.

\section{Effect of Temperature}

Limpo (13) found that the reaction rate increased by a factor of three when the temperature was increased from 90 to $100^{\circ} \mathrm{C}$. Qian-kun and co-workers (12) also found that the iron removal rate was enhanced when temperature was increased from 85 to $98{ }^{\circ} \mathrm{C}$. Finally, Kubu et al. (15), confirmed that increasing the temperature would invariably promote jarosite precipitation.

\section{Hydronium Ion Substitution:}

The precipitation of alkali jarosite has an additional complication which arises from the co-precipitation of hydronium jarosite which tends to substitute itself for the alkali portion of the jarosite compound. This was shown $(11,12)$ through the nonstoichiometric composition of the jarosite solids (the content of the alkali species was deficient). The result is an alkali jarosite with the form: $\left\{\mathrm{H}_{3} \mathrm{O}, \mathrm{NH}_{4}\right\}\left[\mathrm{Fe}_{3}\left(\mathrm{SO}_{4}\right)_{2}(\mathrm{OH})_{6}\right]$. Further test-work (12) indicated that as temperature increased from 80 to $100^{\circ} \mathrm{C}$ hydronium ion substitution also increased. Above $100^{\circ} \mathrm{C}$, however, the rate of hydronium substitution goes in the opposite direction. Since the CEZinc conversion circuit is operating at $98^{\circ} \mathrm{C}$, both ammonium jarosite (equation 1.2) and hydronium jarosite precipitation (equation 2.14 ) had to be studied in order to take into account the overall rate of iron precipitation.

$$
3 \mathrm{Fe}^{3 \cdot}+7 \mathrm{H}_{2} \mathrm{O}(\mathrm{aq})+2 \mathrm{SO}_{4}^{2} \rightarrow \mathrm{H}_{3} \mathrm{O}\left[\mathrm{Fe}_{3}\left(\mathrm{SO}_{4}\right)_{2}(\mathrm{OH})_{6}\right](\mathrm{s})+5 \mathrm{H}^{+}
$$


Jarosite Precipitation Rate Expressions

Qian-kun (12) proposed the following expression for iron precipitation as ammonium jarosite:

$$
\begin{gathered}
-r_{F_{2}\left(S O_{1}\right)}=k_{1}\left[F e_{2}\left(S O_{4}\right)_{3}\right]^{2}\left[\left(N_{4}\right)_{2} S O_{4}\right]^{1 / 2}-k_{-1}\left[H_{2} S O_{4}\right]^{1 / 4} \\
k_{1}=4.733 \times 10^{12} \exp \left(\frac{-18.763 \mathrm{kcal} / \mathrm{mol}}{R T}\right) \\
k_{-1}=14.39 \exp \left(\frac{-3.975 \mathrm{kcal} / \mathrm{mol} /}{R T}\right)
\end{gathered}
$$

Once again, at the operating temperature of the pilot circuit $\left(98^{\circ} \mathrm{C}\right)$ the rate constants are as follows: $k_{1}=42.41$ and $k_{-1}=6.57 \times 10^{-2}$. Unfortunately no units were provided in their paper. In this work, there is no mention of the experimental apparatus used to obtain these kinetic data; consequently it is assumed that the set-up was probably a constant volume batch reactor in which they tried to limit the effects of external mass transfer resistances.

The thesis by Elgersma (14) has shown that the rate of jarosite production, $r^{+}$is proportional to the linear crystal growth rate, $G(\mathrm{~m} / \mathrm{s})$ and the surface area of the jarosite crystal, $A$. The following equation describes this relationship:

$$
r^{\prime}=\rho_{c} G A \quad\left(\frac{m a s s}{t \text { time }}\right)
$$

Rastas (7) in his work on ferrite and jarosite kinetics found the following expression to hold for the rate of iron precipitation as jarosite:

$$
-\frac{d\left[F e^{3 \cdot}\right]}{d t}=k(T)\left[F e^{3 \cdot}\right]^{\prime \prime}\left[\mathrm{H}_{2} \mathrm{SO}_{4}\right]^{1}\left[\mathrm{NH}_{4}\right]^{\gamma}\left[\mathrm{NH}_{4}-J A R\right]^{\delta}
$$

where the species concentrations are in $g / L$ and the reaction orders with respect 
to each species ranged as follows:

$$
\begin{array}{ll}
\alpha=1.9 \text { to } 2.4 & \beta=-3.5 \text { to }-2.2 \\
\gamma=0.5 \text { to } 0.7 & \delta=0.8 \text { to } 1.4
\end{array}
$$

Rastas, when working with industrial CEZinc Jarosite in 1980, found the rate of iron removal could $b \in$ modelled using the following constants for $\alpha, \beta, \gamma$, and $\delta$ :

$$
-\frac{d\left[\mathrm{Fe}^{3 \cdot}\right]}{d t}=k(T)\left[\mathrm{Fe}^{3 \cdot}\right]^{2406}\left[\mathrm{H}_{2} \mathrm{SO}_{4}\right]^{-3719}\left[\mathrm{NH}_{4}^{+}\right]^{106}\left[\mathrm{NH}_{4}-\mathrm{JAR}\right]^{0685}
$$

The rate constant at $98^{\circ} \mathrm{C}$ for the above expression was calculated by Rastas to be:

$$
\mathrm{k}=9.944 \times 10^{1}(\mathrm{~g} / \mathrm{L}){ }^{0568} \mathrm{hr}^{-1} \quad \text { or } \quad 1.657 \times 10^{-2}(\mathrm{~g} / \mathrm{L})^{0568} \cdot \mathrm{min}^{-1} \text {. }
$$

It is important to note that equations 2.15 and 2.18 are not rate laws but are design equations for a constant volume batch reactor. A rate law should not depend on the reaction vessel, but on the local state of the system in terms of temperature, pressure and composition, therefore, it should not have a differential term in it. Another peculiarity in Rastas rate expression, is that he incorporates the jarosite seed concentration into the equation. This term refers to the mass of dry jarosite seed per volume of slurry. If we choose to assume that the jarosite seed concentration is relatively constant, then we could ignore this term by accounting for it in the rate constant. For example, in most of the pilot experiments the jarosite seed concentration was $150 \mathrm{~g} / \mathrm{L}$ giving an overall rate constant, $\vec{k}=$ $5.22 \times 10^{-2}(\mathrm{~g} / \mathrm{L})^{1253} \cdot \mathrm{min}^{-1}$. 


\section{Chapter 3}

\section{EXPERIMENTAL METHODS}

\subsection{Overview}

A total of four jarosite pilot plant process identification experiments were successfully completed. In each of these experiments, the process was operated under "normal" flow conditions (Table III-1) for 12 hours. Following this initial steady-state period, the flow-rate of one of the feed streams was increased by a step change and the process response was recorded by taking successive samples from the effluent streams of each of the five reactors. After seven hours of operating under "step change" conditions, the adjusted feed stream flow was returned to its original value, and the process response was once again recorded. The time required for running an experiment consisted of two full days of preparation, 24 hours of experimentation, and four days of: clean-up, sample preparation and acid titrations. Approximately 300 samples were taken for each experiment (150 each of solids and solutions). Each sample was subsequently assayed for iron, zinc, lead, copper, and lithium representing a total of 1500 determinations and 150 acid titrations per experiment. The cost of each experiment was estimated at $\$ 9500$. This amount covered the cost for analysis of all of the samples as well as the price for the chemicals used in each run. Since the pilot plant required more expensive construction materials due to the corrosive nature of the process, approximately $\$ 10000$ of equipment was purchased.

\subsection{Pilot Equipment}

Originally, it was proposed to carry out the process identification experiments on the actual conversion circuit at CEZinc. This approach was abandoned since the possibility of upsetting the leach circuit performance by executing "step change" tests was too great. It was further realized that a pilot unit allowed the flexibility 
of operating under relatively steady and controlled transient conditions, which would never have been the case if the actual circuit was employed due to the large number of unmeasured process disturbances. In view of these benefits, it was decided to construct a pilot scale set-up to resemble the first five tanks of the conversion circuit at CEZinc. Photographs of the pilot equipment are displayed in Figures 3-1 and 3-2 and a schematic of this circuit is shown in Figure 3-3.

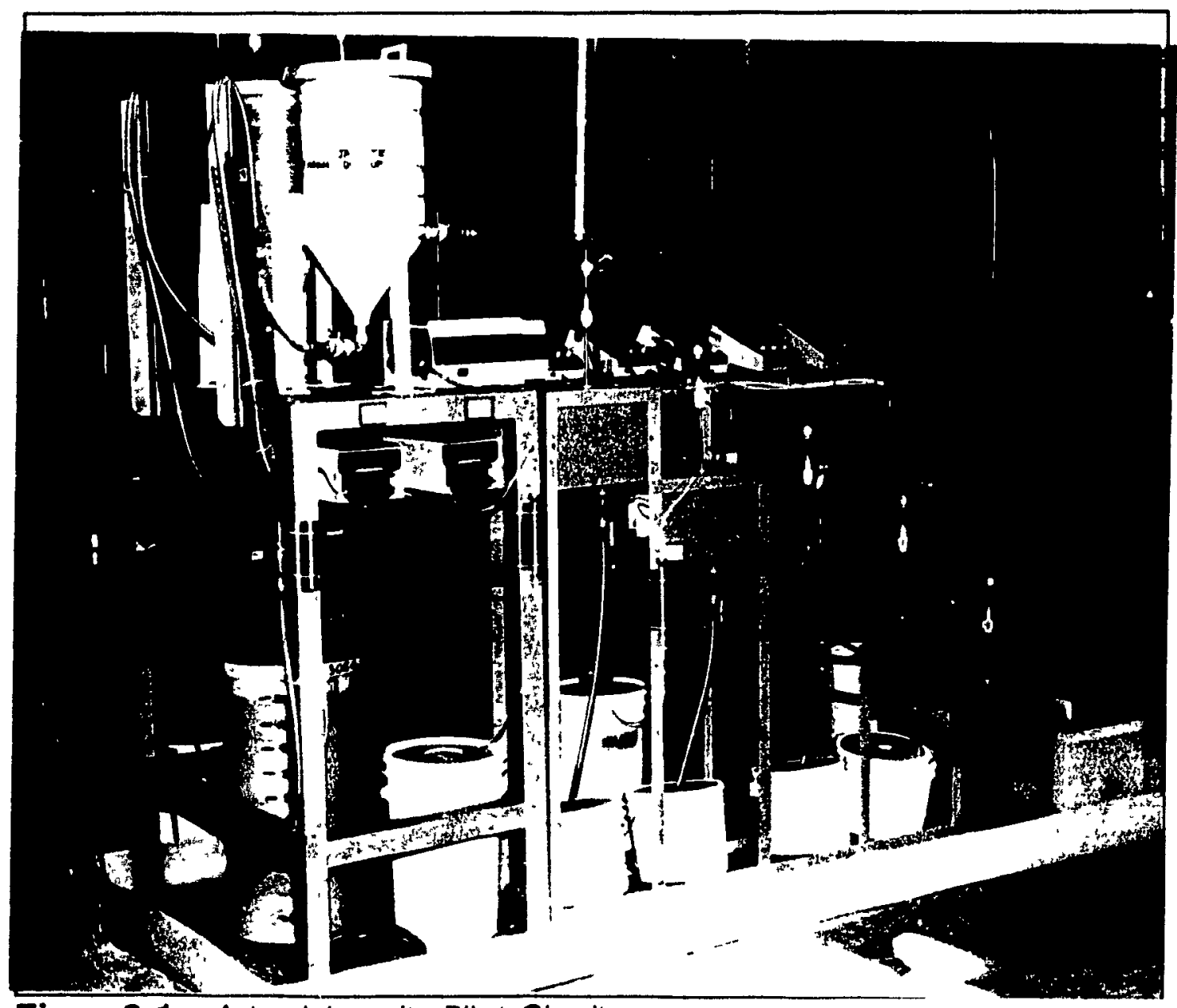

Figure 3-1 Actual Jarosite Pilot Circuit

The pilot reactors consisted of 5 continuous stirred tanks in series. The tanks were maintained at a constant temperature of $98^{\circ} \mathrm{C}$ by the use of external heating jackets. Since the actual process employs live steam injection to maintain the reactor temperatures at $98^{\circ} \mathrm{C}$, water was added to all five tanks for the purpose of 
simulating the dilution effect of the steam.

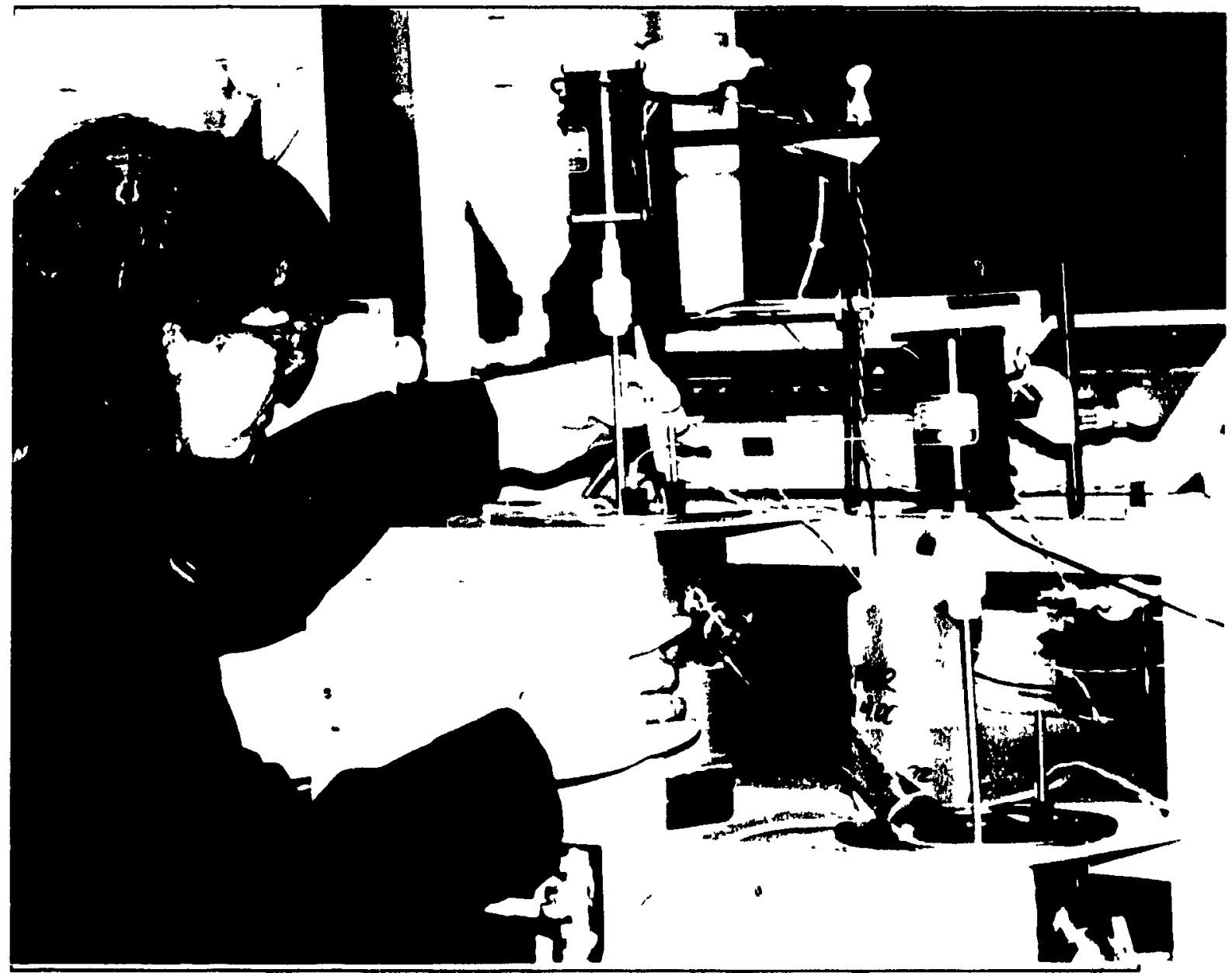

Figure 3-2 Actual Jarosite Pilot Circuit: View of First Tank

Zinc ferrite and jarosite seed slurries were independently pumped to the first tank. In the industrial scale operation at CEZinc, the jarosite seed mixes with the zinc ferrite slurry before it enters the first tank. Since the ratio of zinc ferrite to jarosite continuously varies at the plant, it was decided to have two separate slurry streams entering the first tank so that the effect of varying the jarosite seed flow could be examined.

Two acid streams, spent and raw, were also pumped to the first reactor. Both of 
these acid stream flows were monitored using rotameters (calibration curves are shown in Appendix (1). The spent acid stream flow was substantially larger than that of the raw acid stream (Table III-1). The raw acid stream's sulphuric acid concentration, however, was approximately 10 times larger than that in the spent acid stream.

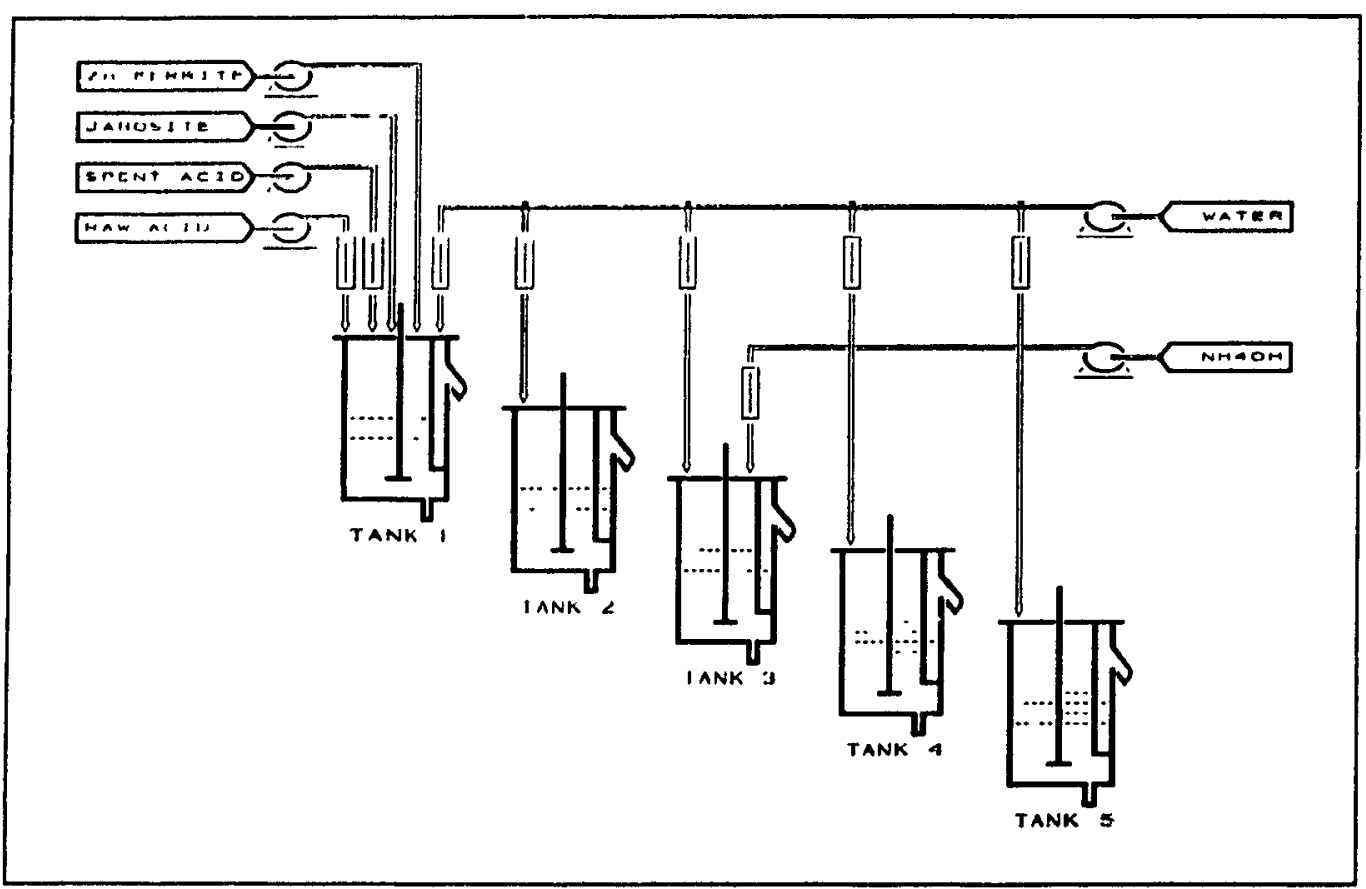

Figure 3-3 Pilot Scale Jarosite Circuit

TABLE III-1

FEED STREAM FLOWS

\begin{tabular}{|c|c|}
\hline FEED STREAMS & FLOW (mL/min) \\
\hline \hline Zn Ferrite Slurry & 14.0 \\
\hline Jarosite Slurry & 12.1 \\
\hline Spent Acid & 16.1 \\
\hline Raw Acid & 0.96 \\
\hline Ammonum Hydroxide & 2.2 \\
\hline Water & 2.5 \\
\hline
\end{tabular}


Ammonia was added to the third reactor, as ammonium hydroxide, as shown in Figure 3-3, with the objective of increasing the rate of ammonium jarosite precipitation. The flow-rate of this stream remained unchanged for all four tests. Ammonium is present in the two slurry streams and in the spent acid strearn. As a result, the ammonium concentration in the first two tanks will normally range from 3 to $4 \mathrm{~g} / \mathrm{L} \mathrm{NH}_{4}{ }^{+}$. Since jarosite precipitation is known to become limited (5) when the residual ammonium concentration is below $4 \mathrm{~g} / \mathrm{L}$ in the circuit, the majority of the ammonium jarosite is produced at the point of ammonium addition (i.e. tank 3).

\section{REACTOR CONSTRUCTION}

Figure 3-4 provides a closer look at the individual tank construction. All of the tank materials were constructed from $316 \mathrm{~L}$ Stainless steel. The tank height was $24 \mathrm{~cm}$ with a $16 \mathrm{~cm}$ diameter. The tanks contained 4 baffles to enhance mixing, a riser pipe near the over-flow exit to prevent short-circuiting of the reagents, and a drain at the bottom for slurry removal after the experiment. The height of the over-flow exit was $17.5 \mathrm{~cm}$ which gave a reactor volume of approximately $3.5 \mathrm{~L}$. The actual operating volume was measureú at 2.8 L once agitation was introduced. Agitation was accomplished by using an over-head mixer and a four blade, $45^{\circ}$ pitch impeller having a length of $2.6 \mathrm{~cm}$. It was postulated that the installation of the riser pipe may result in some solid accumulation in the tank but this was not found to be a problem during the jarosite experiments.

A residence time distribution test was carried out to evaluate the mixing characteristics of this tank design. The results from this test are provided in Appendix III. In this study it was found that these reactors, with the risers intact, closely approximated an ideal continuous stirred-tank reactor (CSTR). It should be noted that, instead of employing a riser pipe to reduce short circuiting of the reagents, another method would have been to increase the impeller speed. Although this practice was not found to effect the rate of zinc ferrite leaching 


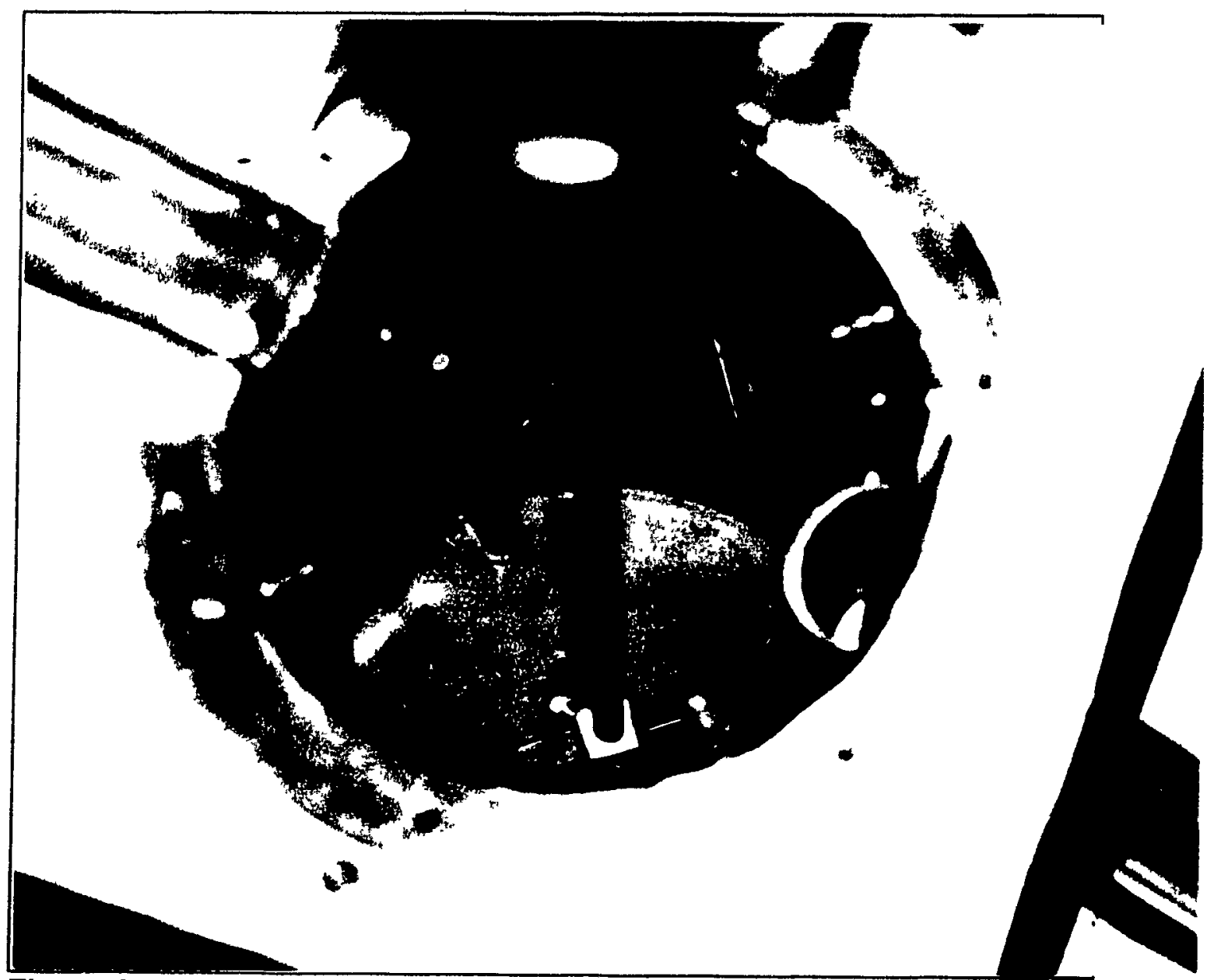

Figure 3-4 Reactor Construction

according to the work by Filippou (9), it may significantly effect the rate of jarosite precipitation by interfering with the crystal growth rate since the crystals may break apart. Consequently the speed of each of the impellers was maintained at 700 $\mathrm{rpm}$ with the exception of the third tank which was maintained at $800 \mathrm{rpm}$.

\section{INSTRUMENTATION}

Figure 3-5 provides a schematic of the instrumentation used in the pilot plant. A thermocouple located in each tank continuously measured the reactor temperature. The temperature was maintained at the desired set-point by using temperature controllers (TC) which automatically turned the power on and off to the heating coils. The $\mathrm{pH}$ in each of the tanks was monitored and the impeller rpm was 
periodically measured using a tachometer and readjusted manually. The eight solution flow-rates (spent acid, raw acid, ammonia and the five water streams) were measured using rotameters and were essentially stable during the experimentation period.

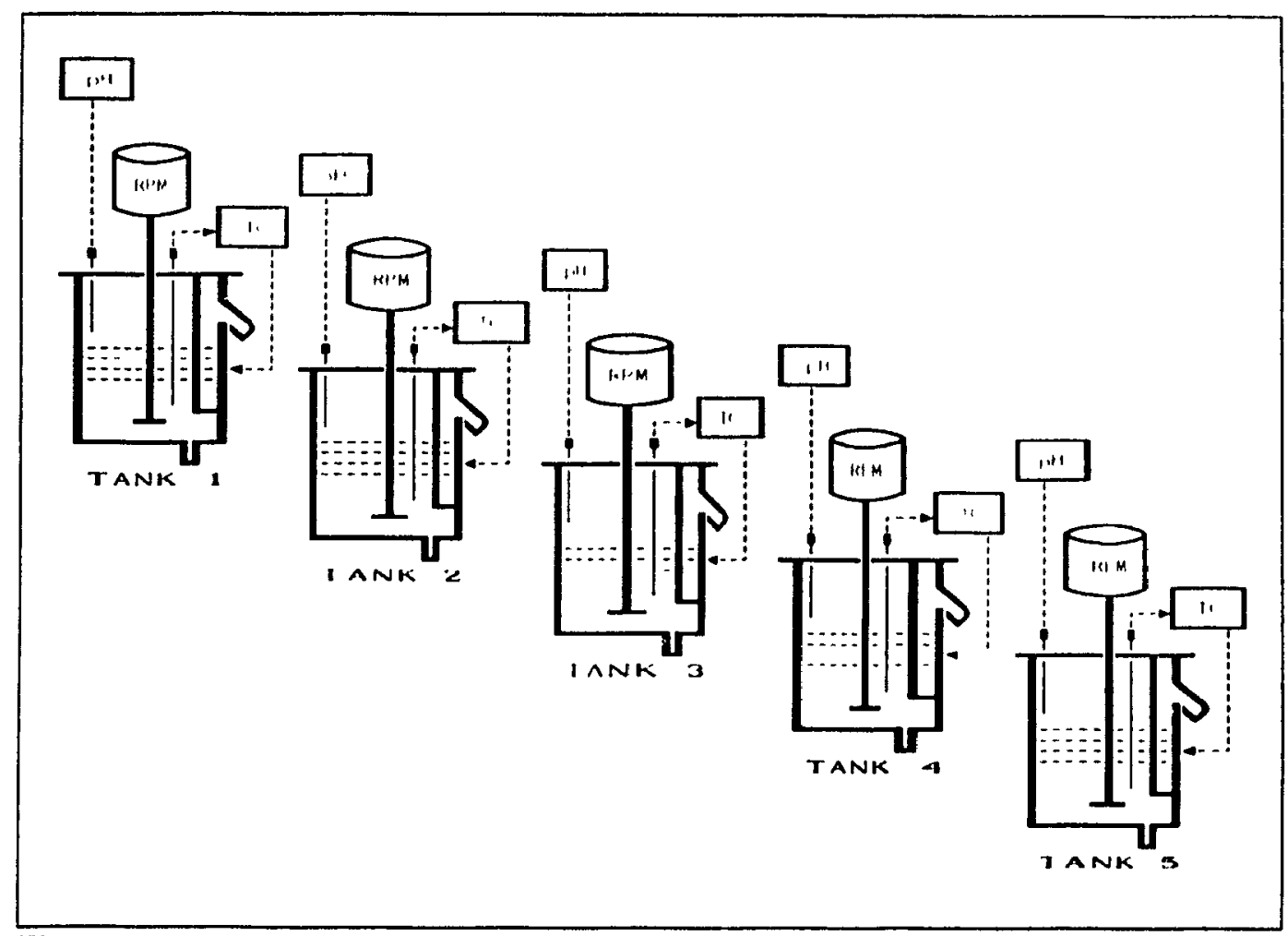

Figure 3-5: Pilot Plant Instrumentation

Self-calibrating peristaltic pumps were used to feed the slurries. In order to measure the slurry flow using these pumps, the desired flow-rate was set and the pump would adjust the shaft rotation in order to achieve this flow (based on water and the tubing used). The actual slurry flow would then be measured using a stop watch and graduated cylinder. The measured value would then be entered into the peristaltic pump controller and the pump would readjust its speed based on this new data point. This procedure would normally have to be repeated two to three times before the correct slurry flow was achieved. This type of peristaltic pump 
had a maximum flow capacity of $100 \mathrm{~mL} / \mathrm{min}$ and an accuracy of $0.1 \mathrm{~mL} / \mathrm{min}$. The minimum slurry flow which could be achieved was $6 \mathrm{~mL} / \mathrm{min}$. Below this value the solids would tend to plug up the tygon tubing.

To ensure that the circuit was operating under similar conditions to those observed at the plant, the acid and iron concentrations were titrated during the initial steadystate period of each experiment and these concentrations were compared with plant values.

\section{EQUIPMENT PROBLEMS}

Since the $\mathrm{pH}$ electrodes used during the pilot study were rated for up to $100^{\circ} \mathrm{C}$, they tended to give erroneous results after four hours of continuous operation at $98^{\circ} \mathrm{C}$. Since solids tended to coat the electrode surface, it was found that if the $\mathrm{pH}$ probes were periodically cleaned every few hours using a concentrated HCL solution then they would return to normal operation. The problem with using $\mathrm{pH}$ as a means of monitoring or controlling the jarosite operation is related to the sensitivity of this measurement. When sulphuric acid concentrations are greater than $15 \mathrm{~g} / \mathrm{L}\left(0.15 \mathrm{~mol} / \mathrm{L} \mathrm{H}_{2} \mathrm{SO}_{4}\right)$ the $\mathrm{pH}$ measurement does not provide an accurate indication of the activity of the hydrogen ion.

During the first test there were some problems with blocking of slurry feed. This situation was rectified by making modifications to the slurry feeding system. Following these feed systems changes, slurry blockage was no longer a problem.

Solids had a tendency to accumulate on the upper portion of the third tank reactor wall. It was believed that the ammonia feed, which was dripped into the first tank, was causing local surface reactions. The impeller agitation speed was increased from 700 to $800 \mathrm{rpm}$ and the problem was rectified. It was fortunate that this relatively small increase in impeller speed solved the solids accumulation problem since high agitation is known to effect the jarosite crystal growth rate. 


\subsection{Operating Procedure}

\section{FEED STOCK OBTAINED FROM CEZinC}

A volume of 500 litres of each of the following solutions was provided by the plant: spent acid, low acid leach solution, and jarosite circuit solution. The zinc ferrite slurry was prepared by mixing the low acid leach solution with the zinc ferrite solids. Jarosite slurry from the plant could not be used directly in the pilot plant experiments since the slurry was found to react during storage as shown in the Jarosite stability test which is summarized in Appendix IV. Consequently, jarosite seed had to be prepared by filtering the plant's jarosite slurry from approximately $25 \%$ solids to $68 \%$ solids using a filter press. Since these filtered jarosite solids remained essentially stable during storage, a batch of jarosite slurry was prepared before each experiment. This was accomplished by mixing the filtered solids with a measured amount of solution taken from the CEZinc jarosite circuit thickener over-flow stream.

\section{FEED STREAM PREPARATION}

The spent acid solution obtained from the plant was used directly in the pilot setup. A $20 \mathrm{~L}$ batch of jarosite slurry was prepared for each experiment by combining the $68 \%$ jarosite solids with enough jarosite circuit solution to produce a slurry which contained $33 \%$ solids. The zinc ferrite slurry was similarly prepared by combining enough low acid leach solution with zinc ferrite solids to obtain a slurry which contained $23 \%$ solids. Batches of zinc ferrite solids were produced at the Noranda Technology Centre, by reacting $50 \mathrm{~kg}$ of calcine, which contains mainly zinc oxide and zinc ferrites, with approximately $25 \mathrm{~L}$ of concentrated sulphuric acid in a $250 \mathrm{~L}$ tank to produce approximately $15 \mathrm{~kg}$ of zinc ferrite solids. One batch would provide enough solids for one experiment. Appendix IV outlines the procedure for the preparation of the zinc ferrite solids in more detail.

Table III-2 compares the composition of industrial zinc ferrite and jarosite solids with their expected elemental compositions. The chemical formulae for zinc ferrite 
and jarosite are $\mathrm{ZnO} . \mathrm{Fe}_{2} \mathrm{O}_{4}$ and $\mathrm{NH}_{4}\left[\mathrm{Fe}_{3}\left(\mathrm{SO}_{4}\right)_{2}(\mathrm{OH})_{6}\right]$. From this table we note that the zinc ferrite composition is close to its elemental composition. The small discrepancy is primarily a consequence of the industrial zinc ferrites containing other species such as ferric hydroxide, lead sulphate, and other ferrites such as magnesium ferrite, etc. The jarosite solids, obtained by filtering the plant's jarosite slurry, are known to contain unleached zinc ferrites. Consequently, it is normal to observe between 2.5 and $4.0 \%$ zinc in these solids. A more detailed examination of the compounds present in these solids is shown in Appendix IV.

Table III-2

COMPARISON OF INDUSTRIAL \& ELEMENTAL SOLID COMPOSITIONS

\begin{tabular}{|c||c|c|c|c||}
\hline SOLID & \multicolumn{2}{|c|}{ EXPECTED ELEMENTAL (Wt. \%) } & \multicolumn{2}{|c|}{ INDUSTRIAL COMPOSITION (Wt. \%) } \\
\cline { 2 - 5 } & $\% \mathrm{Zn}$ & $\% \mathrm{Fe}$ & $\% \mathrm{Zn}$ & $\% \mathrm{Fe}$ \\
\hline Zn FERRITE & 27.1 & 46.3 & 25.3 & 43.5 \\
\hline JAROSITE & 0 & 349 & 2.9 & 33.0 \\
\hline
\end{tabular}

The data in Table III-3 show the average compositions and densities of the aqueous phase of each of the feed streams. The raw and spent acid streams contained the highest concentration of sulphuric acid but the lowest concentrations of zinc and iron compared to the other feed streams. The zinc ferrite stream, on the other hand, had the lowest acid and the highest zinc and iron concentrations. Commercial sulphuric acid (96\%) was used to simulate the plant's raw sulphuric acid stream. Due to safety considerations, ammonium hydroxide (28\% as $\mathrm{NH} 3$ ) was pumped to the third tank instead of ammonia gas which is employed at CEZinc. 
Table III-3

FEED SOLUTION COMPOSITIONS \& DENSITIES

\begin{tabular}{||c||c|c|c|c|c||}
\hline $\begin{array}{c}\text { STREAM } \\
\text { NAME }\end{array}$ & $\begin{array}{c}\text { H2SO4 } \\
(\mathrm{g} / \mathrm{L})\end{array}$ & $\begin{array}{c}\text { Fe } \\
(\mathrm{g} / \mathrm{L})\end{array}$ & $\begin{array}{c}\mathrm{Zn} \\
(\mathrm{g} / \mathrm{L})\end{array}$ & $\begin{array}{c}\mathrm{L} \\
(\mathrm{m} / \mathrm{g} / \mathrm{L})\end{array}$ & $\begin{array}{c}\text { Solution } \\
\text { Density }\end{array}$ \\
\hline \hline Zn FERRITE & 2.0 & 9.1 & 957 & 2.54 & 1.30 \\
\hline JAROSITE & 16.4 & 5.33 & 63.9 & 2.36 & 116 \\
\hline SPENT & 188.2 & $7.0 \mathrm{e}-3$ & 46.4 & 4.15 & 1.28 \\
\hline RAW ACID & 1762.1 & - & - & - & 183 \\
\hline
\end{tabular}

\section{START-UP PROCEDURE}

For the first test, a $17 \mathrm{~L}$ slurry was prepared for the purpose of filling each of the 5 tanks with an initial solution. This slurry contained a mixture of the following: 8.0 $\mathrm{L}$ of zinc ferrite slurry, $2.6 \mathrm{~L}$ of jarosite slurry, $6.1 \mathrm{~L}$ of spent acid, $0.3 \mathrm{~L}$ of water and $68 \mathrm{~mL}$ of raw acid (Tank 1 only).

Following the first test, each of the reactor contents was reserved so that they could be used as the starting solution for the subsequent test. With each of the reactors full of the initial slurries, the band heaters were then programmed to heat the slurry to $70^{\circ} \mathrm{C}$. Once the pilot reactors reached this temperature, all of the feed stream flows were started as follows: five water inlets (which simulated live steam addition at the plant), jarosite slurry \& zinc ferrite slurry flows, spent \& raw acid flows, and the ammonium hydroxide flow. At this point the band heater setpoint was increased to the normal operating temperature of $98^{\circ} \mathrm{C}$

The circuit was then operated under "normal" conditions overnight for 12 hours (refer to Table III-1 for feed stream flows) to ensure that steady state was obtained in all five reactors. The following day, 3 to 4 samples from each of the five tanks 
were taken to quantify the initial steady state conditions. Once all of the steadystate samples were taken, a step change was induced in the circuit by changing the flow of one of the feed streams.

The step change time was recorded and frequent sampling of the first tank was initiated (approximately every 10 minutes for an hour). After 15 minutes, sampling of the second tank began. Sampling of the third tank took place after $\mathbf{3 0}$ minutes and so forth... After seven hours of operating under step change conditions, the flow of the altered input stream was adjusted back to its initial conditions and the time of this change was recorded.

Since this adjustment caused another transient state, the circuit is then sampled as before. After seven hours of this second stage of sampling, the band heaters were turned off and each of the feed stream pumps were stopped. The tanks were then emptied and inspected. The reactor slurries were reserved for subsequent experiments and their volume and temperatures were recorded.

\section{SAMPLING PROCEDURE}

During Test:

Although it was realized that a large sample would be more representative of the exit conditions, this practice would mean disturbing the exit stream flow, and consequently the inlet to the following reactor, for longer periods of time. Since the exit flow was in the order of 40 to $50 \mathrm{~mL} / \mathrm{min}$ it was decided to take a $50 \mathrm{~mL}$ sample (approximately) from the tank exit using a graduated cylinder (this took approximately 1 minute). Before filtration, the slurry density was calculated by measuring the sample volume and weight. Initially the temperature of the slurry sample was recorded at the time of the density measurement. The sample temperature was found to be quite constant with variations between 68 and $72{ }^{\circ} \mathrm{C}$. Consequently this measurement was omitted. 
Once the slurry density was recorded, the sample was filtered using a Büchner funnel. It was important to filter the slurry as quickly as possible since it continues to react in the sample cylinder. The filtrate was saved and the solids were washed with approximately $50 \mathrm{~mL}$ of hot water in order to remove any filtrate which may have adhered to the solid surface. A $10 \mathrm{~mL}$ aliquot was taken from the filtrate sample for analysis by an inductively coupled plasma (I.C.P.) analytical instrument. The remaining filtrate sample was then reserved for subsequent acid titrations.

\section{Analytical Methods:}

In order to stabilize the filtrate samples, $10 \mathrm{~mL}$ of $30 \%$ nitric acid was added to each aliquot. These samples were then sent for iron, zınc, lead, copper and lithium analysis by I.C.P. The remaining filtrate samples, which were not stabilized with nitric acid, were subsequently titratated for acid using a standard sodium carbonate method. This analytical procedure is summarized in Appendix V.

The washed solid samples were dried at $70^{\circ} \mathrm{C}$ overnight. The solids were then weighed using a balance accurate up to 2 decimal places (normally the sample size was in the order of 10 grams). The dried solids were then crushed and sent for iron, zinc, lead, and copper analysis by I.C.P. A few of the feed stream solid samples were sent for sulphate analysis (gravimetric method) in order to give an indication of the compounds present in the solid feeds. Appendix IV provides an outline of these compound determination calculations.

\subsection{Error Analysis}

As will be shown in the subsequent chapter, the mass balances for zinc, iron, and lead in Tank 1 were all above $89 \%$ and below $112 \%$. The following analysis shows that these mass balance results are quite good when we take into account the large number of errors which normally arise during pilot plant experimentation. Although this analysis deals mainly with sources of random error, it also touches upon systematic errors which may have occurred. 
As previously described in Section 3.3, slurry samples were taken at the exit of each tank and the following parameters were measured: slurry density, filtrate density, and percent solıds. Once each sample was filtered, the solutions were titrated for acid and then sent to be analyzed for iron, zinc and lithium using an I.C.P. (Inductively Coupled Plasma) instrument. The I.C.P. was also used to analyze the solids for iron, zinc, and lead.

The error analysis will begin by calculating the errors involved using the sodium carbonate method for acid concentration determinations. Following these calculations the errors in using the ICP instrument will be discussed. Finally the errors involved when measuring the density and the percent solids in the slurry will be covered. A discussion on the use of tie elements for eliminating large sources of error will demonstrate why it was decided to use the raw data without any tie element manipulations.

\section{ERROR IN ACID TITRATION METHOD}

A standard sodium carbonate method was used to analyze the acid concentration in the filtrate samples. A detailed description of this method is shown in Appendix $V$. The prepared titrant used in this method is standardized using a known concentration of $\mathrm{HCL}$. The titrant multiplication factors were 1.683 for Tests $B, C$, and $D$ and was 2.011 for Test $E$ determinations. $A 50 \mathrm{~mL}$ burette with graduations of $0.20 \mathrm{~mL}$, was used for titrant addition. This measurement consequently resulted in a "least count" of $0.10 \mathrm{~mL}$. With this information, the resulting precision in this method can be calculated as:

Tests B, C, D:

$0.10 * 1.683=0.17 \mathrm{~g} / \mathrm{L} \mathrm{H}_{2} \mathrm{SO}_{4}$

Test E:

$$
0.10 * 2.011=0.20 \mathrm{~g} / \mathrm{L} \mathrm{H}_{2} \mathrm{SO}_{4}
$$

Typically a titrant volume of $28 \mathrm{~mL}$ had to be added to the samples from the first tank for acid analysis. Using this value, we can calculate the percent deviation 
from the average acid concentration to be:

$$
\left[\mathrm{H}_{2} \mathrm{SO}_{4}\right]=(28 \mathrm{~mL} \pm 0.10 \mathrm{~mL}) * 1.683=47.12 \pm 0.17 \mathrm{~g} / \mathrm{L}( \pm 0.36 \%)
$$

\section{ERRORS IN USING I.C.P. ANALYSIS}

An Inductively Coupled Plasma (I.C.P.) atomic emission spectroscopy instrument, which employs a matrix matching technique, was used to determine the zinc, iron, and lithium in solution and the zinc, iron, and lead in the solids. At the concentrations of acid, zinc, and iron which were present in the jarosite circuit, the standard deviations would normally range from 1 to $2 \%$. In order to obtain an estimate of the analytical precision, duplicates of several samples were analyzed. Equation 3.1 shows this calculation which is referred to here as the sample standard deviation in (\%).

$$
\% \text { Std. Deviation }=\sqrt{\frac{\sum x^{2}}{N-1}}+X \times 100 \%
$$

where: $\quad N=$ number of samples

$x=$ difference between sample value and sample mean

$X=$ sample mean

The accuracy of the I.C.P. method is determined by spiking a known concentration into each sample and then calculating the percent recovery. The recovery is defined as the difference between the spiked sample and the initial sample concentration divided by the concentration of the spike. Ideally, the accuracy would be close to $100 \%$ and the sample standard deviation would be as low as possible. Table III-4 outlines the errors found during I.C.P. analysis of these samples. In this table, "aq." refers to the aqueous phase and "s" refers to the solid phase analysis. 
Table III-4

ERROR IN I.C.P. ANALYSIS

\begin{tabular}{|c||c|c|c|c|c|c|c|c||}
\hline \multirow{2}{*}{$\begin{array}{c}\text { ANALYTICAL } \\
\text { ERROR }\end{array}$} & \multicolumn{2}{|c|}{ ZINC } & \multicolumn{2}{c|}{ IRON } & \multicolumn{2}{c|}{ LEAD } & \multicolumn{2}{c|}{ LITHIUM } \\
\cline { 2 - 10 } & aq. & $\mathbf{s}$ & aq. & $\mathbf{s}$ & aq. & s & aq. & s. \\
\hline \hline \% STD. DEVIATION & 19 & 1.3 & 2.5 & 1.5 & 20 & 1.2 & 5.5 & - \\
\hline STD (g/L Or \% solids) & 1.7 & 0.1 & 0.6 & 0.5 & - & 0.04 & $.2 \mathrm{ppm}$ & - \\
\hline \% ACCURACY & 101 & 94 & 112 & 116 & 90 & 83 & 82 & - \\
\hline
\end{tabular}

As seen in the above table, the percent standard deviation in the aqueous phase is higher than the deviations in the solid phase. In order to obtain improved component mass balance results, it was hoped that lead could be used as a tie element for calculating the mass fraction of solids in the slurry and that lithium could be used to calculate the filtrate density. Although the lead standard deviations are reasonable, the lead recoveries are too low in the solid phase for lead to be a good tie element. It was planned to use lithium as a tie element in the aqueous phase since it remains inert under the jarosite conversion circuit conditions. Unfortunately, the errors are too large in both standard deviation and accuracy for this measurement to be able to adequately calculate another parameter.

\section{DENSITY AND \% SOLIDS MEASUREMENT}

Since the density and solids could not be inferred through tie element calculations, the following describes the errors involved in each of these measurements. When several measurements are required for calculating a parameter, we can estimate the overall uncertainty in the measurement by using the following equation:

$$
\mathbf{e}_{R}=\left[\left(\frac{\partial R}{\partial x_{1}} e_{1}\right)^{2}+\left(\frac{\partial R}{\partial x_{2}} e_{2}\right)^{2}+\left(\frac{\partial R}{\partial x_{n}} e_{n}\right)^{2}+\ldots\right]^{\frac{1}{2}}
$$


where: $\quad \varepsilon_{1}=$ measurement error of parameter $i$

$R=$ relationship between the measured parameters

$x_{1}=$ measured parameter

A $50 \mathrm{~mL}$ cylinder with $1 \mathrm{~mL}$ graduations, resulting in a "least count" of $+1-0.5 \mathrm{~mL}$, was used to measure the slurry sample volume. The balance used to weigh both the solids and the slurry had a precision of $+1-0.05$ grams. The average slurry volume was $34.7 \mathrm{~mL}$ and had an average weight of 47.81 grams. For the slurry density the average uncertainty was calculated as:

Slurry Density $=1.378 \pm 0.020 \mathrm{~g} / \mathrm{mL}( \pm 1.4 \%)$

The filtrate density was calculated by first placing a $10 \mathrm{~mL} \pm 0.01 \mathrm{~mL}$, in a sample jar which weighed $11.2 \pm 0.3 \mathrm{~g}$. The filtrate weight plus the sample jar had an average weight of $24.4 \pm 0.05$. The filtrate density was then calculated by subtracting the weight of the sample jar from the total weight and then dividing by the sample volume. The resulting uncertainty was:

$$
\text { Filtrate Density }=1.320 \pm 0.033 \mathrm{~g} / \mathrm{mL}(2.5 \%)
$$

The average weight of the dry solids sample was 5.53 grams. The error in the $\%$ solids measurement was subject to the precision of the balance for both the solids and the slurry weight where: $\%$ Solids = $\{$ Solids $(g) /$ Slurry $(g)\}{ }^{*} 100$

$$
\text { Percent Solids }=11.57 \pm 0.11 \%(0.9 \%)
$$

Fixed errors arose, however, due to the excessive handling required for each of the solid samples: filtering, washing, drying and weighing. During these steps, solids losses were always a problem. For example if an average of 0.5 grams were lost during these procedures the average percent solids would drop from $11.57 \%$ to $10.52 \%(1.03 \%$ solids difference $)$. 


\section{FLOW RATE MEASUREMENT}

Rotameters were used to measure the flow of raw acid, spent acid and ammonium hydroxide. The calibration curves are given in Appendix II. Due to the variable ranges in these aqueous stream flows and densities, different sized rotameters were employed. The smallest rotameter was used for the ammonium hydroxide flow and the largest was used for the spent flow. The table below gives the stream name, the corresponding fluctuation normally encounter and the associated error in flow which it produced. Fortunately the largest variability resulted in the ammonium hydroxide flow which does not effect the operation of the first two reactors.

Table III-5

ERROR IN FLOW MEASUREMENTS

\begin{tabular}{|c|c|c|c|}
\hline \multirow{2}{*}{ STREAMS } & \multicolumn{3}{|c|}{ FLUCTUATIONS } \\
\cline { 2 - 4 } & $\begin{array}{c}\text { SCALE } \\
\text { (points) }\end{array}$ & $\begin{array}{c}\text { FLOW } \\
\text { (mL/min) }\end{array}$ & $\begin{array}{c}\text { FLOW } \\
(\%)\end{array}$ \\
\hline \hline Ammonium Hydroxide & +1.3 & $+1-0.4$ & +1.17 \\
\hline Raw Acid & +1.2 & +1.0 .06 & +1.6 \\
\hline Spent AcId & $+/ .1$ & $+/-1.1$ & +1.7 \\
\hline
\end{tabular}

The two slurry streams employed self-calibrating metering pumps which could deliver flows with a precision of $0.1 \mathrm{~mL} / \mathrm{min}$. During the course of the experiment, the flow would tend to drift by $0.2 \mathrm{~mL} / \mathrm{min}$ or approximately $2 \%$ of the average slurry flow rates. 


\section{Chapter 4}

\section{EXPERIMENTAL RESULTS}

\subsection{Parameters Investigated}

Experiments were performed with the purpose of studying the transient process response to various step changes in the main feed stream flows. Alth, ugh data were obtained for all five reactors, for the scope of this thesis, only the : asults from the first tank were analyzed in detail. Table IV-1 summarizes the feed streams which were varied during each of the four process identification experiments. The purpose of conducting these types of tests was to obtain a better understanding of the process dynamics. By inducing step changes in the feed stream flows we can quantify the effect of this variable on the process.

Table IV-1

STEP CHANGE FLOWS

\begin{tabular}{|c|c|c|c|c|}
\hline \multirow[b]{2}{*}{ TEST } & \multirow[b]{2}{*}{ INPUT STREAM VARIED } & \multicolumn{2}{|c|}{ INPUT STREAM FLOW $(\mathrm{mL} / \mathrm{min})$} & \multirow[b]{2}{*}{$\%$ CHANGE } \\
\hline & & NORMAL & STEP CHANGE & \\
\hline$B$ & Raw Acid & 0.96 & 1.44 & 50 \\
\hline C & Jarosite Slurry & 12.1 & $\overline{182}$ & 50 \\
\hline$D$ & Spent Acid & 16.1 & 242 & 50 \\
\hline$E$ & Zn Fernte Slurry & 14.0 & 175 & 25 \\
\hline
\end{tabular}

The following paragraphs provide a description of each of the tests shown in Table IV-1. The first test, denoted as TEST A, does not appear in the above table. This experiment involved using zinc ferrite solids from the plant. It was soon realized that these industrial zinc ferrites solids were actually a mixture of $40 \%$ 
ferrite and $60 \%$ jarosite. If we had used these solids for the entire test program then it would not have been possible to study the effect of changing the jarosite slurry flow rate since the system was already saturated with jarosite seed. Consequently, it was decided to use prepared zinc ferrite, which did not contain any jarosite solids, for the subsequent four experiments (Tests $B$ to $E$ ). Since the data from TEST A could not be compared with the other four tests, it was not included in the analysis.

\section{TEST B - Raw Acid Step Change}

A $50 \%$ step change in the raw acid flow was performed in order to study the effect of increased acid concentration in the circuit. It was realized that step increases in the raw acid flow would result in higher acid concentrations in the first tank and consequently would increase the rate of zinc ferrite leaching. Since the raw acid is a concentrated solution of $96 \% \mathrm{H}_{2} \mathrm{SO}_{4}$, the increased flow would not have a diluting effect on the other species in the liquid phase and would furthermore not have a measurable effect on the residence time in the reactors (i.e. the residence time decreased by $1 \%$ from 60 to 59 minutes as a result of this step change).

\section{TEST C - Jarosite Slurry Step Change}

A step change in the jarosite solids concentration was affected by increasing the jarosite slurry flow by $50 \%$ while maintaining the zinc ferrite slurry flow constant. Although these test conditions would result in an increase in the jarosite seeding, a $14 \%$ reduction in the residence time (i.e. from 60 to 52 minutes) would also occur. Furthermore, since the jarosite slurry stream filtrate contains lower concentrations of acid, zinc, and iron compared with the steady-state reactor concentrations, we would expect the concentrations of all of the species in solution to drop in the first reactor. Furthermore, the jarosite solids contain lower mass fractions of zinc and iron compared to the steady-state solids composition in this first tank. Consequently the mass fraction of zinc and iron-in the overall solid phase should also drop. 
TEST D - Spent Acid Step Change

A $50 \%$ increase in the spent acid flow was performed in order to study the effect of an increased acid concentration in the circuit while diluting the zinc and iron concentrations. This step change would also result in an $18 \%$ reduction (i.e. from 60 to 48 minutes) in the residence time. Increased acid concentrations as well as reduced zinc and iron concentrations should result in an overall increase in the rate of zinc ferrite conversion as described by the kinetic expression given by equation 2.7 .

\section{TEST E - Zinc Ferrite Slurry Step Change}

The effect of a step change in the zinc ferrite flow was studied in order to evaluate increased loading or production on the jarosite circuit. Only a $25 \%$ increase was initiated in this test since a larger change would lie outside any plausible operating scenario at the zinc plant. This step increase would result in an $8 \%$ reduction (from 60 to 55 minutes) in the residence time in the circuit and a subsequent dilution in the concentration of all of the species in solution.

In order to simplify the modelling of the jarosite circuit, it was decided not to study the effect of temperature. Although it is well known that temperature has a large impact on both zinc ferrite leaching and jarosite precipitation the temperature remains fairly constant in the actual conversion circuit at CEZinc. With this in mind, the temperature in the reactors was controlled at $98^{\circ} \mathrm{C}$ by thermocouples connected to temperature controllers which would turn the power on and off to the external band heaters. A second thermocouple monitored the tank temperature and this data was recorded using a data acquisition system. The amount of water added to each of the five tanks was adjusted during the first trial test (TEST A) in order to obtain correct solution densities. Once the required water flows to each tank were determined, these flows were kept constant during subsequent experiments. 


\subsection{Mass Balances for First Reactor}

In each of the four experiments, the reactors experienced five sets of conditions:

1. Initial Steady State: All tests were stanted at the same initial conditions.

2. Step-Up Transient: After intlating a step increase in one of the inlet stream flows, the reactors experienced transient conditions

3. Step-Up Steady State: The reactor would reach a new steady stale condition under the step change flow.

4. Step-Down Transient: When the altered flow was returned to its original value, the reactor was once again under transient conditions.

5. Final Steady State: The reactor would attain a final steady state condition under the step-down flows.

The grouping of the data for the evaluation of the steady state concentrations was accomplished by examining the solution and solids species composition profiles, and selecting a group of points for each of the above outlined states. Data from Test $C$, shown in Figure 4-1 demonstrates this rather subjective procedure.

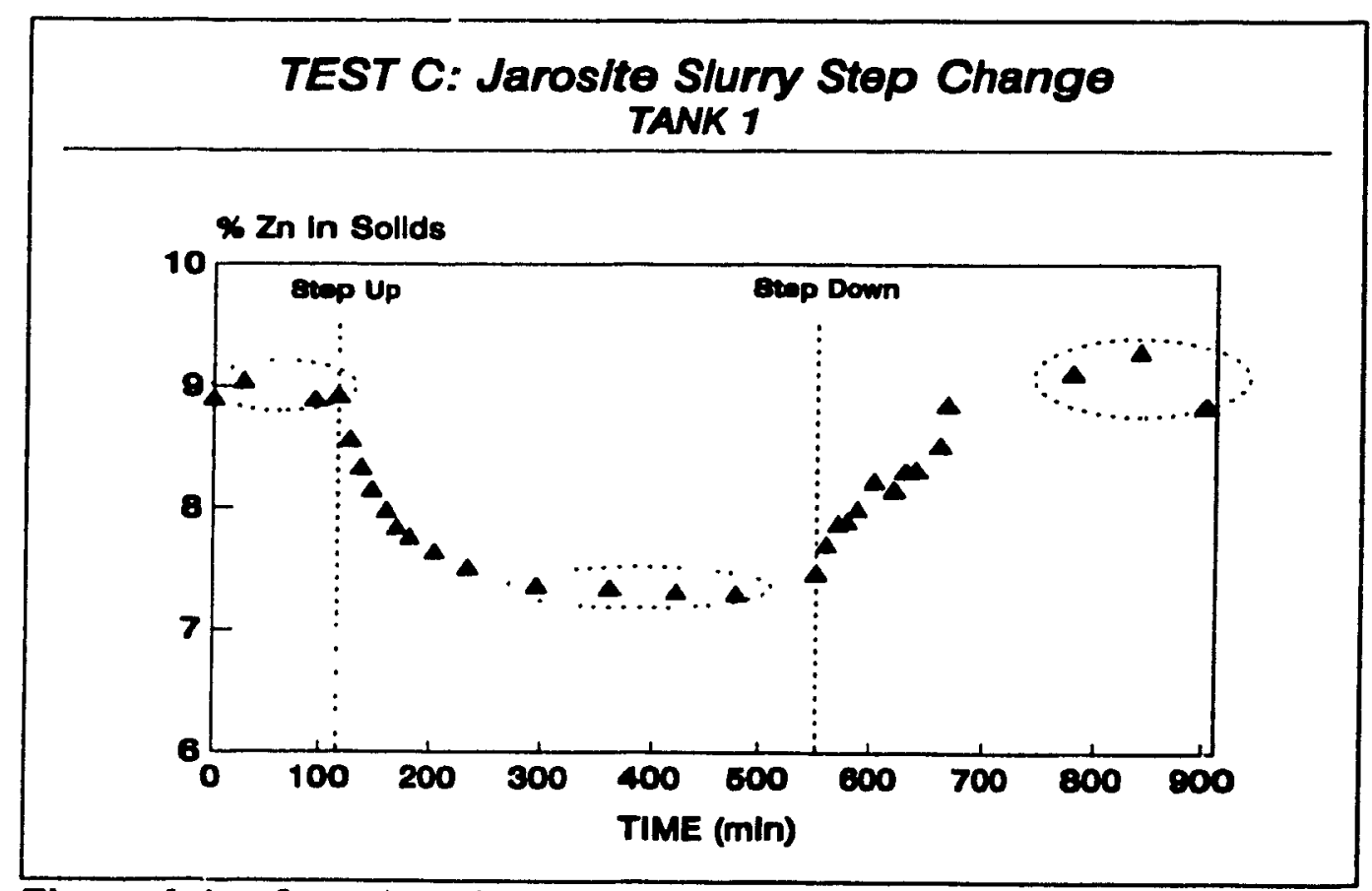

Figure 4-1 Grouping of Data into Process States 
The time span for each of these groups was as follows:

$\begin{array}{ll}\text { Initial Steady State: } & 95 \text { minutes (1.6 hours) } \\ \text { Step-Up Transient: } & 121 \text { minutes (2.0 hours) } \\ \text { Step-Up Steady State: } & 184 \text { minutes (3.1 hours) } \\ \text { Step-Down Transient: } & 118 \text { minutes (2.0 hours) } \\ \text { Final Steady State: } & 121 \text { minutes (2.0 hours) }\end{array}$

From the above information it can be disputed that perhaps one or two additional data points should have been added or discarded from the transient stages. It was found, however, that small adjustments to the number of points in each group did not have a large effect on the steady-state mass balance and reaction extent calculations.

Mass balances for the first reactor were calculated for the three steady state conditions as described above. The streams entering and leaving the first tank are displayed in Figure 4-2. As described in section 3.2, there are five feed streams entering tank 1 and two streams (slurry and water evaporation) leaving this reactor. All of the inlet flows and densities were measured. The exit stream density (refer to section 3.3) was also measured and the exit evaporation rate was determined by conducting an evaporation test using Jarosite filtrate. The results from this study are shown in Appendix III. An attempt was made to measure the exit flow from each of the reactor over-flow streams by taking samples for exactly one minute and recording the sample volume. The resulting calculated flows, however, were found to be erratic from sample to sample. Observations of the exit stream showed that the outlet flow was actually flowing in spurts and a longer average sample would give more steady results than a one minute sample. Since it was impossible to disrupt the exit flow for such long periods of time, it was decided to calculate the outlet flow by performing a mass balance around each tank. 


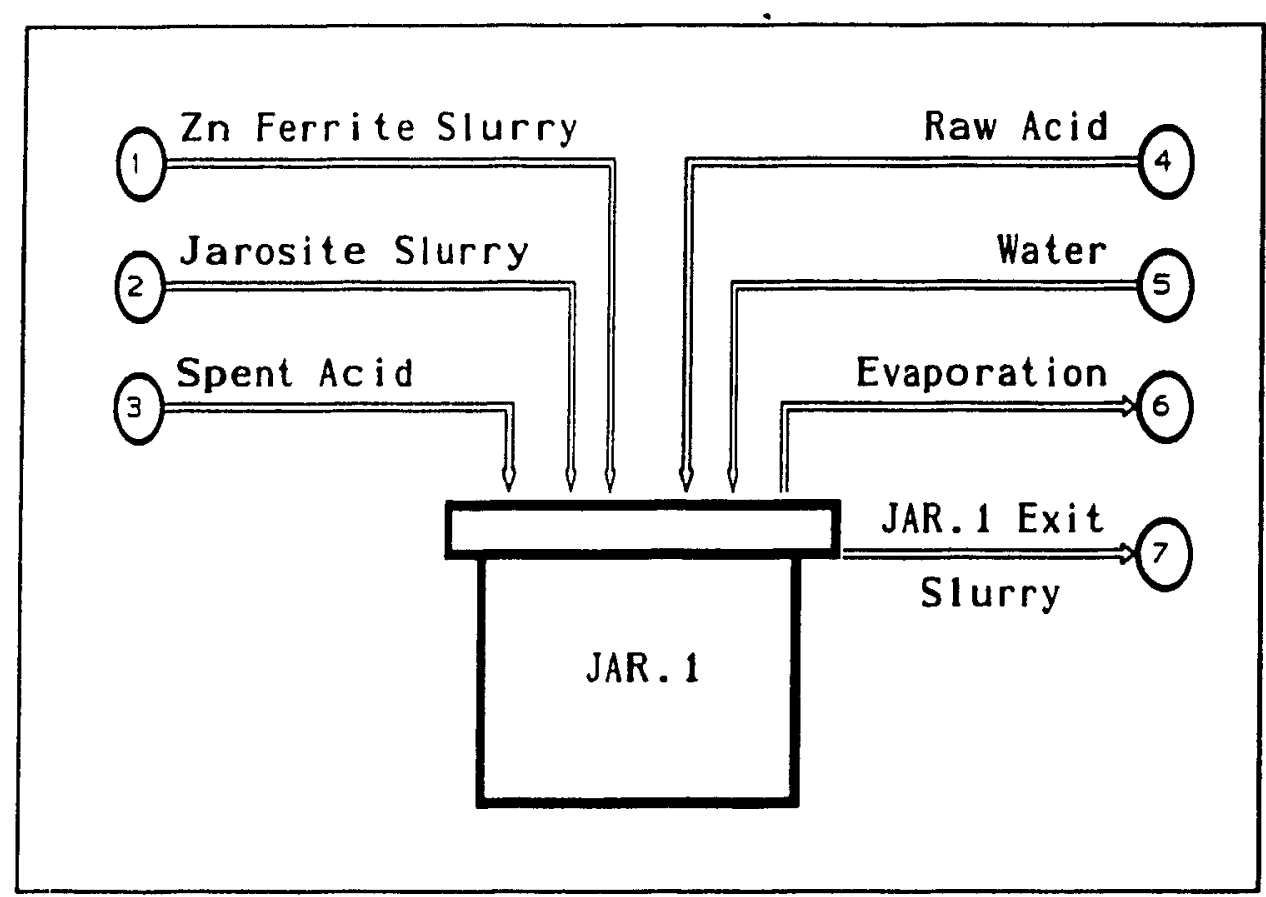

Figure 4-2 Jarosite Tank 1

Tank 1 exit Flow:

$$
Q_{7}=\frac{\sum_{n=1}^{5} \rho_{n} Q_{n}-\dot{M}_{6}}{\rho_{7}}
$$

where,

$$
\begin{array}{ll}
Q_{n}: & \text { volumetric flow of stream } n, m L / m i n \\
\rho_{n}: & \text { density of stream } n, g / m L \\
M_{n}: & \text { Mass flow of stream } n, g / m i n
\end{array}
$$

In order to get an understanding of the amount of data collected for each experiment, Appendix VIII shows the assay results for the first tank in Tests B, C, $\mathrm{D}$ and $\mathrm{E}$. Following each steady state "process condition", an average and a sample standard deviation was computed. The percent standard deviation was 
then calculated by dividing the deviation by the average value.

Table IV-2 shows the measured average slurry densities and the calculated average exit flows during each steady state obtained during Test $B$. The effluent slurry flow from the first tank, shown in the last column, was calculated using Equation 4.1. In this experiment, since a $50 \%$ increase in the aw acid flow did not result in a large increase in the overall flow out of the reactor, we can see that manipulation of this stream does not have a significant effect on the residence time in the reactor.

Table IV-2

TEST B - TANK 1 EXIT FLOW

\begin{tabular}{||c|c||c|c|}
\hline \multirow{2}{*}{ STEADY STATE } & \multirow{2}{*}{$\begin{array}{c}\text { RAW ACID } \\
\text { FLOW }(\mathrm{mL} / \mathrm{min})\end{array}$} & \multicolumn{2}{|c|}{ EXIT STREAM SLURRY } \\
\cline { 3 - 4 } & DENSITY $(\mathrm{g} / \mathrm{mL})$ & FLOW $(\mathrm{mL} / \mathrm{min})$ \\
\hline INITIAL & 0.96 & 1.42 & 40.3 \\
\hline STEP CHANGE & 1.44 & 1.43 & 40.6 \\
\hline FINAL & 1.04 & 1.43 & 40.1 \\
\hline
\end{tabular}

Tables IV-3 and IV-4 show the acid consumption as well as the elemental zinc mass balances for the first tank in Test B. In these tables all of the stream data were measured with the exception of the exit stream flow, which was calculated using equation 4.1 and the filtrate flow, $F_{1}$ calculated using the following:

$$
F_{1}=\frac{\rho_{1} Q_{1}\left(1-X_{\text {sollds }}\right)}{\rho_{\text {tiltrale, }}}
$$

$\rho_{\text {intrate }}: \quad$ filtrate density, $\mathrm{g} / \mathrm{mL}$

$\mathrm{X}_{\text {solds }}$ : $\quad$ mass fraction of solids in the slurry stream 
Table IV-3

TEST B - TANK 1: ACID CONSUMPTION

TANK 1: Initial Steady State

\begin{tabular}{|c|c|c|c|c|c|c|c|}
\hline $\begin{array}{l}\text { Stream } \\
\text { Name }\end{array}$ & $\begin{array}{c}\text { Stream } \\
\#\end{array}$ & $\begin{array}{c}\text { Flow } \\
\text { (mL/min) }\end{array}$ & $\begin{array}{l}\text { Slurry Density } \\
(\mathrm{g} / \mathrm{mL})\end{array}$ & $\begin{array}{c}\text { Filt. Density } \\
(g / \mathrm{mL})\end{array}$ & $\begin{array}{c}\text { Solids } \\
(\%)\end{array}$ & $\begin{array}{l}\text { Filtrate } \\
\text { (mL/mın) }\end{array}$ & $\begin{array}{c}\mathrm{H}_{2} \mathrm{SO}_{4} \\
(\mathrm{~g} / \mathrm{L})\end{array}$ \\
\hline Ferrite Slurry & 1 & 14.0 & 1.473 & 1.298 & 16.5 & 13.3 & 2.00 \\
\hline Jar Slurry & 2 & 12.1 & 1.385 & 1.156 & 30.9 & 10.0 & 16.43 \\
\hline Spent & 3 & 16.1 & $\ddot{*}$ & 1.279 & -. & 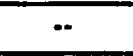 & 188.20 \\
\hline Raw Acid & 4 & 0.96 & $\ddot{*}$ & 1.831 & 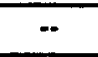 & $\ddot{*}$ & 1762.10 \\
\hline JAR.1 Exit & 7 & 40.3 & 1.419 & 1.355 & 11.7 & 37.3 & 48.84 \\
\hline OVERALL & IN & OUT & CHANGE & $\%$ Reacted & & & \\
\hline$(g / m i n)$ & 4.70 & 1.82 & -2.88 & 38.74 & & & \\
\hline (mol/mın) & $479 e-2$ & $1.86 \mathrm{e}-2$ & $.294 e-2$ & & & & \\
\hline
\end{tabular}

TANK 1: Step Change Steady State

\begin{tabular}{|c|c|c|c|c|c|c|c|}
\hline $\begin{array}{l}\text { Stream } \\
\text { Name }\end{array}$ & $\begin{array}{c}\text { Stream } \\
\#\end{array}$ & $\begin{array}{c}\text { Flow } \\
(\mathrm{mL} / \mathrm{min})\end{array}$ & $\begin{array}{l}\text { Slurry Density } \\
(\mathrm{g} / \mathrm{mL})\end{array}$ & $\begin{array}{c}\text { Filt. Density } \\
(\mathrm{g} / \mathrm{mL})\end{array}$ & $\begin{array}{c}\text { Solids } \\
(\%)\end{array}$ & $\begin{array}{l}\text { Filtrate } \\
(\mathrm{mL} / \mathrm{min})\end{array}$ & $\begin{array}{c}\text { H2SO4 } \\
(g / L)\end{array}$ \\
\hline Ferrite Slurny & 1 & 14.0 & 1.473 & 1.298 & 16.5 & 13.3 & 2.00 \\
\hline Jar Slurry & 2 & 12.1 & 1.385 & 1.156 & 30.9 & 10.0 & 16.43 \\
\hline Spent & 3 & 16.1 &.$\cdot$ & 1.279 & -- & 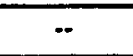 & 188.20 \\
\hline Raw AcId & 4 & 1.44 & .. & 1.831 & $\cdots$ & 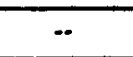 & 1762.10 \\
\hline JAR.1 Ex\|t & 7 & 40.6 & 1.433 & 1.339 & 11.6 & 38.4 & 59.88 \\
\hline OVERALL & $\overline{I N}$ & OUT & CHANGE & $\%$ Reacted & & & \\
\hline$(\mathrm{g} / \mathrm{min})$ & 555 & 2.30 & -3.25 & 41.41 & & & \\
\hline (mol/min) & $5.66 \mathrm{e} \cdot 2$ & $2.34 \mathrm{e}-2$ & $.3 .31 e-2$ & & & & \\
\hline
\end{tabular}

TANK 1: Final Steady State

\begin{tabular}{|c|c|c|c|c|c|c|c|}
\hline $\begin{array}{l}\text { Stream } \\
\text { Name }\end{array}$ & $\begin{array}{c}\text { Stream } \\
\#\end{array}$ & $\begin{array}{c}\text { Flow } \\
(\mathrm{mL} / \mathrm{m} \mathrm{n})\end{array}$ & $\begin{array}{l}\text { Slurry Density } \\
\qquad(\mathrm{g} / \mathrm{mL})\end{array}$ & $\begin{array}{c}\text { Filt. Density } \\
(g / \mathrm{mL})\end{array}$ & $\begin{array}{l}\text { Solids } \\
(\%)\end{array}$ & $\begin{array}{l}\text { Filtrate } \\
\text { (mL/min) }\end{array}$ & $\begin{array}{c}\mathrm{H} 2 \mathrm{SO} 4 \\
(\mathrm{~g} / \mathrm{L})\end{array}$ \\
\hline Ferrite Slurry & 1 & 14.0 & 1.473 & 1.298 & 10.5 & 13.3 & 2.00 \\
\hline Jar Slurry & 2 & 12.1 & 1.385 & 1.156 & 30.9 & 10.0 & 16.43 \\
\hline Spent & 3 & 161 & $\ddot{*}$ & 1.279 & - & 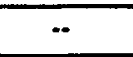 & 188.20 \\
\hline Raw Acid & 4 & 104 & .. & 1.831 & -- & .. & 1762.10 \\
\hline JAR.1 ExIt & 7 & 40.1 & 1.433 & 1.327 & 12.5 & 37.9 & 51.75 \\
\hline OVERALL & IN & OUT & CHANGE & \% Reacted & & & \\
\hline$(g / m i n)$ & 4.84 & 1.96 & -2.88 & 40.47 & & & \\
\hline$(\mathrm{mol} / \mathrm{min})$ & $4.94 \mathrm{e}-2$ & $2.00 e-2$ & $-2.94 \mathrm{e}-2$ & & & & \\
\hline
\end{tabular}


Table IV-4

TEST B - TANK 1: ZINC MASS BALANCE

TANK 1: Initial Steady State

\begin{tabular}{|c|c|c|c|c|c|c|c|c||}
\hline $\begin{array}{c}\text { Stream } \\
\text { Name }\end{array}$ & $\begin{array}{c}\text { Stream } \\
\text { (mL/min) }\end{array}$ & $\begin{array}{c}\text { Flow } \\
(\mathrm{g} / \mathrm{mL})\end{array}$ & $\begin{array}{c}\text { Slurry Dens. } \\
(\mathrm{g} / \mathrm{mL})\end{array}$ & $\begin{array}{c}\text { Filt. Dens. } \\
(\%)\end{array}$ & $\begin{array}{c}\text { Solids } \\
(\mathrm{mL} / \mathrm{min})\end{array}$ & $\begin{array}{c}\text { Zn } \\
(\mathrm{g} / \mathrm{L})\end{array}$ & $\begin{array}{c}\text { 2n } \\
(\%)\end{array}$ \\
\hline \hline Ferrite Slurry & 1 & 14.0 & 1.473 & 1.298 & 16.5 & 13.3 & 95.66 & 25.95 \\
\hline Jar Slurry & 2 & 12.1 & 1.385 & 1.156 & 30.9 & 10.0 & 63.94 & 2.91 \\
\hline Spent & 3 & 16.1 & $\cdots$ & 1.279 & $\cdots$ & $\cdots$ & 46.40 & - \\
\hline JAR.1 Exit & 7 & 40.3 & 1.419 & 1.355 & 11.7 & 37.3 & 88.97 & 9.02 \\
\hline OVERALL & $\mathbb{N}$ & OUT & CHANGE & $\%$ M.BAL & & & & \\
\hline (g/min) & 3.69 & 392 & 0.23 & 1063 & & & & \\
\hline (mol/min) & $4.06 \mathrm{e}-2$ & $5.07 \mathrm{e}-2$ & $7.09 \mathrm{e}-3$ & &
\end{tabular}

TANK 1: Step Change Steady State

\begin{tabular}{|c|c|c|c|c|c|c|c|c||}
\hline $\begin{array}{c}\text { Stream } \\
\text { Name }\end{array}$ & $\begin{array}{c}\text { Stream } \\
(\mathrm{mL} / \mathrm{min})\end{array}$ & $\begin{array}{c}\text { Flow } \\
(\mathrm{g} / \mathrm{mL})\end{array}$ & $\begin{array}{c}\text { Slurry Dens. Dens. } \\
(\mathrm{g} / \mathrm{mL})\end{array}$ & $\begin{array}{c}\text { Solids } \\
(\%)\end{array}$ & $\begin{array}{c}\text { Filt. } \\
(\mathrm{mL} / \mathrm{min})\end{array}$ & $\begin{array}{c}\text { Zn } \\
(\mathrm{g} / \mathrm{L})\end{array}$ & $\begin{array}{c}\text { Zn } \\
(\%)\end{array}$ \\
\hline \hline Ferrite Slurry & 1 & 14.0 & 1473 & 1.298 & 16.5 & 13.3 & 95.66 & 25.95 \\
\hline Jar Slurry & 2 & 12.1 & 1.385 & 1.156 & 30.9 & 10.0 & 63.94 & 2.91 \\
\hline Spent & 3 & 16.1 & $-\cdot$ & 1.279 & $-\cdot$ & $-\cdot$ & 46.40 & - \\
\hline JAR.1 Exit & 7 & 40.6 & 1.433 & 1.339 & 11.6 & 38.4 & 87.93 & 7.56 \\
\hline OVERALL & $\mathbb{N}$ & OUT & CHANGE & $\%$ M.BAL & & & & \\
\hline (g/min) & 3.69 & 3.88 & O.19 & 105.3 & & & &
\end{tabular}

TANK 1: Final Steady State

\begin{tabular}{|c|c|c|c|c|c|c|c|c|}
\hline $\begin{array}{l}\text { Stream } \\
\text { Name }\end{array}$ & $\begin{array}{c}\text { Stream } \\
\#\end{array}$ & $\begin{array}{c}\text { Flow } \\
\text { (mU/min) }\end{array}$ & $\begin{array}{l}\text { Slurry Dens. } \\
\qquad(\mathrm{g} / \mathrm{mL})\end{array}$ & $\begin{array}{c}\text { Filtrate } \\
\text { Dens.g/mL) }\end{array}$ & $\begin{array}{c}\text { Solids } \\
(\%)\end{array}$ & $\begin{array}{l}\text { Filltrate } \\
(\mathrm{mL} / \mathrm{min})\end{array}$ & $\begin{array}{l}\mathrm{Zn} \\
(g / L)\end{array}$ & $\begin{array}{l}\mathrm{Zn} \\
(\%)\end{array}$ \\
\hline Ferrite Slurry & 1 & 14.0 & 1.473 & 1.298 & 16.5 & 13.3 & 95.66 & 25.95 \\
\hline Jar Slurry & 2 & 121 & 1.385 & 1.156 & 30.9 & 10.0 & 63.94 & 2.91 \\
\hline Spent & 3 & 161 & .- & $\overline{1.279}$ & .. & .. & 46.40 & - \\
\hline JAR.1 ExIt & 7 & 40.1 & 1.433 & 1.327 & 12.5 & 37.9 & 86.79 & 8.11 \\
\hline OVERALL & $\overline{\mathbb{N}}$ & OUT & CHANGE & $\%$ M.BAL & & & & \\
\hline$(\mathrm{g} / \mathrm{min})$ & 3.69 & 3.87 & 017 & 104.7 & & & & \\
\hline$(\mathrm{mol} / \mathrm{min})$ & $4.06 \mathrm{e}-2$ & $5.03 e-2$ & $7.35 \mathrm{e}-3$ & & & & & \\
\hline
\end{tabular}


The acid consumption and zinc mass balances are calculated by dividing the outlet mass flow from the reactor by the inlet flows. An example of this calculation is given by equation 4.3 .

$$
\% \text { Mass Bal. }=\frac{\dot{M}_{7} s_{7} s_{7_{1}}+C_{7_{1}} F_{7}}{\sum_{n=1}^{2} \dot{M}_{n} s_{n} s_{n_{1}}+\sum_{n=1}^{4} C_{n_{1}} F_{n}} \times 100 \%
$$

where, $\quad M_{n}$ : Mass flow of stream $n, g / m i n$

$s_{n}$ : Mass fraction of solids in stream $n, \%$

$s_{n 1}$ : Mass fraction of component $i$ in solids in stream $n, \%$

$F_{n}$ : Filtrate flow in stream $\mathrm{n}, \mathrm{mL} / \mathrm{min}$

$C_{n}$ : Component i concentration in stream $n, g / m L$

The change in the number of moles of component is calculated from;

$$
\Delta \text { moles }{ }_{1}=N_{7} F_{7}-\left(N_{1}, F_{1}+N_{2} F_{2}+N_{3}, F_{3}+N_{4} F_{4}\right)
$$

where: $N_{n 1}$ is the molar concentration of component $i$ in stream $n(m o l / m L)$. This result will be used later to estimate the reaction extent.

In order to correct for discrepancies in the mass balances, the change in the number of moles for the zinc and iron was adjusted using the mass balance closure result (which was normally close to $100 \%$ ). This was accomplished by dividing the outlet molar flow rate of element $i$ by its calculated percent mass balance result.

The percentage of acid consumed along with the solids that were leached in the first reactor is shown in Table IV-5 for each of the four experiments. The average initial acid consumption was approximately $37 \%$ for each of the tests. In each of these experiments, however, the final acid concentration usually differed from that observed during the initial steady-state condition due to problems in returning the 
manipulated feed streams back to precisely their original flow-rates.

If we take an average of the four experiments, we find that the initial amount of solids that were leached was $19.0 \%+/-1.9$. An explanation for this large standard deviation between the experiments is most likely due to the variable composition of the zinc ferrite solids. As previously mentioned, the zinc ferrite solids were prepared in batches with a different batch used for each test. The solid compounds present in each batch have been calculated in Appendix IV and have shown to contain between 90 to $94 \%$ zinc ferrite and between 0 to $5 \%$ ferric hydroxide. Since ferric hydroxide leaches readily under the conditions in the first reactor, the solids leached would vary according to the amount of ferric hydroxide present in the ferrite feed stream.

Table IV-5

TANK 1: ACID CONSUMED AND SOLIDS LEACHED

\begin{tabular}{||c||c|c|c||c|c|c||}
\hline \multirow{2}{*}{$\begin{array}{c}\text { TEST } \\
\text { DESCRIPTION }\end{array}$} & \multicolumn{2}{|c|}{ H2SO4 Consumption (\%) } & \multicolumn{3}{|c||}{ Solids Leached (\%) } \\
\cline { 2 - 7 } & INIT & STEP & FINAL & INIT & STEP & FINAL \\
\hline \hline B - Raw AcId & 38.7 & 41.4 & 40.5 & 217 & 21.2 & 16.7 \\
\hline C - Jar. Seed & 36.9 & 41.5 & 37.9 & 17.6 & 9.5 & 19.3 \\
\hline D - Spent AcId & 35.3 & 46.4 & 41.2 & 19.2 & 19.3 & 24.4 \\
\hline E - Ferrile & 38.6 & 38.3 & 44.1 & 18.0 & 15.7 & 21.1 \\
\hline
\end{tabular}

Mass Balance results for zinc, iron, and lead from the tests $B, C, D$, and $E$ are provided in Table IV-6a for Tank 1 and Table IV-6b for Tank 2 . From the results of the first tank, we see that all of the mass balances are above $89 \%$ and below $112 \%$. This result is quite acceptable considering the experiments were carried out on a pilot scale. The mass balances from the second tank which lie between 
88 to $130 \%$ are comparatively larger than the results from the first tank. If we compare the results from these two tables, it becomes clear that low mass balances in the first reactor are followed by high mass balances in the second tank since the errors are compounded.

\section{Table IV-6a}

TANK 1: MASS BALANCES FOR ZINC, IRON AND LEAD

\begin{tabular}{|c|c|c|c|c|c|c|c|c|c|}
\hline \multirow{2}{*}{$\begin{array}{c}\text { TEST } \\
\text { DESCRIPTION }\end{array}$} & \multicolumn{3}{|c|}{ Zn MASS BALANCE (\%) } & \multicolumn{3}{|c|}{ Fe MASS BALANCE (\%) } & \multicolumn{3}{|c|}{ Pb MASS BALANCE (\%) } \\
\hline & INIT & STEP & FINAL & INIT & STEP & FINAL & INIT & STEP & FINAL \\
\hline B - Raw Acid & 106 & 105 & 105 & 91 & 91 & 102 & 89 & 90 & 99 \\
\hline C - Jar. Seed & 92 & 91 & 101 & 97 & 100 & 100 & 101 & 104 & 103 \\
\hline D - Spent Acid & 93 & 98 & 94 & 100 & 112 & 100 & 98 & 103 & 95 \\
\hline E - Ferrite & 92 & 97 & 99 & 97 & 98 & 91 & 96 & 101 & 97 \\
\hline
\end{tabular}

Table IV-6b

TANK 2: MASS BALANCES FOR ZINC, IRON AND LEAD

\begin{tabular}{|c|c|c|c|c|c|c|c|c|c|}
\hline \multirow{2}{*}{$\begin{array}{c}\text { TEST } \\
\text { DESCRIPTION }\end{array}$} & \multicolumn{3}{|c|}{ Zn MASS BALANCE $(\%)$} & \multicolumn{3}{|c|}{ Fe MASS BALANCE (\%) } & \multicolumn{3}{|c|}{ Pb MASS BALANCE (\%) } \\
\hline & INIT & STEP & FINAL & INIT & STEP & FINAL & INIT & STEP & FINAL \\
\hline B - Raw Acld & 97 & 100 & 101 & 105 & 111 & 99 & 119 & 130 & 117 \\
\hline C - Jar. Seed & 104 & 108 & 100 & 100 & 98 & 100 & 111 & 110 & 117 \\
\hline D - Spent Acid & 100 & 104 & 106 & 91 & 88 & 95 & 110 & 115 & 116 \\
\hline E - Ferrite & 106 & 100 & 101 & 101 & 101 & 100 & 116 & 112 & 113 \\
\hline
\end{tabular}




\subsection{Statistical Analysis}

To quantify whether a process change occurred during each of the step change process identification experiments, a statistical examination of the steady-state averages was conducted. A hypothesis test for the sample means was carried out by using a t-distribution with a $95 \%$ confidence limit. The details of this calculation procedure are provided in Appendix VI. The hypothesis states that there is a significant difference between the sample means. Consequently, if the hypothesis is accepted we can assume that a process change occurred. If, however, the hypothesis is rejected, we can conclude that there is no significant difference between the initial and the step change steady-state mean. The results from this hypothesis testing are summarized in Tables IV-7a,b for the aqueous concentrations and in Tables IV-8a,b for the solid species.

\section{Table IV-7a}

\section{COMPARISON OF INITIAL \& STEP CHANGE STEADY STATE ACID CONCENTRATIONS FOR TANK 1}

(0.2 $\mathrm{g} / \mathrm{L}$ analytical error)

\begin{tabular}{|c|c|c||c|c|c||}
\hline $\begin{array}{c}\text { TEST } \\
\text { DESCRIPTION }\end{array}$ & $\begin{array}{c}\text { AVG. INIT } \\
\text { [acid] }(\mathbf{g} / \mathbf{L})\end{array}$ & $\begin{array}{c}\text { AVG. STEP } \\
\text { [acid] }(g / \mathbf{l})\end{array}$ & $\begin{array}{c}\text { INITIAL STD } \\
(\mathbf{g} / \mathbf{L})\end{array}$ & $\begin{array}{c}\text { STEP STD } \\
(\mathbf{g} / \mathbf{L})\end{array}$ & $\begin{array}{c}\text { T-lest } \\
\text { RESULT }\end{array}$ \\
\hline \hline B- Raw Acid & 48.8 & 59.9 & 0.6 & 1.9 & accept \\
\hline C. Jar. Seed & 46.5 & 46.9 & 0.1 & 0.4 & reject \\
\hline D. Spent Acid & 43.8 & 62.8 & 2.5 & 3.0 & accept \\
\hline E- Ferrile & 48.0 & 42.9 & 2.1 & 0.5 & accept \\
\hline
\end{tabular}

As expected, the acid concentration was found to increase during tests $B$ and $D$ where the flows of the strong acid streams were increased. The acid was found to decrease during Test $E$ due to the dilution effect of the zinc ferrite slurry. In Test $C$ where the hypothesis was rejected, the acid concentration in the jarosite 
slurry is approximately the same as the concentration found in the first tank; thus no significant difference was expected.

Increased leaching of the zinc ferrites resulted in a rise in the iron concentration after the step change in the Raw acid stream flow (Test B, Table IV-7b). Increased ferrite leaching in Test $D$, however, was not enough to result in a rise in the iron concentration. This result can be attributed to the dilution effect of the spent acid stream as well as the reduced residence time experienced in the first reactor as a consequence of this step change.

During the jarosite slurry step change test (Test $C$ ) a significant decrease in the iron concentration was observed. This change may have resulted from either a dilution effect since the jarosite filtrate has a lower iron concentration than that found in the first tank or from increased jarosite precipitation.

Table IV-7b

COMPARISON OF INITIAL \& STEP CHANGE STEADY STATE IRON CONCENTRATIONS FOR TANK 1

(0.5 - $0.9 \mathrm{~g} / \mathrm{L}$ analytical error)

\begin{tabular}{|c|c|c|c|c|c|}
\hline $\begin{array}{c}\text { TEST } \\
\text { DESCRIPTION }\end{array}$ & $\begin{array}{l}\text { AVG. INIT } \\
{[\mathrm{Fe}](g / L)}\end{array}$ & $\begin{array}{l}\text { AVG. STEP } \\
{[\mathrm{Fe}](\mathrm{g} / \mathrm{L})}\end{array}$ & $\begin{array}{l}\text { INITIAL STD } \\
(g / L)\end{array}$ & $\begin{array}{c}\text { STEP STD } \\
(g / L)\end{array}$ & $\begin{array}{l}\text { T.TEST } \\
\text { RESULT }\end{array}$ \\
\hline B - Raw Acid & 249 & 27.6 & 0.9 & 0.8 & accept \\
\hline C-Jar. Seed & 245 & 20.5 & 1.6 & 0.1 & accept \\
\hline D-Spent AcId & 357 & 353 & 14 & 0.3 & reject \\
\hline E- Ferrite & 236 & 24.4 & 0.9 & 0.8 & reject \\
\hline
\end{tabular}


Since the sample variance for the soluble zinc analysis was quite large, the hypothesis was rejected for each of the four experiments. Consequently, no conclusions can be drawn from this data.

Table IV-8a

COMPARISON OF INITIAL \& STEP CHANGE STEADY STATE

IRON IN SOLIDS FOR TANK 1

( $0.5 \%$ solids analytical error)

\begin{tabular}{|c||c|c||c|c|c||}
\hline $\begin{array}{c}\text { TEST } \\
\text { DESCRIPTION }\end{array}$ & $\begin{array}{c}\text { AVG. INIT } \\
\mathrm{Fe}(\%)\end{array}$ & $\begin{array}{c}\text { AVG. STEP } \\
\mathrm{Fe} \%\end{array}$ & $\begin{array}{c}\text { INITIAL STD } \\
(\%)\end{array}$ & $\begin{array}{c}\text { STEP STD } \\
(\%)\end{array}$ & $\begin{array}{c}\text { T-lest } \\
\text { Result }\end{array}$ \\
\hline \hline B - Raw AcId & 327 & 303 & 0.5 & 0.3 & accept \\
\hline C - Jar. Seed & 35.6 & 35.4 & 0.5 & 03 & reject \\
\hline D. Spent AcId & 358 & 35.3 & 0.4 & 03 & reject \\
\hline E - Ferrte & 354 & 338 & 0.1 & 01 & accept \\
\hline
\end{tabular}

Although both tests $B$ and $D$ resulted in increased acid concentrations, which should translate into increased zinc ferrite leaching, the iron in the solids was found to drop significantly in Test B only (Table IV-8a). Surprisingly, a significant drop in the iron concentration occurreci in Test $E$ where the zinc ferrite solids flow was increased. Since the zinc ferrite solids contain more iron than the tank 1 solids, this process change should have resulted in an increase in the percent iron. The discrepancies in the above results can be attributed to the large (i.e. 0.5 mass fraction \%) analytical error involved in iron determinations. 
Table IV-8b

COMPARISON OF INITIAL \& STEP CHANGE STEADY STATE ZINC IN SOLIDS FOR TANK 1

( $0.1 \%$ solids analytical error)

\begin{tabular}{|c|c|c||c|c|c||}
\hline $\begin{array}{c}\text { TEST } \\
\text { DESCRIPTION }\end{array}$ & $\begin{array}{c}\text { AVG. INIT } \\
\text { Zn (\%) }\end{array}$ & $\begin{array}{c}\text { AVG. STEP } \\
\text { Zn (\%) }\end{array}$ & $\begin{array}{c}\text { INTIAL STD } \\
(\%)\end{array}$ & $\begin{array}{c}\text { STEP STO } \\
(\%)\end{array}$ & $\begin{array}{c}\text { T-TEST } \\
\text { RESULT }\end{array}$ \\
\hline \hline B- Raw AcId & 9.0 & 7.6 & 0.2 & 0.3 & accept \\
\hline C- Jar. Seed & 9.0 & 7.3 & 0.1 & 0.03 & accept \\
\hline D- Spent Acld & 9.2 & 84 & 0.0 & 0.2 & accept \\
\hline E- Ferrite & 8.6 & 103 & 0.1 & 0.2 & accept \\
\hline
\end{tabular}

The mass fraction of zinc in the solid phase (Table IV-8b) decreased substantially during the step change steady-state in tests $B$ and $D$. This composition change is due to increased zinc ferrite leaching resulting from higher acid concentrations in the first reactor following the step increase in the acid stream flows. The large drop in the zinc composition in the solids observed during Test $\mathrm{C}$ was a consequence of the increased jarosite slurry flow to the reacior. Since the industrial jarosite solids contain only a small percentage of zinc this result was expected.

In all of the above statistical results, with the exception of the iron assay in the solids, the standard deviation within the steady state conditions is normally larger than the analytical error. This observation demonstrates that other errors resulted from random variations in the feed stream flows and compositions as well as from sample handling.

It should be noted that in order to use the above hypothesis test, it is necessary 
to assume that the population variances between the sample sets are essentially the same. To verify this criterion, an $F$ test was performed on the sample variances. Results from this calculation demonstrated that there were no significant differences between the sample variances. This conclusion helps to validate the use of the t-distribution hypothesis test.

\subsection{Determination of the Rate Constant}

For a constant volume CSTR with multiple reactions, the change in the molar concentration of component $i$ with time can be written as follows:

$$
\frac{d C_{1}}{d t}=\frac{\left(F_{F E E D_{1}}-F_{E X I T}\right)}{V}+\sum_{i=1}^{J} v_{\mu} r_{1}
$$

At steady-state, the change in the number of moles of $i$ with time is equal to zero. By combining the definition of the reaction extent;

$$
F_{E X I T_{,}}-F_{F E E D,} \equiv \sum_{J=1}^{J} v_{J} \varepsilon_{J}
$$

with

$$
F_{E X I T}-F_{F E E D,}=\sum_{J-1}^{J} v_{J}, r_{J} V
$$

we can obtain the following:

$$
r_{J}=\frac{\varepsilon_{J}}{V}
$$

There are two main reactions occurring in the conversion circuit. The first is the dissolution of zinc ferrite, and the second is the precipitation of jarosite. Using the reaction rate expressions obtained from the literature review, we can calculate a reaction rate constant. This result will then be used in the modelling work which is covered in the subsequent chapter. 
For the kinetics of zinc ferrite dissolution, a rate law of the form suggested by Elgersma can be assumed:

$$
r_{1}=k_{1} \sqrt{\frac{\left[H^{+}\right]}{\left[F e^{3+}\right]}}
$$

For jarosite precipitation, equation 4.10 can be used:

$$
r_{2}=k_{2} \frac{\left[\mathrm{Fe}^{3 .}\right]^{2406}\left[\mathrm{NH}_{4}\right]^{106}[\mathrm{NH} 4-\mathrm{JAR}]^{0685}}{\left[\mathrm{H}_{2} \mathrm{SO}_{4}\right]^{3719}}
$$

Due to the high concentration of acid present in the first jarosite reactor, we expect a very small amount of jarosite precipitation. With this assumption, the jarosite reaction extent can be neglected and the extent of the first reaction can be calculated from the experimental results:

$$
\varepsilon_{1}=\frac{\left(F_{F E E D_{n}}-F_{n}\right)}{v_{1}}
$$

To calculate the rate constant, $k_{1}$, we can combine equations 4.8 and 4.9 to give:

$$
k_{1}=\frac{\varepsilon_{1}}{V_{\text {TANK, }}} \sqrt{\frac{\left[F e^{3 \cdot}\right]}{\left[H^{\cdot}\right]}} \quad\left(\frac{\mathrm{mol}}{\mathrm{min} \cdot L}\right)
$$

Table IV-9 gives a summary of the reaction extents and the corresponding rate constants calculated using the average steady-state experimental data for the three components in solution. Within each experiment's steady state condition, the reaction extent calculated from 4.11 must be the same for all components. Furthermore, the rate constant $k_{1}$ must be the same in all cases. With this in mind, an average rate constant was calculated and found to be equal to:

$1.76 \times 10^{-3}+/-0.28$ (mol/L.min). 
Table IV-9

REACTION EXTENTS AND RATE CONSTANTS

\begin{tabular}{|c|c|c|c|c|c|c|c|c|c|c|c|}
\hline \multirow{2}{*}{ TEST } & \multirow{2}{*}{ COMP. } & \multirow{2}{*}{$\begin{array}{l}\text { STOIC. } \\
\text { COEFF. }\end{array}$} & \multicolumn{3}{|c|}{ INITIAL } & \multicolumn{3}{|c|}{ STEP CHANGE } & \multicolumn{3}{|c|}{ FINAL } \\
\hline & & & $1] \mathrm{g} / \mathrm{L}$ & EXT. & $k$ & $\| g / L$ & EXT. & $k$ & ] $g / L$ & EXT. & $k$ \\
\hline \multirow{4}{*}{$\begin{array}{c}\text { B } \\
\text { Raw Acid } \\
\text { Slep }\end{array}$} & $\mathrm{H} 2 \mathrm{SO}_{4}$ & -4 & 4884 & 734 & 1.75 & 59.88 & 8.28 & 1.88 & 51.75 & 7.35 & 1.73 \\
\hline & $\mathrm{Zn}(2+)$ & 1 & 8897 & 709 & 1.69 & 87.93 & 8.38 & 1.90 & 86.79 & 7.35 & 1.73 \\
\hline & $\mathrm{Fe}(3+)$ & 2 & 24.86 & 7.54 & 1.80 & 27.55 & 7.58 & 1.72 & 25.59 & 5.95 & 1.40 \\
\hline & \multicolumn{3}{|c|}{ AVERAGE } & 7.32 & 1.75 & & 8.08 & 1.83 & & 6.88 & 1.62 \\
\hline \multirow{4}{*}{$\begin{array}{c}\text { C } \\
\text { Jarosite } \\
\text { Step }\end{array}$} & $\mathrm{H} 2 \mathrm{SO}_{4}$ & .4 & 46.50 & 7.56 & 1.84 & 46.85 & 7.12 & 1.57 & 48.00 & 7.43 & 1.88 \\
\hline & $Z n(2+)$ & 1 & 8126 & 598 & 1.45 & 77.31 & 5.06 & 1.12 & 91.23 & 7.18 & 1.82 \\
\hline & $\mathrm{Fe}(3+)$ & 2 & 24.54 & 6.72 & 1.63 & 20.45 & 4.88 & 1.08 & 27.50 & 6.29 & 1.59 \\
\hline & \multicolumn{3}{|c|}{ AVERAGE } & 6.75 & 1.64 & & 5.69 & 1.26 & & 6.97 & 1.76 \\
\hline \multirow{4}{*}{$\begin{array}{c}\text { D } \\
\text { Spent } \\
\text { Step }\end{array}$} & $\mathrm{H} 2 \mathrm{SO}_{4}$ & -4 & 4377 & 7.38 & 1.23 & 62.80 & 8.34 & 2.09 & 50.22 & 7.01 & 1.94 \\
\hline & $\mathrm{Zn}(2+)$ & 1 & 8939 & 608 & 1.84 & 86.68 & 7.78 & 1.95 & 87.81 & 7.63 & 2.12 \\
\hline & $\mathrm{Fe}(3+)$ & 2 & 3275 & 884 & 2.67 & 35.32 & 9.07 & 2.28 & 34.50 & 8.43 & 2.34 \\
\hline & \multicolumn{3}{|c|}{ AVERAGE } & 7.47 & 1.25 & & 8.40 & 2.11 & & 7.69 & 2.13 \\
\hline \multirow{4}{*}{$\begin{array}{c}E \\
\text { ZnFerrite } \\
\text { Step } \\
\end{array}$} & $\mathrm{H} 2 \mathrm{SO}_{4}$ & -4 & 4797 & 7.34 & 1.72 & 42.85 & 7.38 & 1.87 & 53.20 & 6.68 & 1.55 \\
\hline & $\mathrm{Zn}(2+)$ & 1 & 8375 & 5.63 & 1.32 & 88.53 & 5.82 & 1.47 & 88.81 & 7.12 & 1.65 \\
\hline & $\mathrm{Fe}(3+)$ & 2 & 2364 & 623 & 1.46 & 24.44 & 6.23 & 1.57 & 25.58 & 6.63 & 1.54 \\
\hline & \multicolumn{3}{|c|}{ AVERAGE } & 6.40 & 1.50 & & 6.48 & 1.64 & & 6.81 & 1.58 \\
\hline
\end{tabular}

EXT. = Reaction Extent $\left(1 \times 10^{-3} \mathrm{~mol} / \mathrm{min}\right)$

$\mathbf{k}=$ Rate constant $\left(1 \times 10^{3} \mathrm{~mol} / \mathrm{L} \cdot \mathrm{min}\right)$

\subsection{Process Identification from Step Responses}

Another means of analyzing data from step response identification experiments is to use parametric methods. If the process is assumed to be a simple first order plus delay model then the Laplace transfer function would take the following form:

$$
P(s)=\frac{\mathrm{Kexp}^{-1 / s}}{\tau s+1}=\frac{Y(s)}{X(s)}
$$


where $\mathrm{K}$ is the process gain, $\tau$ is the dominant time constant of the process, and $\theta$ is the process dead time. The terms $Y(s)$ and $X(s)$ refer to the Laplace transforms of the output and input variables respectively. The estimation of the process gain from step response data is straightforward. The gain is defined as the ratio of the magnitude of the output response to the change in the input step. The process time constant is equal to the time it takes for the output response to reach $63.2 \%$ of its final value $(\exp \{-1\}=0.632)$. The process dead time is the time it takes after a step change is invoked until the output starts to respond. Figure 4-3 provides an illustration of this calculation procedure. The data used in this graph are from Test $D$ where the Spent acid flow was increased by $50 \%$.

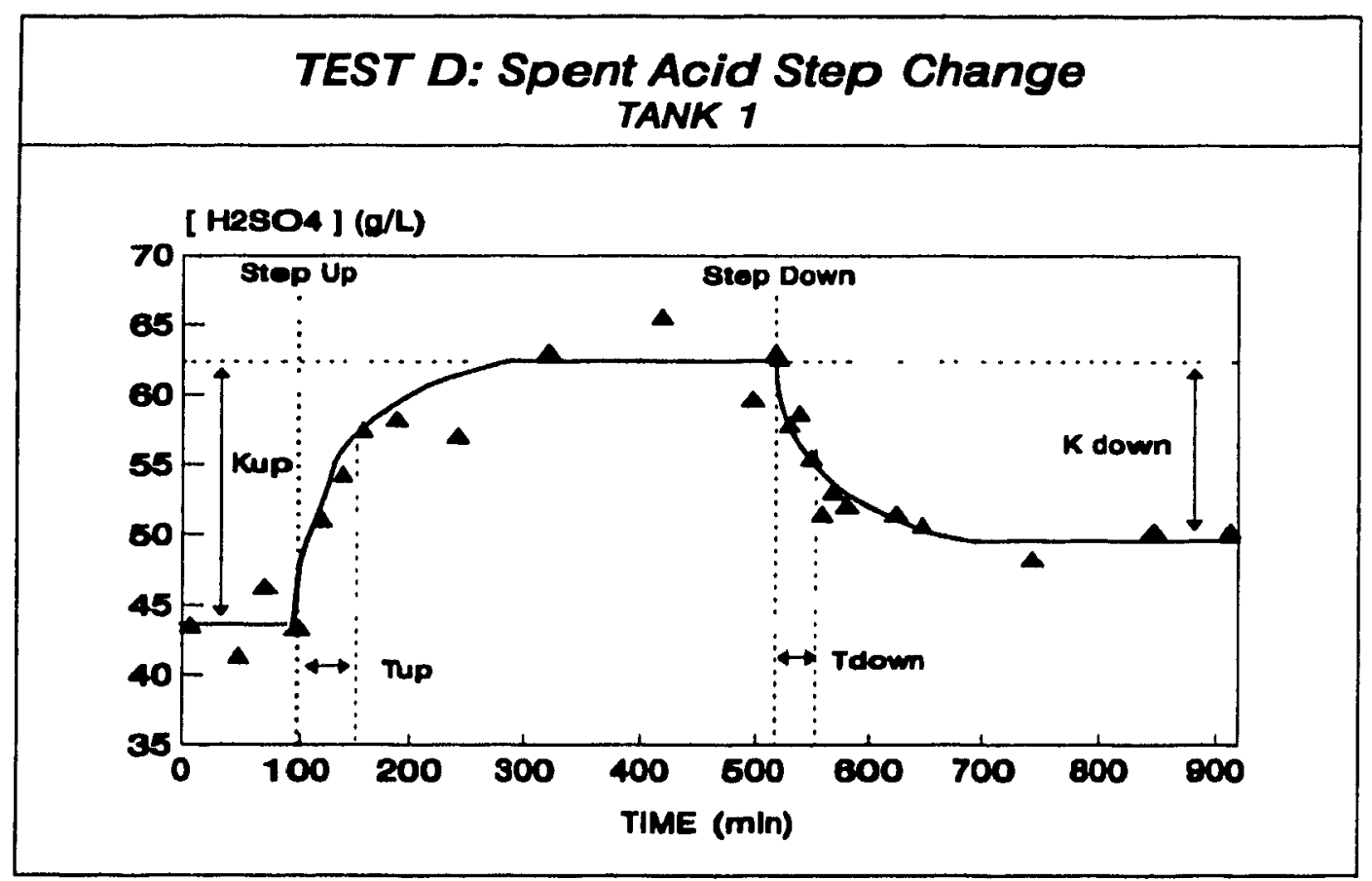

Figure 4-3 Process Gain \& Time Constant Estimation

Table IV-10 summarizes the process gains and time constants which were calculated using data from the first tank. Since it was found that the first tank responded immediately to all of the step changes in the input stream flows, there was no appreciable amount of process dead time. 
Also included in this table are the estimated gains that would be observed in the jarosite conversion circuit at CEZinc. These actual process gains were calculated by using the observed pilot plant changes in compositions and relating these values to the same percentage increase in the normal feed rate flows to the industrial circuit.

Table IV-10

TANK 1: PROCESS GAINS AND TIME CONSTANTS

\begin{tabular}{|c|c|c|c|c|c|c|}
\hline \multirow[t]{2}{*}{ STEP TEST } & \multirow[t]{2}{*}{ COMPONENT } & \multicolumn{2}{|c|}{$\mathrm{K}$ pilot (per $\mathrm{mL} / \mathrm{min}$ ) } & \multirow{2}{*}{$\begin{array}{l}\text { K plant " } \\
\text { per } \mathrm{m} 3 / \mathrm{hr}\end{array}$} & \multicolumn{2}{|c|}{$\tau$ pilot (min) } \\
\hline & & Up & Down & & Up & Down \\
\hline \multirow{3}{*}{$\begin{array}{c}\text { B } \\
\text { RAW ACID STEP }\end{array}$} & $\mathrm{H} 2 \mathrm{SO} 4(\mathrm{~g} / \mathrm{L})$ & 23.1 & 203 & 111 & 100 & 15 \\
\hline & $F e(g / L)$ & 56 & 4.9 & 27 & 100 & - \\
\hline & $\mathrm{Zn}(\%)$ & .30 & -2.7 & .15 & 100 & 25 \\
\hline \multirow{2}{*}{$\begin{array}{c}\mathrm{C} \\
\text { JAROSITE STEP } \\
\end{array}$} & $\mathrm{Fe}(\mathrm{g} / \mathrm{L})$ & .07 & -11 & .03 & 60 & 90 \\
\hline & $\mathrm{Zn}(\%)$ & .03 & -0.3 & .0 .1 & 80 & 110 \\
\hline \multirow{2}{*}{$\begin{array}{c}D \\
\text { SPENT ACID } \\
\end{array}$} & $\mathrm{H} 2 \mathrm{SO} 4(\mathrm{~g} / \mathrm{L})$ & 2.0 & 1.6 & 0.8 & 50 & 35 \\
\hline & $\mathrm{Zn}(\%)$ & -0.09 & -0.04 & .0 .03 & 90 & 95 \\
\hline \multirow{2}{*}{$\begin{array}{c}\text { E } \\
\text { Zn FERRITE }\end{array}$} & $\mathrm{H} 2 \mathrm{SO} 4(\mathrm{~g} / \mathrm{L})$ & -1.5 & -2.8 & .03 & 85 & 145 \\
\hline & $\mathrm{Zn}(\%)$ & 05 & 06 & 01 & 50 & 75 \\
\hline
\end{tabular}

" calculated using "Up" response

$\mathrm{K}$ pilot $=\quad \mathrm{g} / \mathrm{L}($ or $\% \mathrm{Zn}$ ) change in concentration for each $\mathrm{mL} / \mathrm{min}$ change in flow

$\mathrm{K}$ plant $=\mathrm{g} / \mathrm{L}$ change in concentration for each $\mathrm{m}^{3} / \mathrm{hr}$ change in flow (used normal plant flows with same percentage increase as pilot experiments)

$\tau=\quad$ process time constant $(\mathrm{min})$

From these results it is observed that the largest gains are found as a result of changing the flow of the raw acid stream followed by changes in the spent acid stream. Process hysteresis is apparent through the calculation of the process 
time constant. For example, the time constant for changes in the raw acid stream flow is four times larger during the step up response. The opposite was observed during the step changes in the slurry streams where the time constant during the step down response was normally larger than during the step up transient.

Results from a step change test in the spent acid flow, conducted at CEZinc, gave a process gain equal to $0.6 \mathrm{~g} / \mathrm{L}_{[}\left[\mathrm{H}_{2} \mathrm{SO}_{4}\right]$ per $\mathrm{m}^{3}$ spent. This result is comparable to the estimated process gain from the pilot plant step change data which gave a result of $0.8 \mathrm{~g} / \mathrm{L}\left[\mathrm{H}_{2} \mathrm{SO}_{4}\right]$ per $\mathrm{m}^{3}$ spent (i.e. within $25 \%$ ).

\subsection{Discussion of Tank 1 Results}

\section{TEST B - Raw Acid Step Change}

As expected, an increase in the raw acid stream flow resulted in increased zinc ferrite leaching in the first reactor. This result was shown through the rise in the acid and iron concentrations in the first reactor as well as a drop in both the mass fraction of iron and zinc in the solids.

This step change would also show an increase in the solution density and a decrease in the slurry's solid mass fraction. After examination of the slurry and solution densit.es, however, it is difficult to determine any definite trend that would imply that the solution density was increasing or that the mass fraction of solids in the slurry was decreasing.

\section{TEST C - Jarosite Slurry Step Change}

Increasing the Jarosite slurry flow by $50 \%$ had the smallest impact on the operation of the first reactor. The only change that was found to be statistically significant was a reduction of the iron in solution by $4 \mathrm{~g} / \mathrm{L}$. Interestingly, this reduction in iron is not only due to dilution effects since the drop would have been in the order of $1 \mathrm{~g} / \mathrm{L}$. It is postulated that some additional jarosite precipitation 
must have occurred. If this was the case, then it would explain why the acid concentration did not drop by $2 \mathrm{~g} / \mathrm{L}$ due to dilution since sulphuric acid is a product of the jarosite precipitation reaction (refer to equation 1.2).

As expected, there was an obvious increase in the solids concentration in the reactor effluent following the step increase in jarosite seed, however, no increase in the slurry density was observed due to the lack of precision in this measurement.

TEST D - Spent Acıd Step Change

In Test $\mathrm{B}$, an additional $085 \mathrm{~g} / \mathrm{min}$ acid was introduced during the step change while in Test $D$ the increase in acid was almost twice this amount at $1.5 \mathrm{~g} / \mathrm{min}$. The $17 \%$ reduction in residence time in the reactor, due to the increased spent flow, affected the amount of additional zinc ferrite leaching. This result is apparent when we compare results of Test $D$ to those of $B$. For example, even though the increase in acid was almost twice as large in Test $D$, the reduction of the percent zinc in the solids, which gives an indication of the extent of zinc ferrite leaching, was $0.8 \%$ compared to $1.4 \%$ in Test $B$.

\section{TEST E - Zinc Ferrite Slurry Step Change}

An increase in the zinc ferrite slurry flow simulates an increase in production. Since zinc ferrite has a higher percentage of zinc and iron in the solids we are not surprised to see the percent zinc increase in the first reactor after the step change is introduced. As described in section 4.3, the iron did not respond as expected. The discrepancy in the iron composition in the solids was thought to be a consequence of large variances in the analytical technique. 


\section{Chapter 5}

\section{DYNAMIC MODEL}

\subsection{Deterministic Dynamic Model}

The development of a deterministic dynamic model begins with writing the appropriate transient mass, component and energy balances for the system. In this study, since the reactor temperature was maintained essentiaily constant at $98^{\circ} \mathrm{C}$, the energy was not considered.

It was desired to incorporate as many fundamental relationships into the model as possible. It was realized that the utilization of available fundamental relationships would result in a more robust model which would be able to predict, with some degree of accuracy, the reactor performance under varying operating conditions. Possible deterministic relationships may include known equilibrium, reaction stoichiometry, kinetic and equipment geometry relations.

During the course of developing the jarosite circuit model, an experiment was carried out to evaluate the mixing characteristics in the reactor (Appendix III). From this test, we concluded that the reactors could be modelled by assuming that they behave as ideal stirred tank reactors. Consequently, the overall mass balance for the reacting system is:

$$
\frac{d\left(\rho_{E X I T} V\right)}{d t}=\sum_{n=1}^{m} \rho_{F E E D} Q_{F E E D}-\sum_{n=1}^{p} \rho_{E X I T} Q_{E X I T}
$$

where: $\quad m$ and $p$ are the number of feed and exit streams, respectively.

The component mass balance for the same system can be written as: 


$$
\frac{d\left(C_{i_{E x t r}} V\right)}{d t}=\sum_{n=1}^{m}\left(C, Q_{n}\right)_{F E E D}-\sum_{n=1}^{p}\left(C, Q_{n}\right)_{E X I T}+\sum_{J=1}^{k} v_{J J} r_{J} V
$$

where: $\quad k$ is the number of reactions occurring.

Since each of the reactor's main exit streams flow by gravity, we can assume that the tank volume remains constant. Also since the experiments showed that the slurry and the filtrate densities were found to vary in Tank 1 by less than $3 \%$ during each process identification experiment, we can assume that they remain constant in the model. Using the above assumptions of constant tank volume and constant density, equations 5.1 and 5.2, can be simplified as follc'ws (for the case of one exit stream):

$$
Q_{E X I T}=\frac{\sum_{n=1}^{m} \rho_{F E E D_{n}} Q_{F E E D_{n}}-\dot{M}_{E V A P}}{\rho_{E X I T}}
$$

and the component mass balances can be written as:

$$
\frac{d(C,)_{E X I T}}{d t}=\frac{\sum_{n=1}^{m}\left(C, Q_{n}\right)_{F E E D}-(C, Q)_{E X I T}}{V}+\sum_{J=1}^{k} v_{, J} r_{J}
$$

If we assume a pseudo-homogeneous rate law (mass/L.min) for the heterogeneous reactions, then we can write transient component mass balances for the solids as follows:

$$
\frac{d\left(C_{s_{1}}\right)_{E X I T}}{d t}=\frac{\sum_{n=1}^{m}\left(s_{l_{n}} s_{n} \rho_{n} Q_{n}\right)_{F E E D}-\left(C_{s_{1}} Q\right)_{E X I T}}{V}+\sum_{i=1}^{k} v_{1}, r_{l} M_{l}
$$

where: $\quad \mathrm{C}_{\mathrm{s}}$ : $\quad$ solid component concentration (mass/volume)

$S_{\mathrm{in}}$ : $\quad$ mass fraction of solid component $i$ in the solid phase 


$$
\begin{array}{ll}
s_{n}: & \text { mass fraction of solids in stream } n \\
M_{1}: & \text { molecular weight of solid component } i
\end{array}
$$

To simplify the jarosite model, only the main reactions which occur in the system were considered. The first reaction, given by equation 5.6 below, represents the dissolution of zinc ferrite. The subsequent two reactions are the precipitation of ammonium jarosite and hydronium jarosite, respectively. Studies on jarosite precipitation $(11,12)$ have shown that when operating the jarosite conversion process close to $100^{\circ} \mathrm{C}$ approximately $20 \%$ of the jarosite will be precipitated in the hydronium form and the remainder will be as ammonium jarosite. These two reactions are given by equations 5.7 and 5.8 .

$$
\begin{gathered}
\mathrm{ZnO} \mathrm{Fe}_{2} \mathrm{O}_{3}(s)+8 \mathrm{H}^{\prime} \rightarrow \mathrm{Zn}^{2 \cdot}+2 \mathrm{Fe}^{3 \cdot}+4 \mathrm{H}_{2} \mathrm{O}(\mathrm{aq}) \\
3 \mathrm{Fe}^{3 \prime}+\mathrm{NH}_{4}^{\prime}+2 \mathrm{SO}_{4}^{2-}+6 \mathrm{H}_{2} \mathrm{O}(\mathrm{aq}) \rightarrow \mathrm{NH}_{4}\left[\mathrm{Fe}_{3}\left(\mathrm{SO}_{4}\right)_{2}(\mathrm{OH})_{6}\right](s)+6 \mathrm{H}^{+} \\
3 \mathrm{Fe}^{3+}+2 \mathrm{SO}_{4}^{2-}+7 \mathrm{H}_{2} \mathrm{O}(\mathrm{aq}) \rightarrow \mathrm{H}_{3} \mathrm{O}\left[\mathrm{Fe}_{3}\left(\mathrm{SO}_{4}\right)_{2}\left(\mathrm{OH}_{6}\right](\mathrm{s})+5 \mathrm{H}^{+}\right.
\end{gathered}
$$

For modelling purposes, the two jarosite reactions are combined so that there is $80 \%$ ammonium and $20 \%$ hydronium jarosite formation. This combined jarosite reaction is as follows:

$$
\begin{aligned}
& 15 \mathrm{Fe}^{3 \prime}+4 \mathrm{NH}_{4}^{\prime}+10 \mathrm{SO}_{4}^{2-}+31 \mathrm{H}_{2} \mathrm{O}(\mathrm{aq}) \rightarrow \\
& 4 \mathrm{NH}_{4}\left[\mathrm{Fe}_{3}\left(\mathrm{SO}_{4}\right)_{2}(\mathrm{OH})_{6}\right](\mathrm{s})+\mathrm{H}_{3} \mathrm{O}\left[\mathrm{Fe}_{3}\left(\mathrm{SO}_{4}\right)_{2}(\mathrm{OH})_{6}\right](s)+29 \mathrm{H}^{+}
\end{aligned}
$$

As shown in Appendix IV, during the batch preparation of the zinc ferrite solids, ferric hydroxide may be formed. Since the percentage of ferric hydroxide was sometimes found to be as high as 5\% (as calculated in Appendix IV) the dissolution reaction may be significant. 
The ferric hydroxide reaction takes place as follows:

$$
\mathrm{Fe}(\mathrm{OH})_{3}+3 \mathrm{H}^{\prime} \rightarrow \mathrm{Fe}^{3+}+3 \mathrm{H}_{2} \mathrm{O}
$$

The following numbers were assigned to each of the above reactions for reference:

Reaction $1 \Rightarrow r_{1} \quad$ Zinc Ferrite Dissolution

$\mathrm{A}+8 \mathrm{~B} \rightarrow \mathrm{C}+2 \mathrm{D}+4 \mathrm{E}$

Reaction $2 \Rightarrow r_{2} \quad 80 \%$ Ammonium \& 20\% Hydronium Jarosite Precipitation $15 \mathrm{D}+4 \mathrm{~F}+10 \mathrm{G}+31 \mathrm{E} \rightarrow 4 \mathrm{H}+1+$ $29 \mathrm{~B}$

Reaction $3 \Rightarrow r_{3} \quad$ Ferric Hydroxide Dissolution

$\mathrm{J}+3 \mathrm{~B} \rightarrow \mathrm{D}+3 \mathrm{E}$

where:
$\mathrm{A}=\mathrm{ZnO} . \mathrm{Fe}_{2} \mathrm{O}_{3}(\mathrm{~s})$
$\mathrm{D}=\mathrm{Fe}^{3+}$
$\mathrm{G}=\mathrm{SO}_{4}{ }^{2 \cdot}$
$\mathrm{J}=\mathrm{Fe}(\mathrm{OH})_{3}(\mathrm{~s})$
$\mathrm{B}=\mathrm{H}^{+}$
$\mathrm{E}=\mathrm{H}_{2} \mathrm{O} \quad \mathrm{H}=\mathrm{NH}_{4}\left[\mathrm{Fe}_{3}\left(\mathrm{SO}_{4}\right)_{2}(\mathrm{OH})_{6}\right]$ (s)
$\mathrm{C}=\mathrm{Zn}^{2+}$
$\mathrm{F}=\mathrm{NH}_{4}{ }^{+} \quad \mathrm{I}=\mathrm{H}_{3} \mathrm{O}\left[\mathrm{Fe}_{3}\left(\mathrm{SO}_{4}\right)_{2}(\mathrm{OH})_{6}\right]$

\subsubsection{Incorporation of the Rate Equations}

It has been shown in the literature that the rates of zinc ferrite dissolution and of jarosite precipitation are controlled by their reaction kinetics. Ferric hydroxide dissolution, however, is known to occur readily under the highly acidic conditions prevailing in the first jarosite reactor. To simplify the model, the ferric hydroxide reaction is assumed to occur instantaneously.

In the literature review, there were two rate expressions given for zinc ferrite 
dissolution (Filippou (6) and Elgersma (9)) which could be employed in this study. Preliminary simulations showed that Elgersma's expression provided a better representation of the experimental data since it incorporated the "retarding" effect of ferric ions during zinc ferrite dissolution:

$$
r_{p}^{\cdot}=k \sqrt{\gamma_{H}} \cdot \sqrt{\frac{[H+]}{\left[F e^{3+}\right]}} \quad\left(\frac{\text { mass }}{\text { time'area }}\right)
$$

with $\mathrm{k}=8.70 \times 10^{-3} \mathrm{~g} /\left(\min \cdot \mathrm{m}^{2}\right)$ at $98^{\circ} \mathrm{C}$

The pseudo-homogeneous rate constant per unit volume of the reaction mixture, $\mathrm{k}^{+}$can be obtained from:

$$
k^{+}=\frac{k S C_{s}}{M_{A}}
$$

where: $\quad k: \quad$ rate constant, $g / m i n \cdot m^{2}$

S: $\quad$ Specific area of $\mathrm{Zn}$ Ferrite particles, $\mathrm{m}^{2} / \mathrm{g}$

$\mathrm{C}_{\mathrm{s}}$ : $\quad$ Zn Ferrite solids concentration, $\mathrm{g} / \mathrm{L}$

$\mathrm{M}_{\mathrm{A}}$ : $\quad$ Molecular Weight of $\mathrm{Zn}$ Ferrite, $(241.1 \mathrm{~g} / \mathrm{mol})$

Given that the specific area of zinc ferrite particles range from 2.00 to $2.67 \mathrm{~m}^{2} / \mathrm{g}$ (9) and that the average zinc ferrite particle concentration in the pilot reactors was close to $55 \mathrm{~g} / \mathrm{L}$, the rate constant for industrial zinc ferrite, $\mathrm{k}^{+}$ranges from: $4.0 \times 10^{-3}$ to $5.8 \times 10^{-3} \mathrm{~mol} / \mathrm{L}$.min. If we wish to express this in terms of $k_{1}$ which is equal to the rate constant multiplied by the square root of the ionic activity coefficient (calculated in Appendix VII to be equal to 0.16) we obtain a range of: $1.6 \times 10^{-3}$ to $2.1 \times 10^{-3} \mathrm{~mol} / \mathrm{L}$. $\mathrm{min}$. If we refer back to section 4.4 , we find that the experimental rate constant of $1.76 \times 10^{-3}$ (mol/L.min) lies within the above range. Preliminary simulations have shown that a rate constant of $1.63 \times 10^{-3}$ (mol/L.min) gives the best description of the transient experimental data. Since, this rate 
constant also falls within the range of the steady state experimental values given in Table IV-9, it was used in the simulation of the first jarosite reactor.

Although two applicable jarosite precipitation kinetic expressions were found in the literature it was decided to use the rate expression given by Rastas since the form of the equation could be more readily used in this study. At $98^{\circ} \mathrm{C}$ the rate constant was found by Rastas to be equal to $1.657 \times 10^{-2}(\mathrm{~g} / \mathrm{L})^{0568}$ per min. Since equation 2.20 was actually written as the rate of iron removal and not as a rate expression, the rate constant was corrected for the stoichiometry of reaction 5.9 as follows:

$$
k=\frac{k^{*}}{-15}\left(\frac{1}{M_{F \theta}}\right)^{0568}
$$

This corrected rate constant is now used in equation 5.13:

$$
r_{2}=1.124 \times 10^{-4} \frac{\left[\mathrm{Fe}^{3 \cdot}\right]^{2}{ }^{406}\left[\mathrm{NH}_{4}^{+}\right]^{1.06}\left[\mathrm{NH}_{4}-\mathrm{JAR}\right]^{0685}}{\left[\mathrm{H}_{2} \mathrm{SO}_{4}\right]^{3719}}
$$

\subsubsection{TANK 1 Transient Model}

The transient mass balances for the first reactor were written using the stream numbering shown in figure 5-1. The flow rates of these feed streams are given in Table III-1. The raw acid stream was made up of $96 \% \mathrm{H}_{2} \mathrm{SO}_{4}(1760 \mathrm{~g} / \mathrm{L})$ and the spent acid stream contained $180 \mathrm{~g} / \mathrm{L} \mathrm{H}_{2} \mathrm{SO}_{4}, 55 \mathrm{~g} / \mathrm{L}$ zinc and several other species at lower concentrations $\left(\mathrm{Mn}, \mathrm{Mg}, \mathrm{NH}_{4}{ }^{+}\right)$. Water was also added to this tank to simulate live steam injection which occurs in the plant's jarosite circuit. 


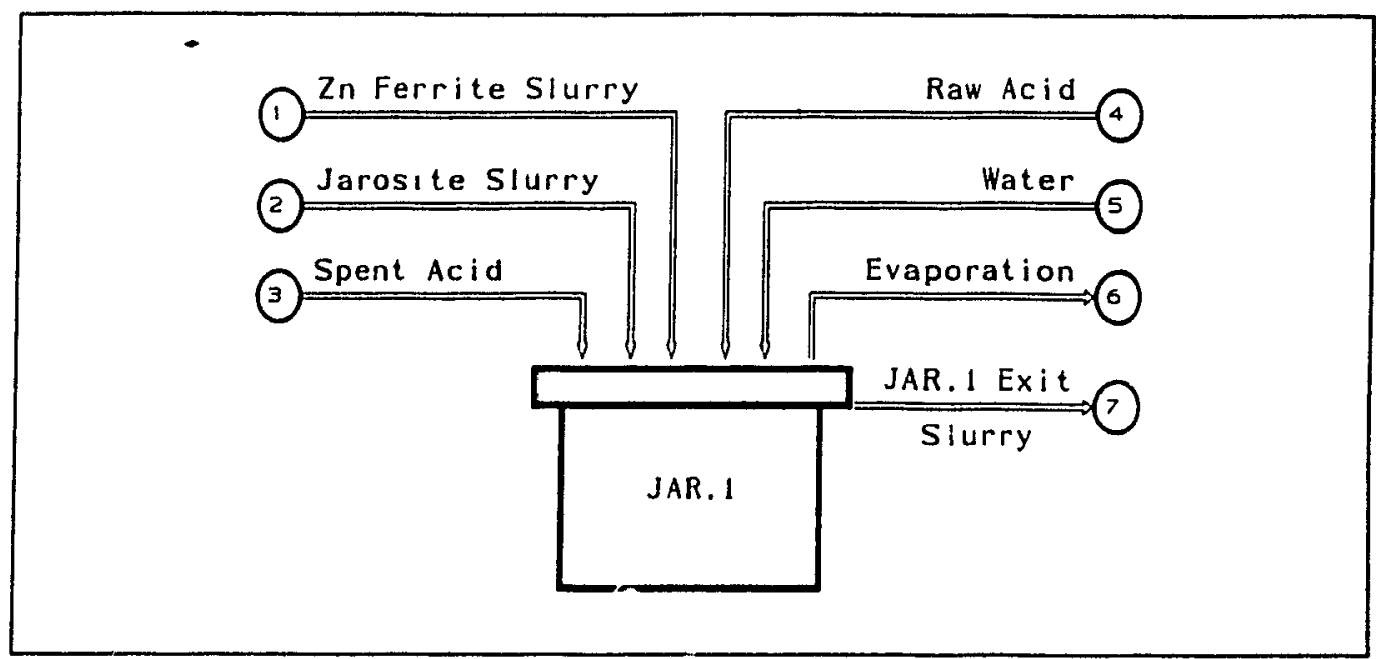

Figure 5-1 Jarosite Tank 1

Equation 5.14 shows how the first tank's exit stream flow was calculated and equations 5.15 to 5.17 give the transient component balances for the sulphuric acid, zinc, and iron in solution respectively.

$$
Q_{E X I T}=\frac{\rho_{1} Q_{1}+\rho_{2} Q_{2}+\rho_{3} Q_{3}+\rho_{4} Q_{4}+\rho_{5} Q_{5}-\rho_{6} Q_{6}}{\rho_{7}}
$$

Component B: $\mathrm{H}^{+}$

$$
\frac{d C_{B_{1}}}{d t}=\frac{C_{B_{1}} Q_{1}+C_{B_{2}} Q_{2}+C_{B_{3}} Q_{3}+C_{B_{4}} Q_{4}-C_{B_{7}} Q_{7}-3 J}{V_{\text {TANK }}}-8 r_{1}+29 r_{2}
$$

Component C: $\mathrm{Zn}^{2+}$

$$
\frac{d C_{C_{2}}}{d t}=\frac{C_{C_{1}} Q_{1}+C_{C_{2}} Q_{2}+C_{C_{3}} Q_{3}-C_{C_{7}} Q_{7}}{V_{\text {TANK } 1}}+r_{1}
$$

Component D: $\mathrm{Fe}^{3+}$

$$
\frac{d C_{D_{1}}}{d t}=\frac{C_{D_{1}} Q_{1}+C_{D_{2}} Q_{2}+C_{D_{1}} Q_{3}-C_{D_{7}} Q_{7}+J}{V_{\text {TANK } 1}}+2 r_{1}-15 r_{2}
$$


In the above equations, $J$ refers to the molar flow rate of $\mathrm{Fe}(\mathrm{OH})_{3}$ entering the reactor.

The mass fraction of zinc and iron in the solids were also modelled by writing component mass balances ( $\mathrm{g} / \mathrm{L}$. $\mathrm{min}$ ) for the total solids, the jarosite solids, and the zinc ferrite solids concentrations as follows:

Component S: Solids

$$
\frac{d C_{s_{1}}}{d t}=\frac{s_{1} \rho_{1} Q_{1}+s_{2} \rho_{2} Q_{2}-s_{7} \rho_{7} Q_{7}-J M_{J}}{V_{\text {TANK }}}-r_{1} M_{A}+5 r_{2} M_{H}
$$

Component A: $\quad \mathrm{ZnO} . \mathrm{Fe}_{2} \mathrm{O}_{3}$

$$
\frac{d C_{s_{17}}}{d t}=\frac{s_{A_{1}} s_{1} \rho_{1} Q_{1}+s_{A_{2}} s_{2} \rho_{2} Q_{2}-C_{s_{1,}} Q_{7}}{V_{\text {TANK } t}}-r_{1} M_{A}
$$

Components H-I: Jarosite

$$
\frac{d C_{s_{H-1,}}}{d t}=\frac{s_{H-1} s_{2} \rho_{2} Q_{2}-C_{s_{H, 1}} Q_{7}}{V_{\text {TANK }}}+5 r_{2} M_{H}
$$

The mass fraction of zinc in the solid phase was calculated using the following equation:

$$
\% Z n \text { Solids }=\frac{C_{s_{\lambda_{1}}} \% Z n_{A}+C_{s_{t h}} \% Z n_{H-1}}{C_{s,}} \times 100 \%
$$

where, $\quad \% Z n_{1}: \quad \% Z n$ in species; $i$

The same procedure applies for the calculation of the percent iron in the solids. 


\subsection{Process Simulation Results}

Following the reactor characterization test, four "step change" experiments were carried out using the pilot system with the purpose of validating the deterministic model.

The transient component balance equations for sulphuric acid, zinc and iron in solution and for zinc and iron in the solids were programmed using the MATLAB software package. To solve these differential equations a $4^{\text {th }}$ and $5^{\text {th }}$ order RungeKutta numerical integration technique was employed. In this study, the sensitivity of the rate constants for zinc ferrite dissolution and jarosite precipitation were explored.

In the figures which follow, the vertical lines drawn on each graph represent the step up and the step down times for each experiment.

\section{TANK 1 RESULTS}

For the first jarosite tank, it was found that the best model involved using the previously calculated rate constants of $k_{1}=1.63 \times 10^{-3}$ ( $\mathrm{mol} / \mathrm{L}$. $\mathrm{min}$ ) for zinc ferrite leaching and $k_{2}=1.124 \times 10^{-4}(\mathrm{~mol} / \mathrm{L})^{0568}$ per min jarosite precipitation.

\section{SULPHURIC ACID CONCENTRATION PROFILES}

Figures 5-2 to 5-4 demonstrate the changes observed in the sulphuric acid concentrations for Tests $B, D$, and $E$ respectively. The results from Test $C$ were not included since the change in the sulphuric acid concentration was not found to be statistically significant in this experiment (refer to section 4.3 where the t-test hypothesis was rejected).

In all these figures, the model provides a reasonable representation of the changes in the sulphuric acid concentration data. 


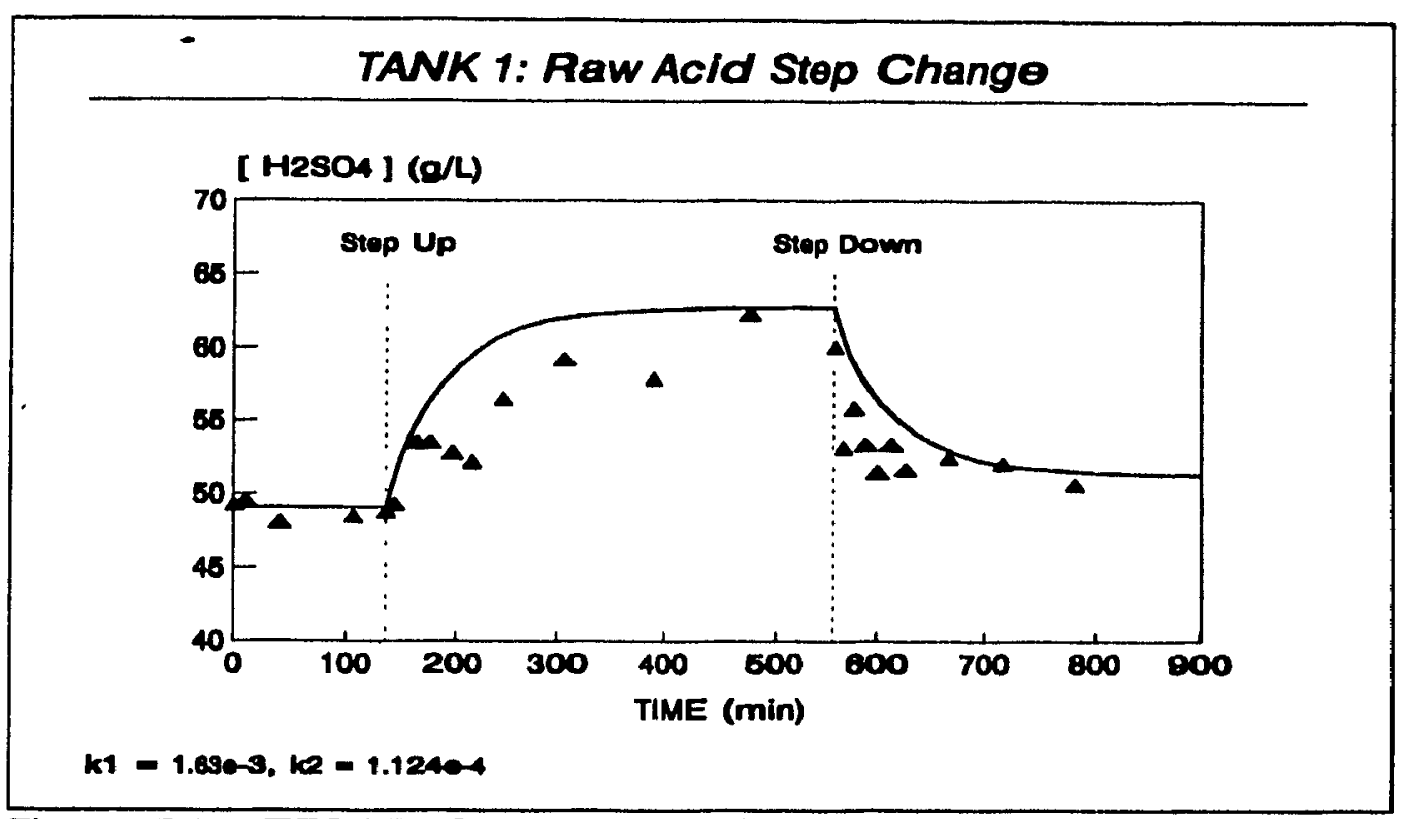

Figure 5-2 TEST B Sulphuric Acid Concentration Changes

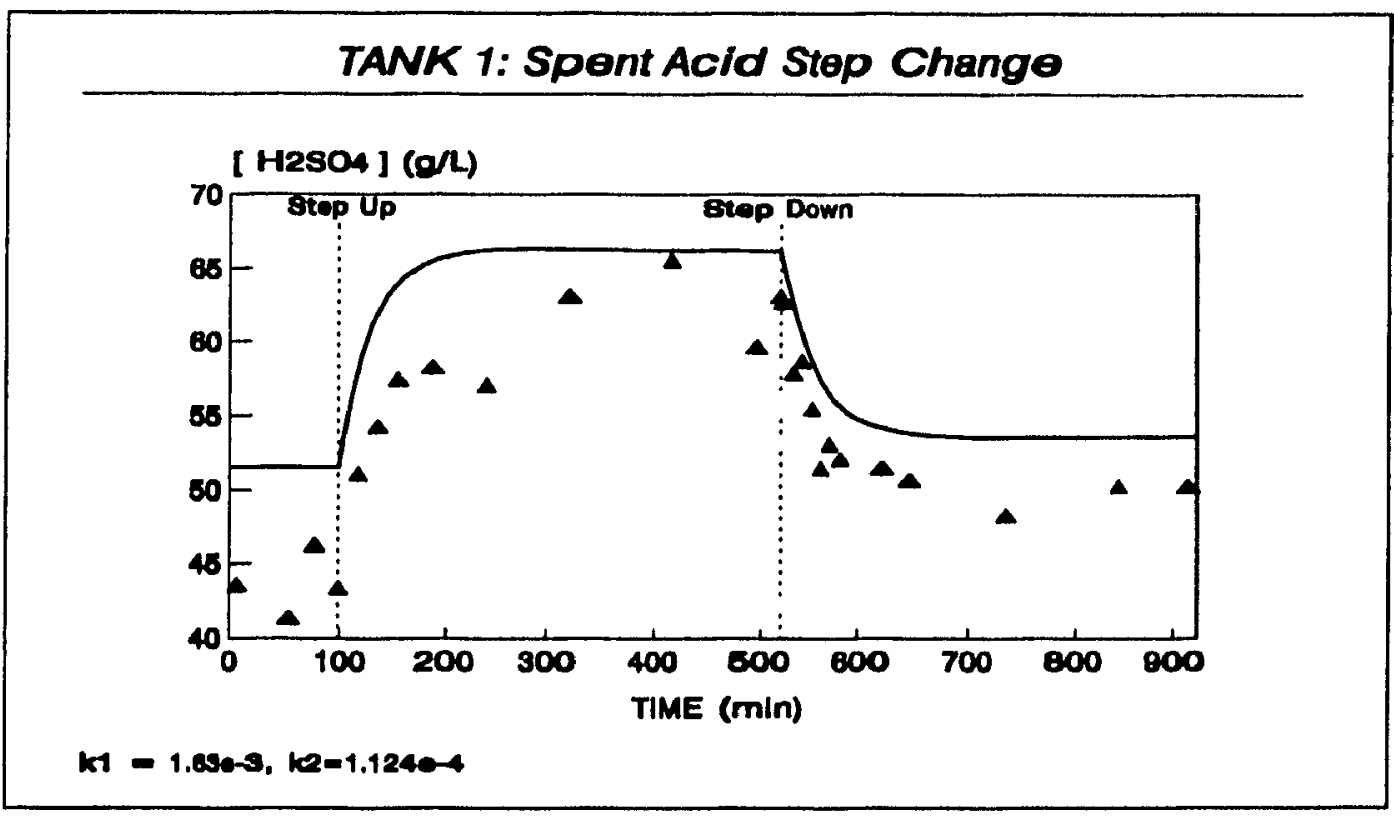

Figure 5-3 TEST D Sulphuric Acid Concentration Changes 


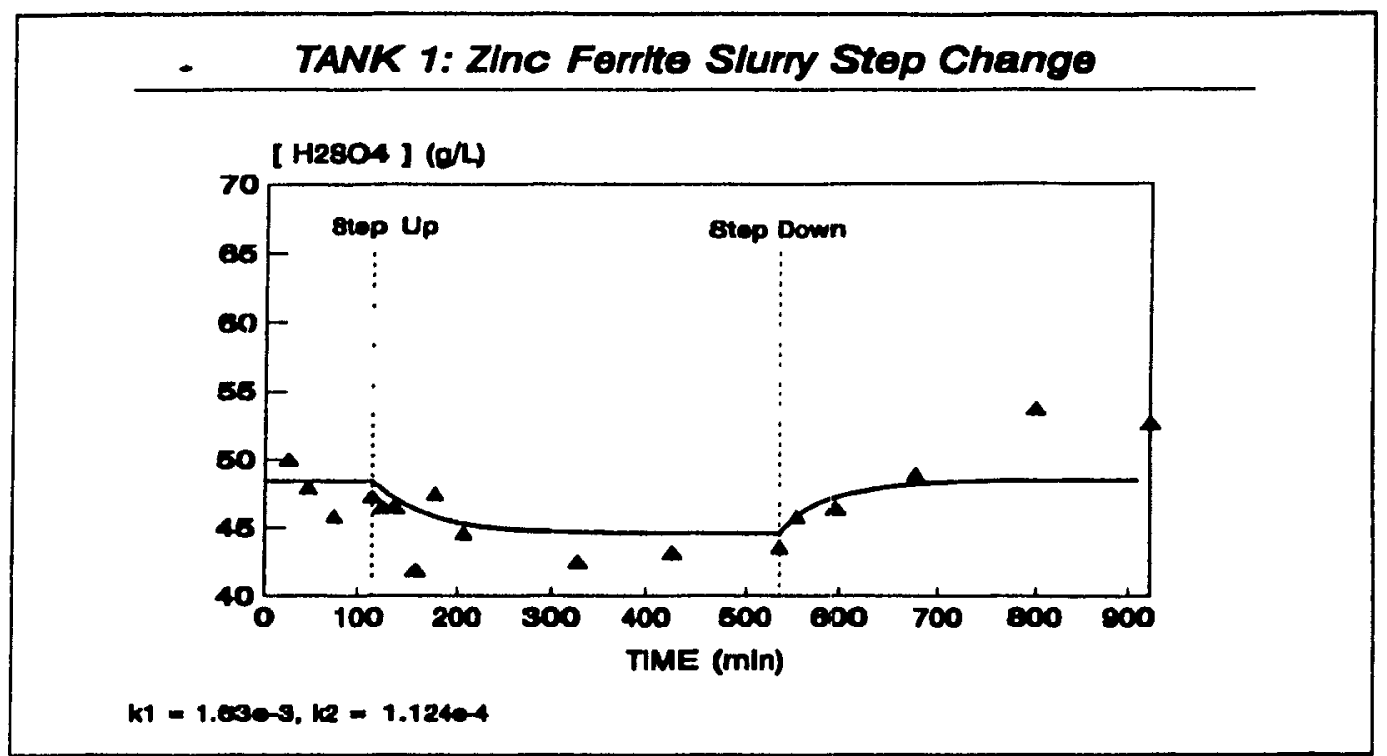

Figure 5-4 TEST E Sulphuric Acid Concentration Changes

\section{FERRIC IRON CONCENTRATION PROFILES}

The transient model provides a closer fit to the iron concentration data from Test B, Figure 5-5, compared with that of Test C, Figure 5-6. One factor which contributes to this difference is the standard deviation in the iron assay which is around $0.6 \mathrm{~g} / \mathrm{L}$.

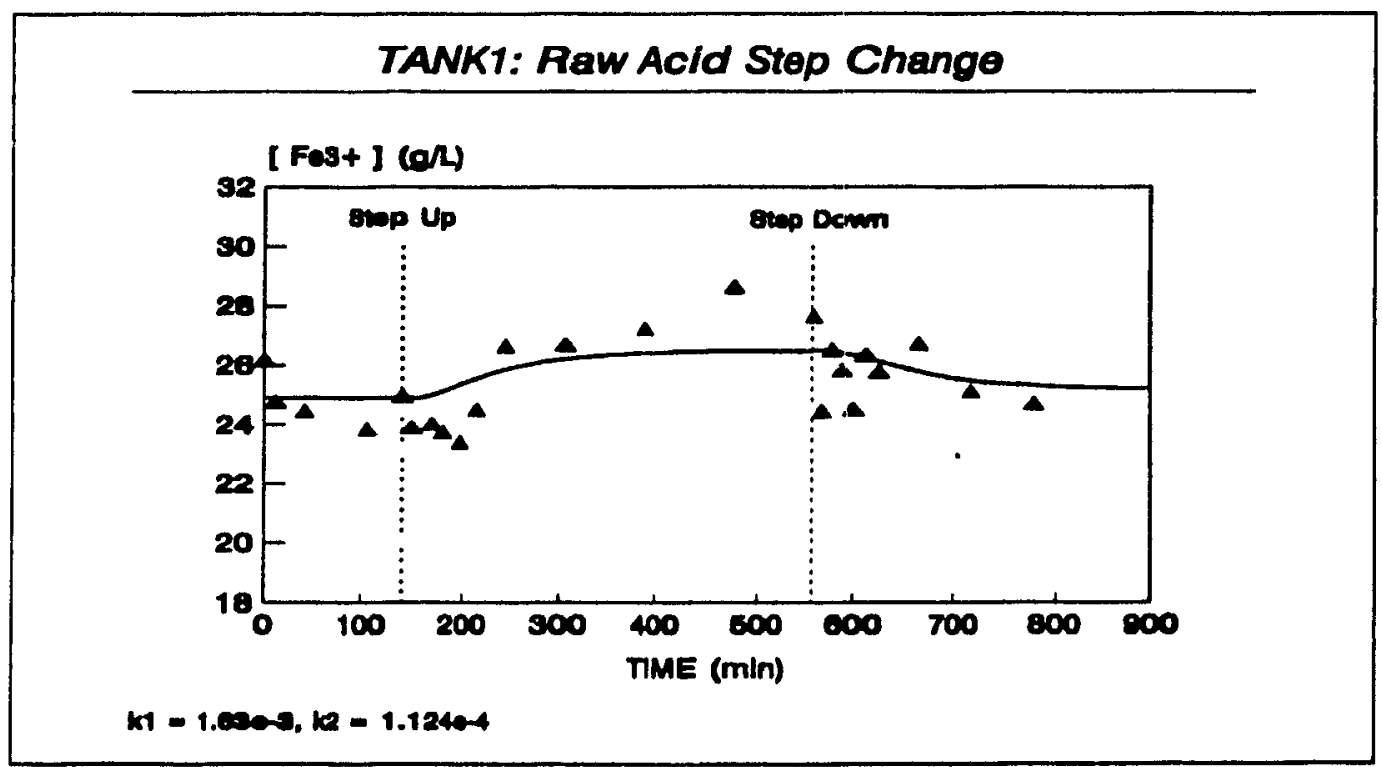

Figure 5-5 TEST B Ferric Iron Concentration Changes 


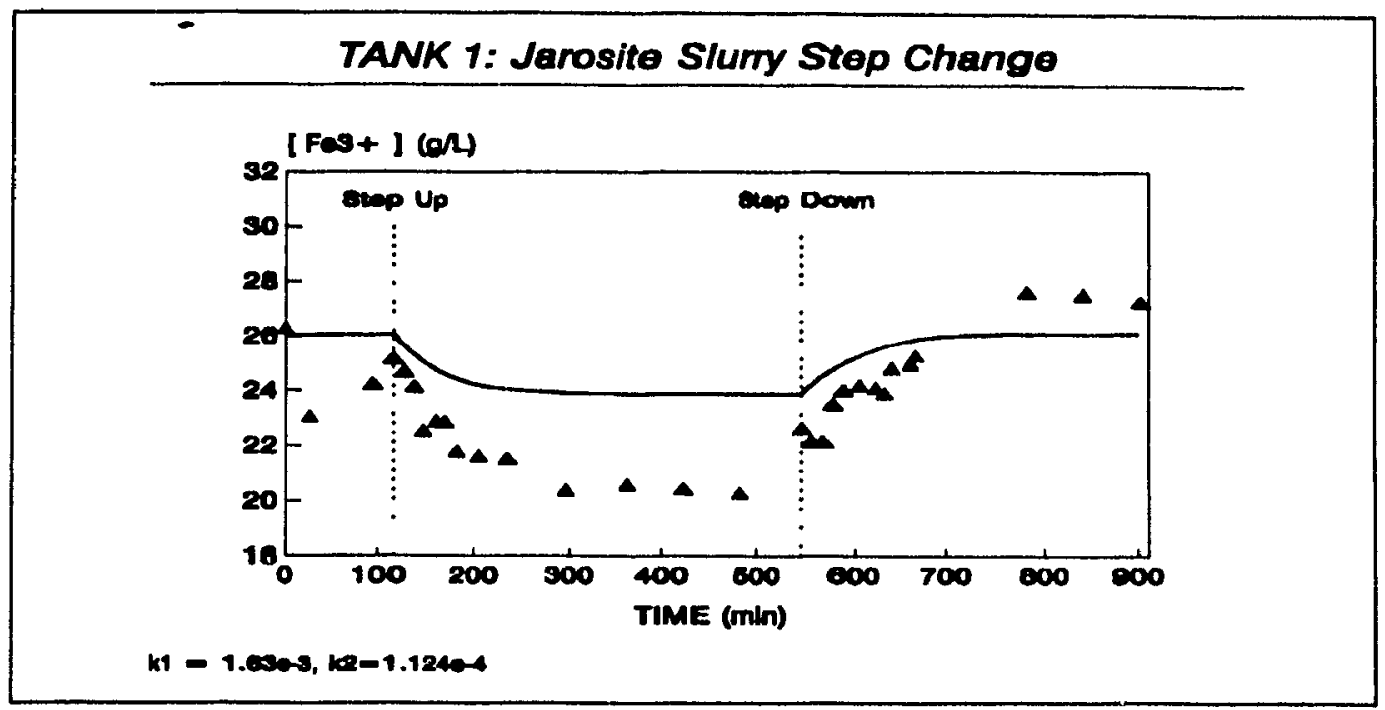

Figure 5-6 TEST C Ferric Iron Concentration Changes

\section{ZINC CONCENTRATION PROFILES}

In section 4.3, all of the hypotheses regarding the significance in the steady state zinc concentration differences were rejected. This was a result of the large sample variance which was partially due to the large analytical error associated with the zinc assay measurement. This technique has a standard deviation of $1.7 \mathrm{~g} / \mathrm{L}$. Figure 5-7 below demonstrates the model's prediction of this variable data.

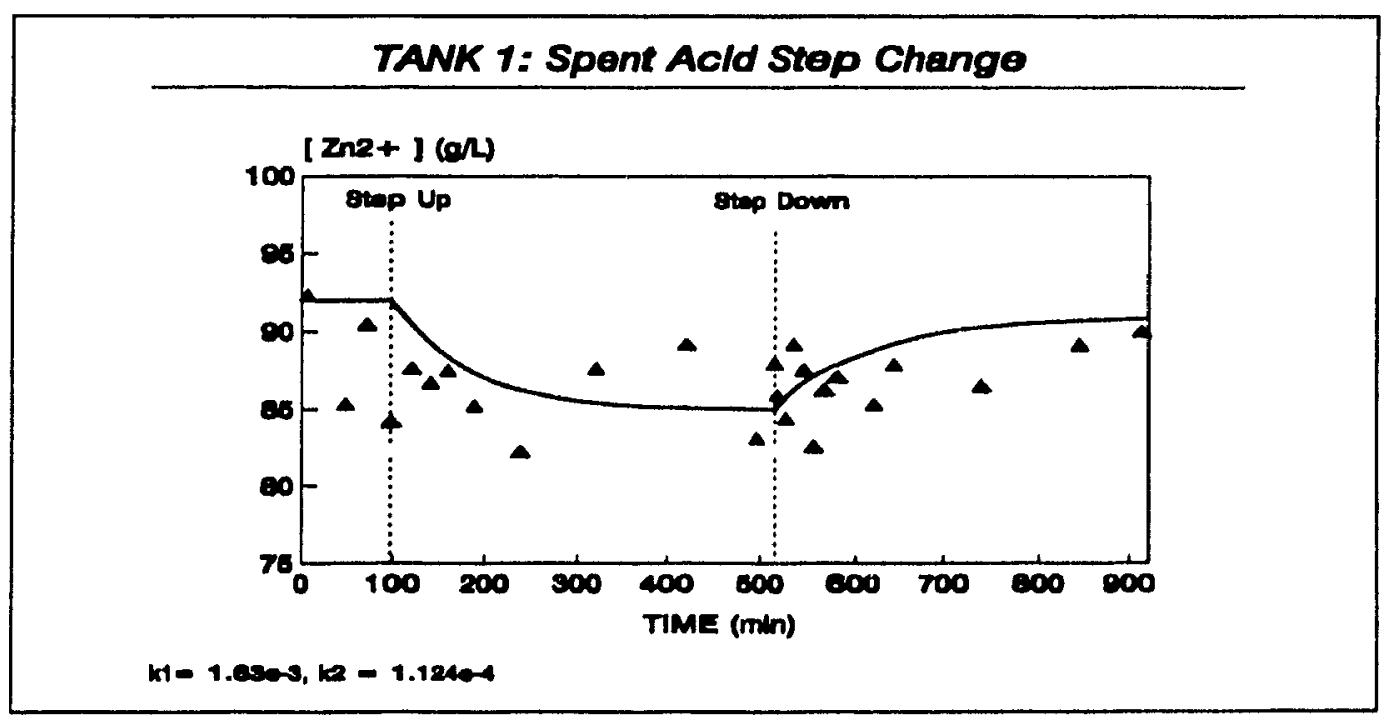

Figure 5-7 TEST D Zinc Concentration Changes 
ZINC MASS_FRACTION IN SOLIDS PROFILES

Some of the best representations of the experimental data are seen when we compare the model's predictions with the percent zinc in the solids data. These results are shown in Figures 5-8 to 5-11 which look at Tests $B$ to $E$ respectively.

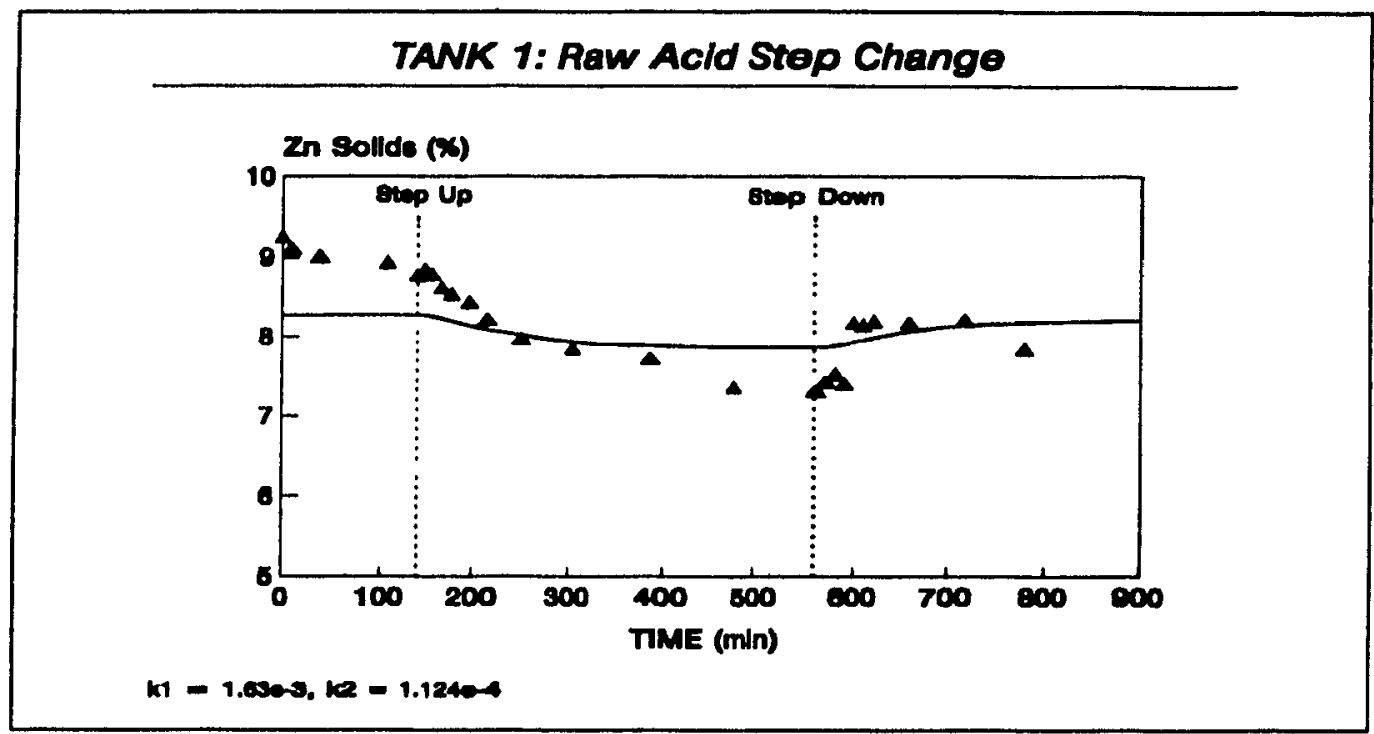

Figure 5-8 TEST B Percent Zinc in Solids Changes

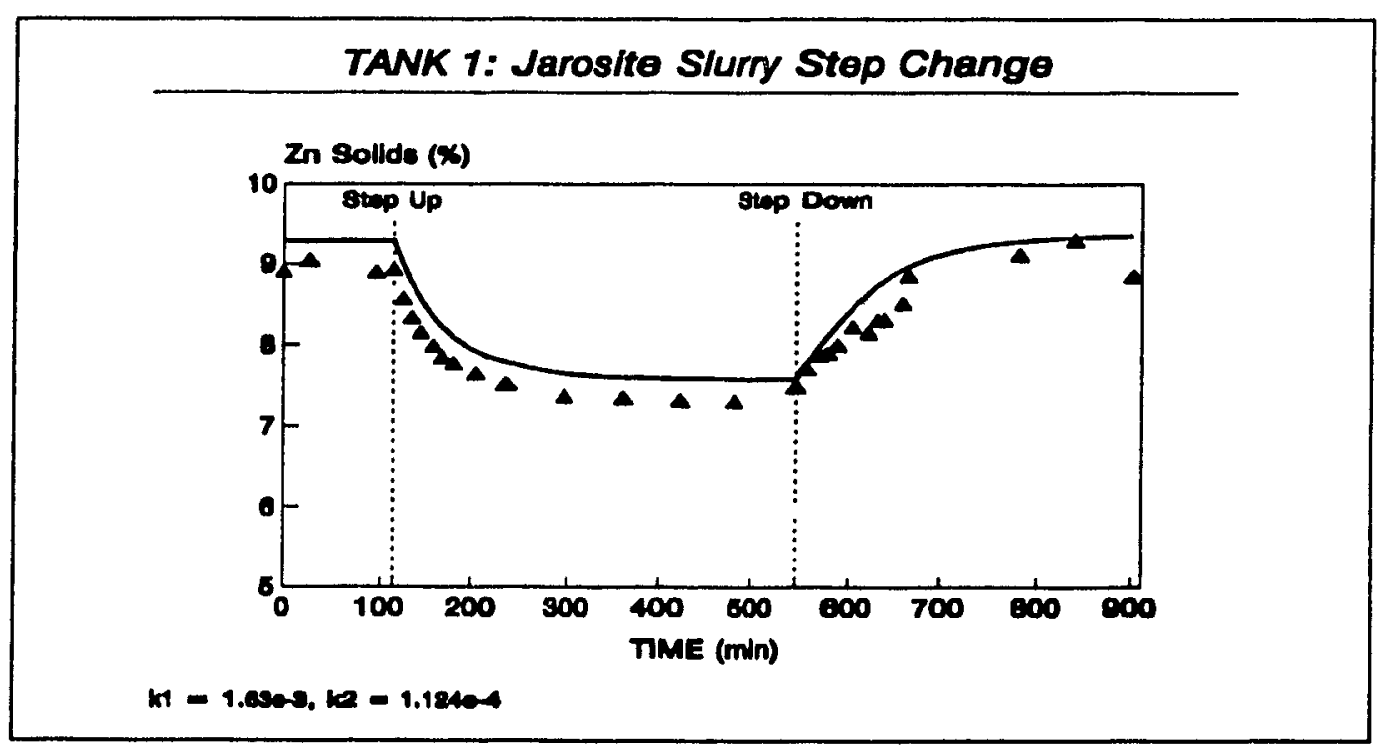

Figure 5-9 TEST C Percent Zinc in Solids Changes

As expected, the zinc mass fraction drops in Test $B$ and $D$ due to increased zinc 
ferrite leaching which resulted from the larger acid inputs. Test $C$ experienced a large drop in the percent zinc following the jarosite slurry step change. This drop was due to the diluting effect of the jarosite solids which contain a low percentage of zinc. The same explanation can be used for Test $E$ where this time the zinc ferrite step change increased the percent zinc in the solids.

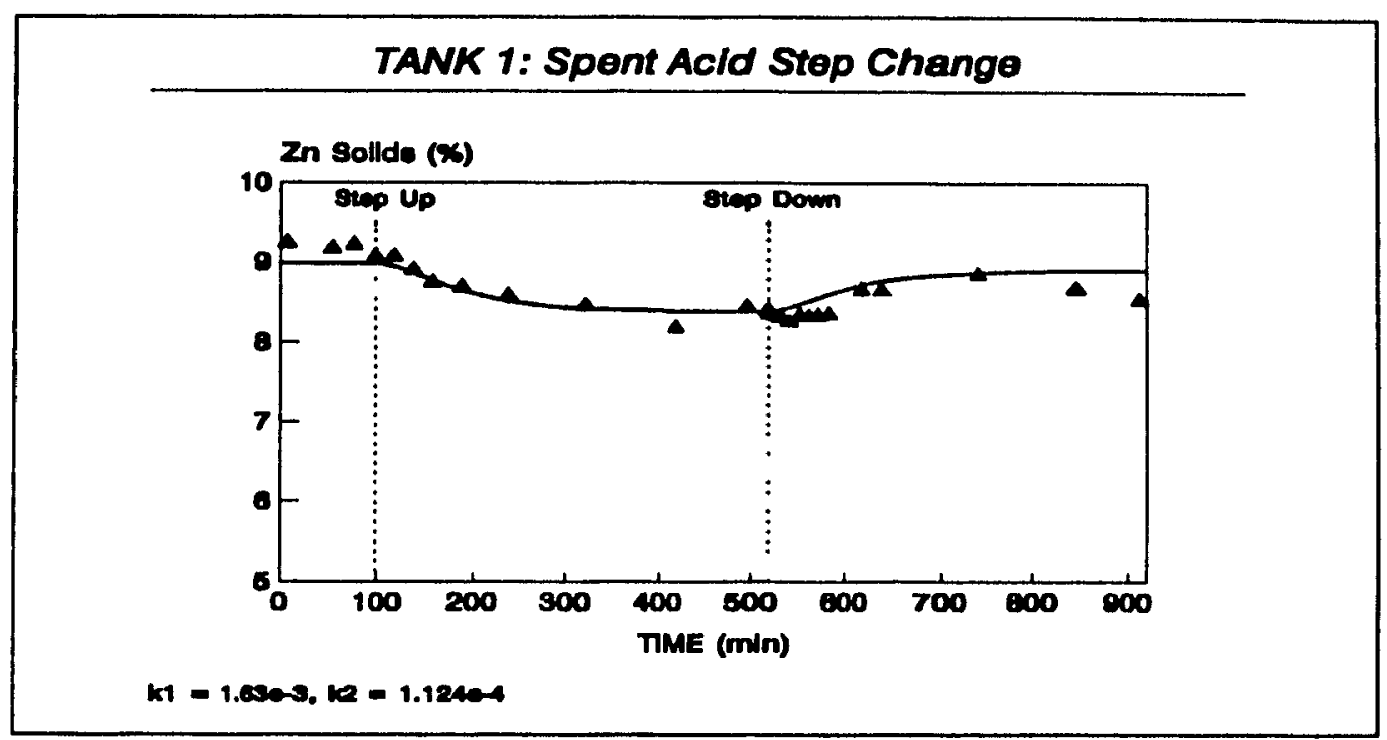

Figure 5-10 TEST D Percent Zinc in Solids Changes

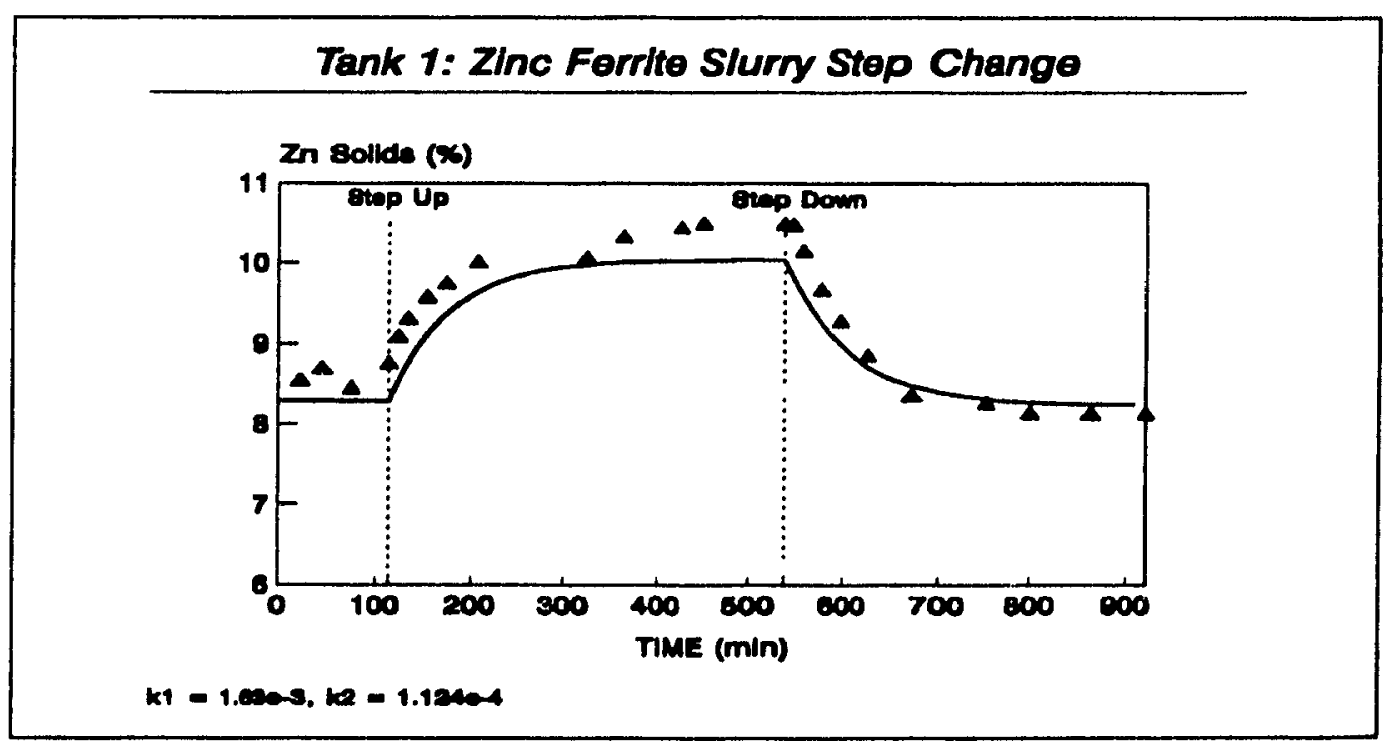

Figure 5-11 TESTE Percent Zinc in Solids Changes 
The modelling results from the percent iron in the solids will not be discussed since the data was found to be quite erratic. This can be partially explained by the large analytical standard deviation of $0.5 \% \mathrm{Fe}$.

\subsubsection{Tank 1 Jarosite Rate Constant Sensitivity}

One of the questions that was studied was what was the degree of jarosite precipitation in the first reactor knowing that the jarosite precipitation kinetics are reduced under high acidities. Figure 5-12 shows the model results when the jarosite precipitation reaction is ignored (ie. $k 2=0$ ). From this Figure we see that the two curves are essentially the same which implies that there is negligible jarosite precipitation in the first reactor.

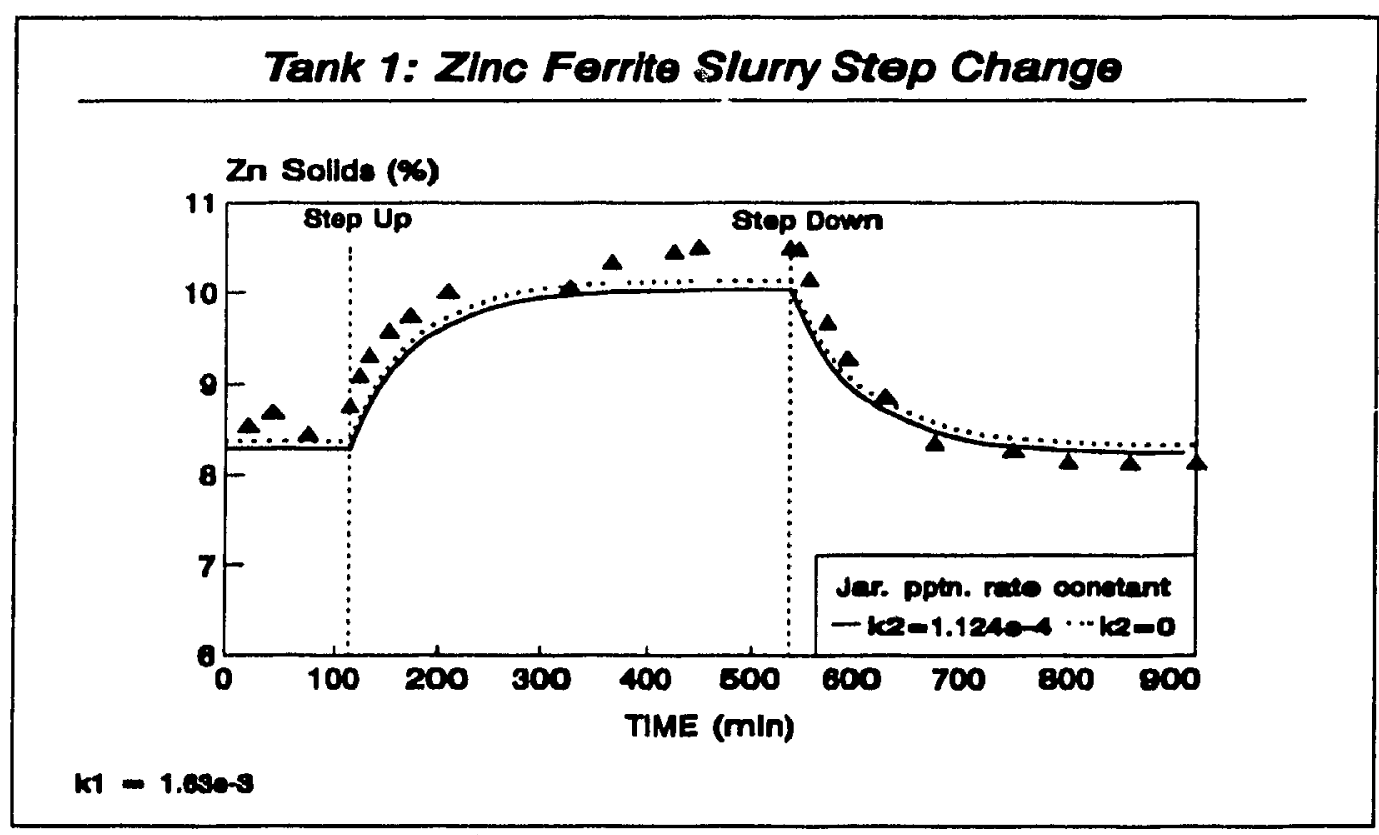

Figure 5-12 TEST E Effect of Jarosite Precipitation 


\subsubsection{Tank 2 Results}

In the second tank the best results from the model were obtained when the zinc ferrite rate constant was reduced from $1.63 \times 10^{-3}$ to $0.85 \times 10^{-3}$ ( $\mathrm{mol} / \mathrm{L}$. $\mathrm{min}$ ). This was necessary since the rate constant for the first tank was originally calculated with the assumption that the zinc ferrite solids concentration was $55 \mathrm{~g} / \mathrm{L}$. In the second tank, the zinc ferrite solids concentration drops due to continued zinc ferrite dissolution. Unfortunately, the experimental results cannot be used to calculate the zinc ferrite solids concentration in the second reactor since jarosite precipitation is occurring. As the best modelling results were realized for a rate constant of $0.85 \times 10^{-3}$, we can propose that the zinc ferrite solids concentration may have been reduced from $55 \mathrm{~g} / \mathrm{L}$ to $29 \mathrm{~g} / \mathrm{L}$. The fact that the rate constant changes as a function of the solids concentration demonstrates the limitations of modelling heterogeneous reactions as pseudo-homogeneous reactions.

Since the rate constant that fitted the results from the second tank was found to be quite different from that of the first reactor, it was desired to study its sensitivity. This was accomplished by comparing the following cases:

Case 1: drop the zinc ferrite rate constant to $0.85 \times 10^{-3}$ and maintain jarosite precipitation rate constant as in Tank 1

Case 2: maintain zinc ferrite rate constant at $1.63 \times 10^{-3}$ and maintain jarosite precipitation rate constant as in Tank 1

Case 3: maintain zinc ferrite rate constant at $1.63 \times 10^{-3}$ and assume no jarosite precipitation occurs $(k 2=0)$

\section{SULPHURIC ACID CONCENTRATION PROFILES}

If we refer to Figures 5-13 and 5-14 we find that the best modelling results occur using the first case conditions in which the zinc ferrite rate constant is reduced by $52 \%$. Further examination of these figures shows that the worst results occurs 
when the jarosite precipitation reaction is ignored. This was expected since jarosite precipitation was assumed to occur in the second reactor.

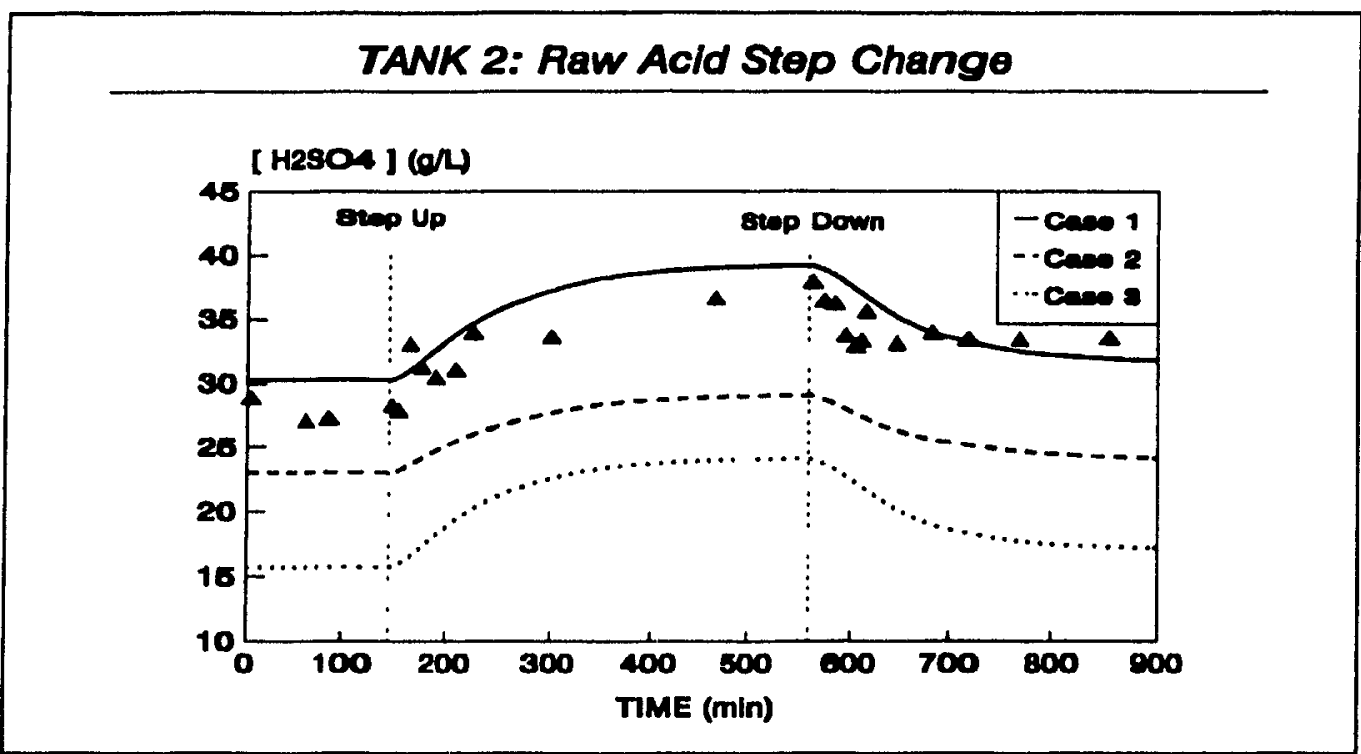

Figure 5-13 TEST B Sulphuric Acid Concentration Changes

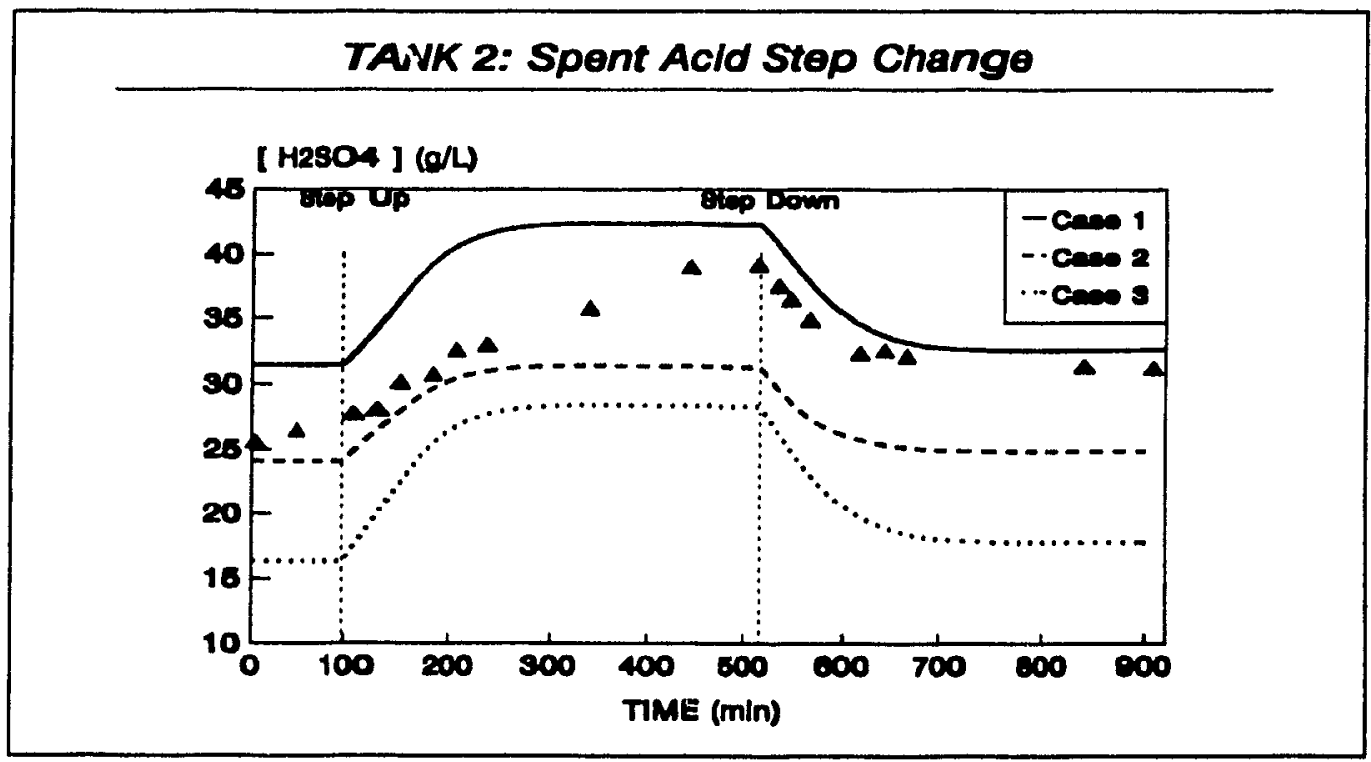

Figure 5-14 TEST D Sulphuric Acid Concentration Changes 
FERRIC IRON CONCENTRATION PROFILES

For the case of the iron concentration, as seen in Figures 5-15 and 5-16, the most important parameter seems to be the jarosite precipitation rate constant. If we ignore this reaction, the model is no longer representative of the experimental data. These Figures further demonstrate the negligible effect of the zinc ferrite rate constant on the iron concentration profile.

\section{TANK 2: Ruw Acid Step Change}

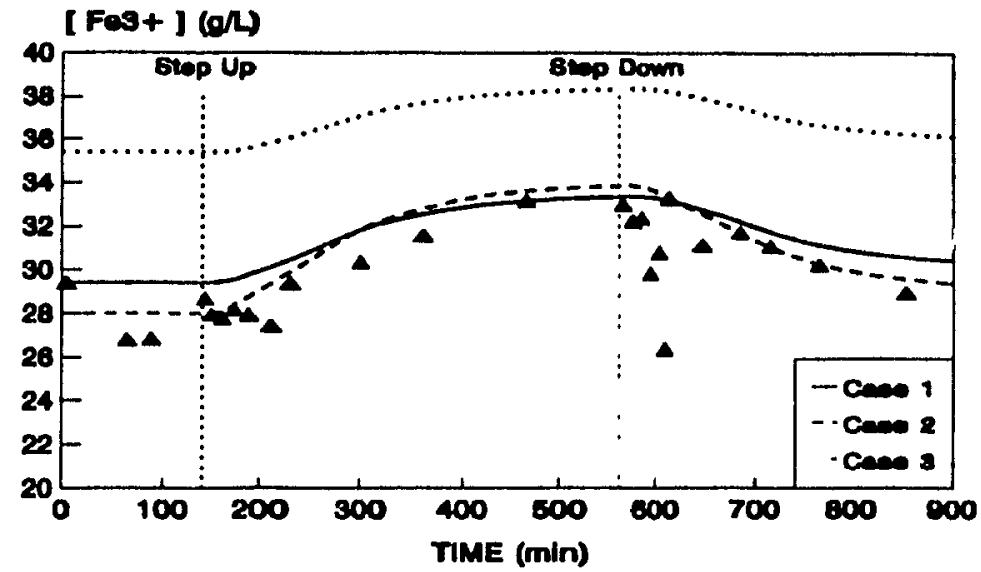

Figure 5-15 TEST B Ferric Iron Concentration Changes

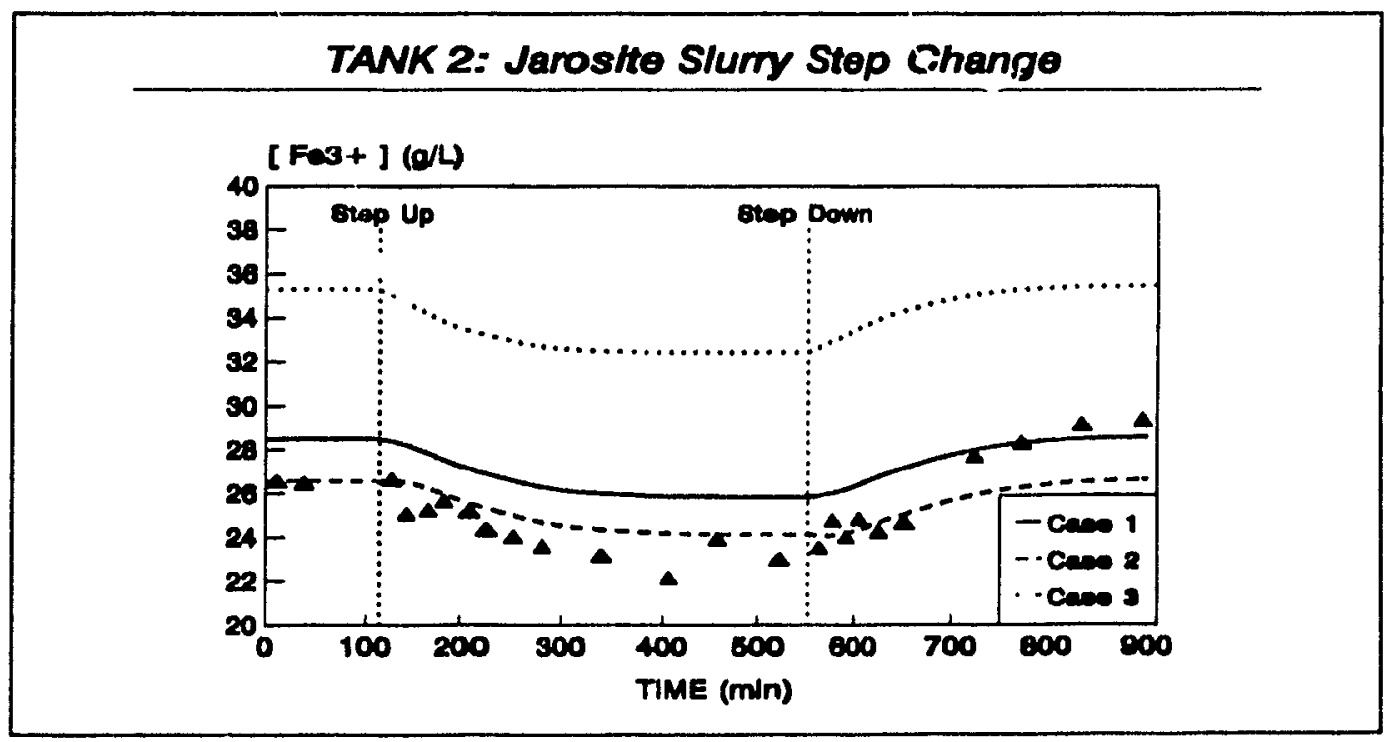

Figure 5-16 TEST C Ferric Iron Concentration Changes 
ZINC CONCENTRATION PROFILES

As expected, the zinc concentration is more sensitive to the adjustments in the zinc ferrite rate constant since the zinc in solution is not affected by changes in the rate of jarosite precipitation.

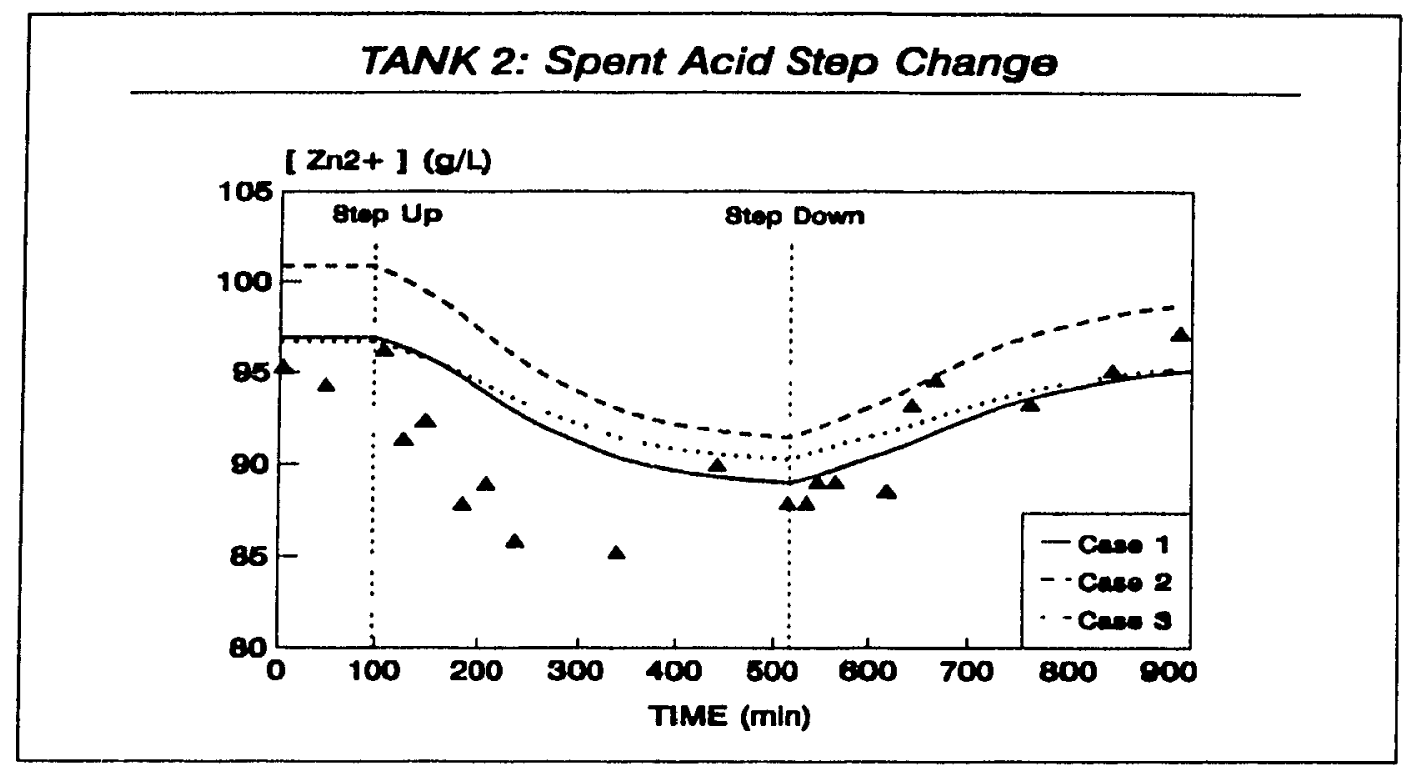

Figure 5-17 TEST D Zinc Concentration Changes

ZINC MASS FRACTION IN SOLIDS PROFILES

TANK 2: Jarosite Slurry Step Change

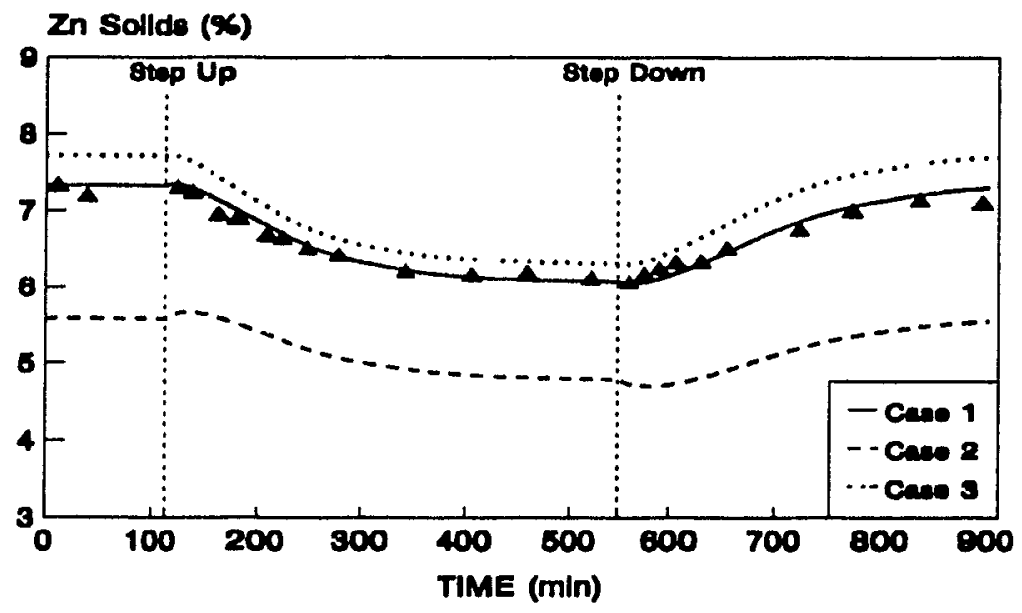

Figure 5-18 TEST C Percent Zinc in Solids Changes 
In all of the fests, the percent zinc is more strongly effected by changes in the ferrite rate constant. Interestingly, however, Test $D$ results seem to be strongly effected by the jarosite precipitation reaction.

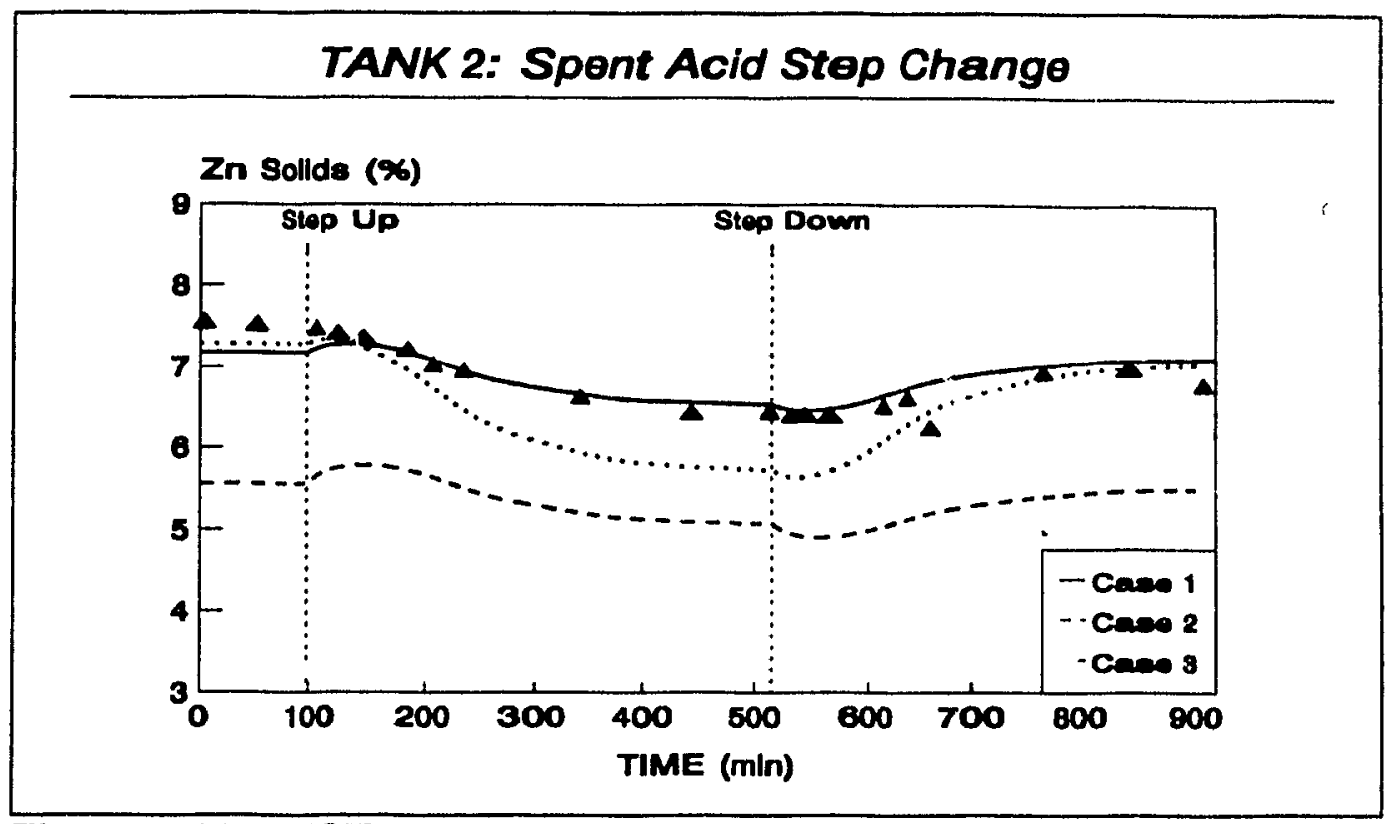

Figure 5-19 TEST D Percent Zinc in Solids Changes

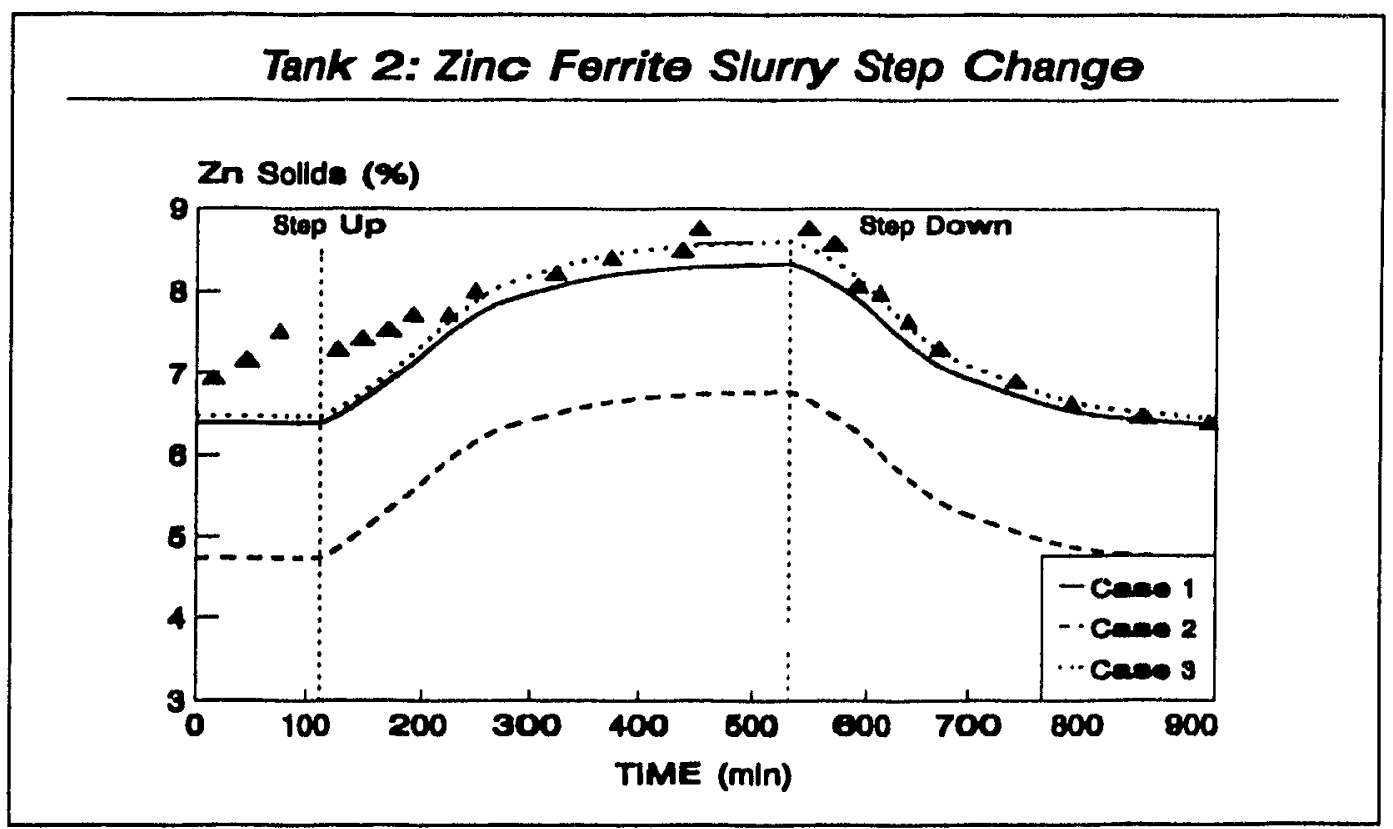

Figure 5-20 TEST E Percent Zinc in Solids Changes 


\subsection{Process Control Strategy}

\section{CONTROL OBJECTIVES}

For optimal operation of the jarosite conversion circuit it is important to maximize the extraction of zinc ferrite and to minimize the iron in solution at the exit of the circuit. The main reactions occurring in this system are zinc ferrite dissolution and jarosite precipitation. High initial acid concentrations will result in high zinc extractions while low exiting acid concentrations will enhance jarosite precipitation. Consequently, the key to optimally running this circuit is to regulate the acid addition to the first jarosite reactor so that we can reduce the variance in the acid and iron concentrations at the exit of the circuit.

\section{MEASURED AND CONTROLLED VARIABLES}

At CEZinc the acid concentration is measured on-line in the first jarosite reactor using an Outokumpu automatic titrator. This instrument is able to deliver acid concentration data every 15 minutes. This data is then transmitted to the Rosemount Distributed Control System (D.C.S.). Other on-line measurements include the main feed stream flows to this tank. For example, the inlet spent acid, raw acid and slurry volumetric flow-rates are all measured and can be controlled at a specified set-point. Live steam is used to regulate the reactor temperature which is also measured on-line.

\section{PROCESS DISTURBANCES}

Because the addition of raw acid to the first jarosite reactor has a dual purpose, its set-point is occasionally adjusted to control the electrolyte volume in the cell house (refer to figures 1-2). It is realized, however, that changes to this stream's flow set-point will impact the performance of the jarosite circuit operation.

The composition of the slurry is a disturbance which depends on the performance of the other unit operations in the leach circuit (refer to Fig. 1-3). This variable composition will effect the reaction kinetics as well as the acid consumption in the 
circuit. Because the temperature is controlled through live steam injection, a net addition of water is added to the circuit which also acts as a disturbance.

\section{CONTROL LOOP CONFIGURATION}

The control strategy depicted in the Figure 5-1 provides one possible method for maintaining the acid and iron concentrations at the target values. This example shows the acid concentration being measured on-line out of tanks 1 and 5 (A). This information, along with the other available data from the D.C.S., such as the feed stream flows, would be used to optimally manipulate the spent acid flow-rate to the first tank to regulate the acid and iron concentrations out of the circuit. This strategy may also include the addition of raw acid as a ratio (FC) of the inlet slurry flow-rate to the first jarosite tank (changes to the electrolyte storage tank volume strategy, which uses the raw acid flow, would be necessary). The controller boxes (C) would include the dynamic model information which would result in the design of a non-linear controller.

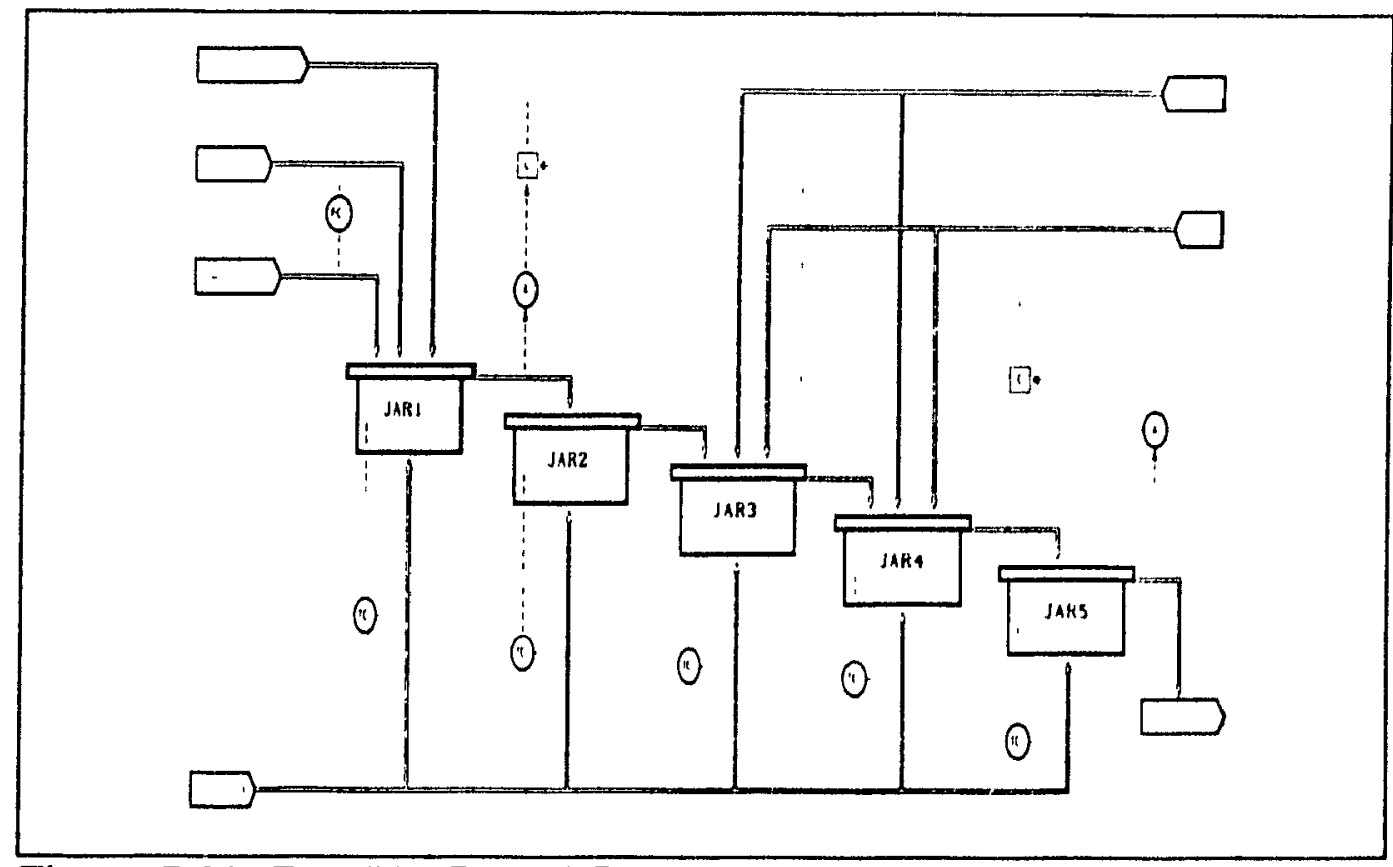

Figure 5-21 Possible Control Strategy 


\section{Chapter 6}

\section{CONCLUSION}

\subsection{Conclusions}

The first five tanks of the jarosite conversion circuit were successfully piloted and results were obtained from four process identification experiments. These data showed the transient effects that the major feed streams had on the reactor performance. Although data was collected from all five reactors, the scope of the thesis was limited to analyzing the results from the first two reactors.

A certain degree of confidence in the experimental results was realized when the data from these pilot experiments gave high mass balance closures for both zinc and iron. Furthermore, since the transient responses from the process identification experiments were as expected, this information was used to validate the dynamic conversion circuit model.

Following the development of the dynamic model, case studies confirmed that the available kinetic data could be used to model the jarosite circuit's acid, and iron concentrations in solution as well as the mass fraction of zinc in the solids. Problems with the analysis of iron in the solid phase resulted in difficulties with model validation. Using the experimental results, the calculated zinc ferrite rate constant of $1.76 \times 10^{-3} \mathrm{~mol} / \mathrm{L}$. min was found to agree with the literature value.

The results from the first tank have shown that the parameter that has the largest impact on the degree of zinc ferrite dissolution is the flow-rate of the raw acid stream. This was observed after changes in this stream's flow did not impact the reactor's residence time. The stream which was found to have the largest effect on the acidity in the first reactor resulted from changes in spent acid flow-rate. Finally the simulation results helped to highlight the initiation of jarosite 
precipitation in this circuit. This reaction was found to be negligible in the first reactor, where the acidity is relatively high, and was shown to be important in the second tank.

\subsection{Proposal for Future Studies}

Future work will involve extending the MATLAB jarosite conversion circuit model to the first five jarosite reactors. Eventually, further work may be under-taken to extend this model to the entire series of jarosite reactors at CEZinc (10 tanks). This type of model would be validated using available plant data. With a model of this nature, it is possible to use it for optimization studies as well as incorporate it in an advanced non-linear control strategy for maintaining the acid and iron at their optimal levels in these reactors. 


\section{Chapter 7}

\section{REFERENCES}

1) Dutrizac, J.E., "Jarosite Type Compounds and their Applications in the Metallurgical Industry", Hydrometallurgy Research, Development \& Plant Practice, AIME Conference Proceedings, 1983.

2) Ghibu,C. \& Dupuis, D., "Development of an Expert System to assist the Operator of a Modern Electrolytic Zinc Refinery: Preliminary Results", Proceedings of the CANMET Symposium on Expert Systems in the Mineral Industry (1987)

3) Laguitton, D., Bilodeau, M., Dupuis, D., et al, "Expert System Advisor for Operators of a Zinc Leaching Plant", 6th IFAC Symposium on Auto. in Mining, Mineral, and Metal Processing (1989).

(4) Smith, J.M., "Chemical Engineering Kinetics", $3^{\text {th }}$ Edition, McGraw-Hill Book Company, 1981.

(5) Rosato, L., Private Communication with G. Holcroft, 1992.

6) Elgersma, F. et al, "Acidic Dissolution of Zinc Ferrite", Hydrometallurgy, 29 (1992), p.173-189.

7) Rastas, J. \& Fugleberg, "Kinetics of the Ferrite Leaching \& Jarosite Precipitation", Erzmetall, Bd, 32 (1979) H.3 
8) Ismay, A., "A Review of Zinc Plant Leach \& Iron Precipitation Technology" NTC Technical Memorandum No.157, Dec, 1983.

9) Filippou, D. \& Demopoulos, G., "A Reaction Kinetic Model for the Leaching of Industrial Zinc Ferrite Particulates in Sulphuric Acid Media", Canadian Metallurgical Quarterly, Vol.31, No.1, pp. 41-54, 1992.

10) Steintveit, G.A., "Highlights in the Development of the Hydrometallurgical Zinc industry", key note paper presented at the Zinc ' 83 conferenc ?.

11) Dutrizac,J.E., "An Overview of Iron Precipitation in Hydrometallurgy" International Symposium on Crystallization \& Precipitation, Oct. 1987.

12) Qian-kun, W. \& Rong-jun, Ma., "The Jarosite Process --Kinetic Study", Zinc '85, Chap. 42 p. 675

13) Limpo, J.L., Luis, A., Siguin, D. and Hernandez, A., "Kinetics and Mechanism of the Precipitation of Iron as Jarosite", Rev. Metal. Cenim, Vol.12, No.3, (1976), pp. 123-134)

(14) Elgersma, F., "Integrated Hydrometallurgical Jarosite Treatment", PhD Thesis, Delft University of Technology, 1992.

(15) Kubu, H, Kawahara, M. et al, "The Rate of the Precipitation Reaction of Iron in Jarosite Method", Journal of the Mining and Mistallurgical Institute of Japan, Vol. 98, No.1138, Dec. 1982. 


\section{APPENDIX I}

\section{NOMENCLATURE}
A surface area of the crystals
t time
$a_{i} \quad$ activity of ionic species $i$
$T$ temperature
aq aqueous species
TC temperature controller
$C_{1}$ molar concentration of species $i$
$\mathrm{V}$ reactor volume
$\mathrm{C}_{\mathrm{s}}$ mass concentration of species $\mathrm{i}$
$V_{9} \quad$ grain volume
$F$ molar flow rate
$x$ conversion
FC flow controller
$v_{1} \quad$ stiochiometric coeff. of comp. i
$F_{g}$ shape factor
$\kappa$ stoichiometric coefficient matrix
$G$ crystal growth rate
$\rho$ density
$k$ rate constant
$\phi \quad$ reaction rate vector
$M \quad$ molecular weight
[] concentration
$M \quad$ Mass flow rate
$\Sigma$ summation
$N_{1} \quad$ number of moles of species i
$Q \quad$ volumetric flow rate
R universal gas constant
$r$ reaction rate ( $\mathrm{mol} /$ time-volume)
$r_{p} \quad$ global rate: (mol/time-area)
$\mathrm{r}^{+} \quad$ rate of production
$r_{s} \quad$ radius of solid particle
s solid species
$s_{i} \quad$ mass fraction of solid comp. i
$s_{n} \quad$ mass fraction of solids in stream $n$
$S_{g} \quad$ grain surface area
$S$ initial surface area 


\section{APPENDIX II}

\section{CALIBRATION CURVES}

Faw Acid Rotamotor Callbration

(06.6-06.6\% Haso4 at 23 dog.C)

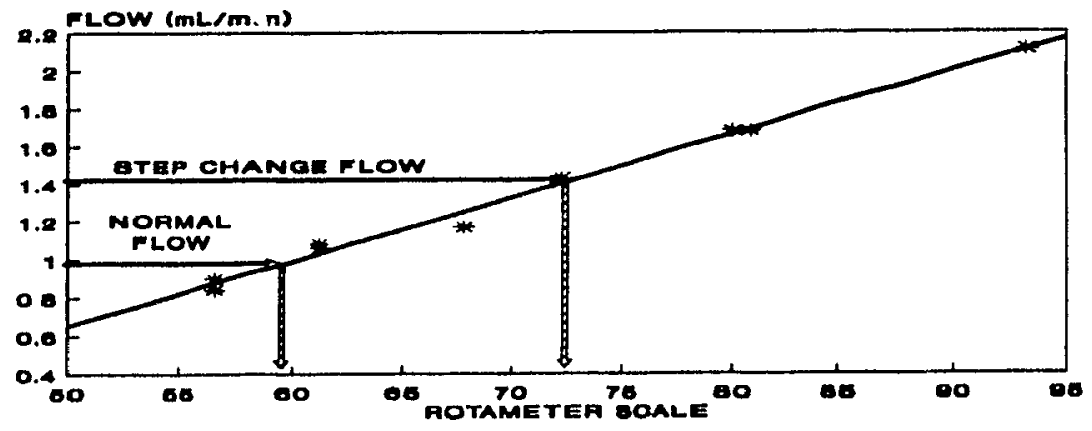

(ailimant eid 0
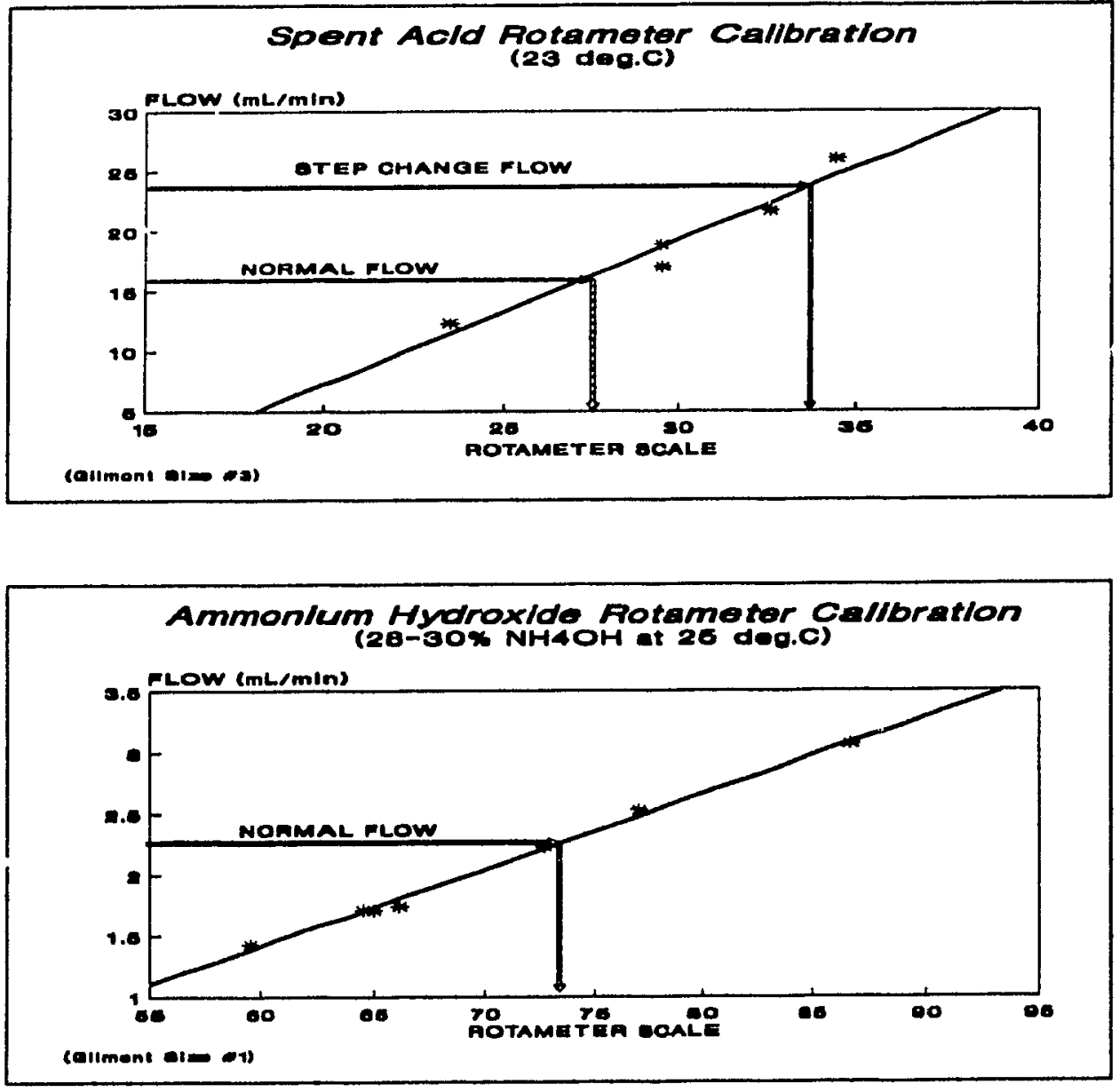


\section{APPENDIX III}

\section{TANK CHARACTERISATION AND TRACER SELECTION STUDY}

\section{RESIDENCE TIME DISTRIBUTION (RTD) STUDY ON PILOT REACTOR \\ Objective}

Peform a step input of $150 \mathrm{~g} / \mathrm{L}$ Jarosite slurry and take samples at the reactor exit every 5 minutes. The change in the solids concentration with time will be used to evaluate the RTD function and consequently the mixing characteristics of the pilot reactors.

\section{Procedure}

- Fill tank with water and heat to $70^{\circ} \mathrm{C}$

- Operate impeller at $650 \mathrm{rpm}$ : Tank Volume $=3000 \mathrm{~mL}$

- Flow $100 \mathrm{~mL} / \mathrm{min}$ water into the tank

this will result in an average residence time of $30 \mathrm{~min}$

- At $\mathrm{t}=0$ feed $150 \mathrm{~g} / \mathrm{L}$ Jarosite.slurry at a rate of $103 \mathrm{~mL} / \mathrm{min}$

- Take samples every 5 minutes for 90 minutes ( 3 times residence time) sample volume $=25 \mathrm{~mL}$ ( 15 seconds to fill)

- maintain temperature at $70^{\circ} \mathrm{C}$ in tank using external band heaters

- Slurry Preparation: $\quad 15 \mathrm{~L}$ water ${ }^{*} 150 \mathrm{~g} / \mathrm{L}$ solids $=2250 \mathrm{~g}$ Jarosite solids Heat slurry before adding to tank

\section{RTD Models}

RTD for an "Ideal Stirred Tank" after a Step Function Input:

$$
J_{1}(\theta)=1-\exp ^{\left(\frac{n}{\pi}\right)}
$$

RTD for a "Two Stirred Tanks in Series Model" after a Step Function Input:

$$
J_{2}(\theta)=1-\exp ^{\left(\frac{201}{\pi}\right)}\left[1+\frac{2 \theta}{\bar{\theta}}\right]
$$


STEP CHANGE EXPERIMENTAL RESULTS

\begin{tabular}{|c|c|c|c|c|}
\hline \multirow{2}{*}{$\begin{array}{l}\text { TIME } \\
(\mathrm{min}) \\
\end{array}$} & \multirow{2}{*}{$\begin{array}{c}\text { SOLIDS CONC. } \\
(\mathrm{g} / \mathrm{L}) \\
\end{array}$} & \multicolumn{3}{|c|}{ RTD FUNCTION $J(\theta) \quad\left(\theta_{\text {AVG }}=30 \mathrm{mIn}\right)$} \\
\hline & & EXPERIMENTAL & IDEAL STR & 2 STR in Series \\
\hline 0 & 0.0902 & 0.001 & 0.000 & 0.000 \\
\hline 2 & 02290 & 0.040 & 0.064 & 0.008 \\
\hline 5 & 0.4703 & 0.107 & 0.154 & 0.045 \\
\hline 10 & 0.8769 & 0220 & 0.283 & 0.144 \\
\hline 15 & 12608 & 0326 & 0.393 & 0.264 \\
\hline 20 & 16111 & 0.423 & 0.487 & 0.385 \\
\hline 25 & 1.9244 & 0.510 & 0565 & 0.496 \\
\hline 30 & 2.2093 & 0589 & 0.632 & 0.594 \\
\hline 35 & 2.4278 & 0.650 & 0.689 & 0.677 \\
\hline 40 & 2.6256 & 0.705 & 0.736 & 0.745 \\
\hline 45 & 2.8072 & 0.755 & 0.777 & 0.801 \\
\hline 50 & 2.9397 & 0.792 & 0.811 & 0.845 \\
\hline 55 & 3.0602 & 0.826 & 0.840 & 0.881 \\
\hline 60 & 3.1790 & 0.859 & 0.865 & 0.908 \\
\hline 65 & 3.2911 & 0890 & 0.885 & 0.930 \\
\hline 70 & 3.3653 & 0.910 & 0.903 & 0.947 \\
\hline 75 & 3.4440 & 0.932 & 0.918 & 0.960 \\
\hline 80 & 3.5135 & 2.951 & 0.931 & 0.969 \\
\hline 85 & 3.5578 & 0.964 & 0.941 & 0.977 \\
\hline 90 & 3.6036 & 0.976 & 0950 & 0.983 \\
\hline 95 & 36505 & 0989 & 0958 & 0.987 \\
\hline 100 & 36885 & 1.000 & 0.964 & 0.990 \\
\hline
\end{tabular}




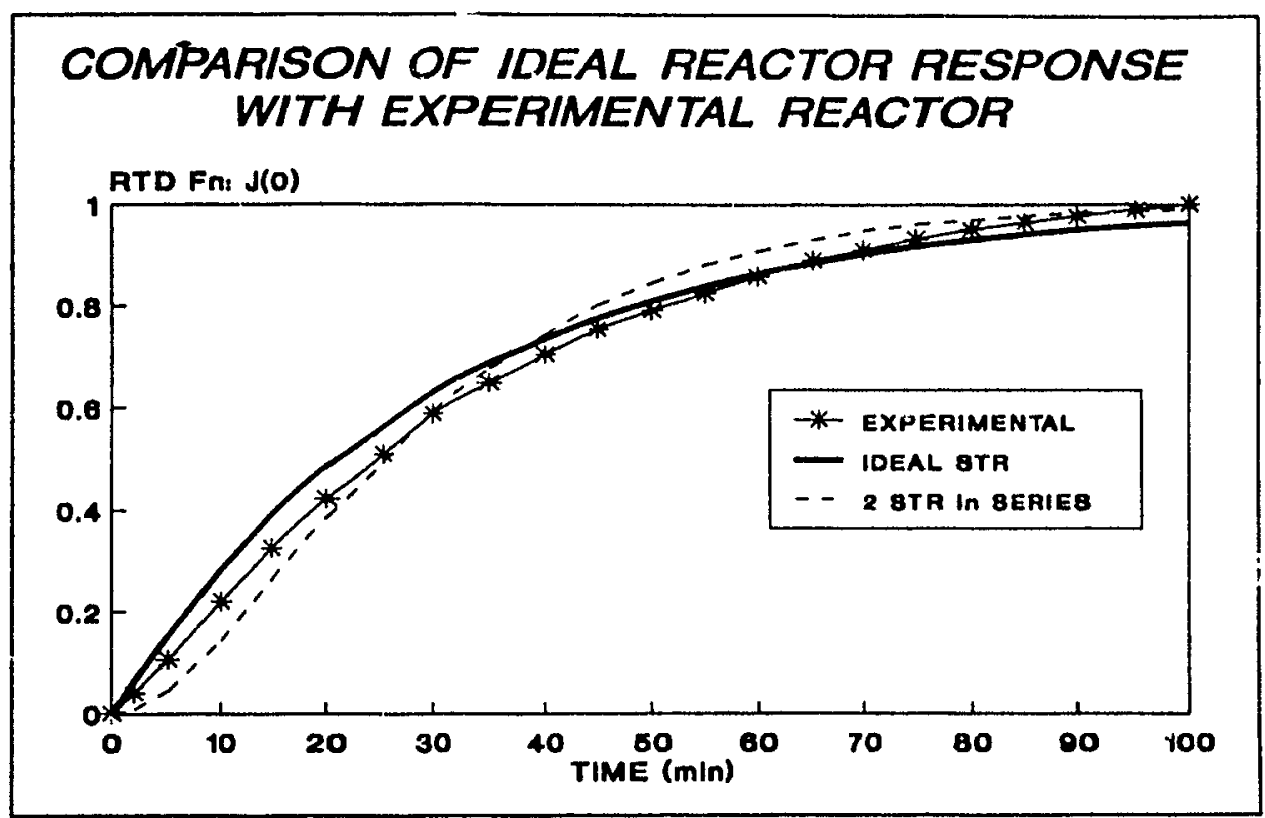

From the above figure, we can see that the pilot scale reactor configuration can be closely approximated by a ideal stirred tank reactor model.

\section{JAROSITE BATCH TEST RESULTS FOR TRACER SELECTION}

If we wish to eventually model the industrial jarosite reactors, it will be necessary to have an idea of the mixing characteristics in these tanks. A method for determining the state of mixing is to perform a residence time distribution (RTD) study. This can be carried out by the step of impulse addition of a tracer at the reactor inlet.

An ideal tracer would be inert and would be readily detected in the exit stream. In the case of the jarosite conversion circuit, the selection of an appropriate tracer is a difficult task since jarosite tends to react with many species. It was postulated that lithium sulphate would remain inert during jarosite precipitation. To verify this assumption, a batch test was carried out to simulate the jarosite conversion process. In this test a known quantity of lithium sulphate was added $\left(\mathrm{Li}_{2} \mathrm{SO}_{4} \cdot \mathrm{H}_{2} \mathrm{O}\right)$ to a beaker. The analytical results, clearly show that lithium sulphate was not present in the solids. If we refer to the 
figure below, we note that the lithium concentration remained essentially unchanged during the course of the experiment.

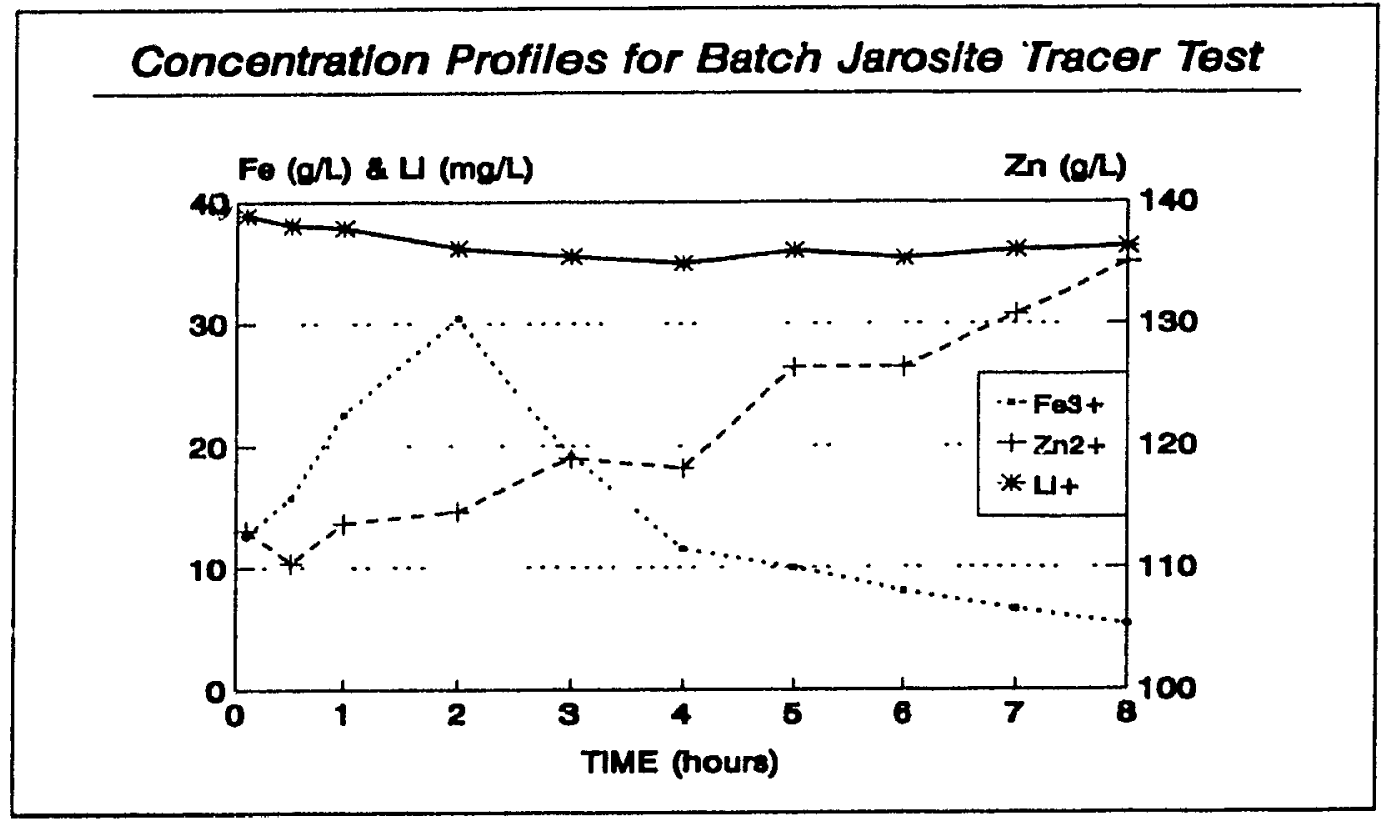

From these results we are able to conclude that lithium sulphate is inert under these conditions.

We were surprised to find traces ( $3 \mathrm{ppm})$ of lithium already present in the initial plant solution. Consequently further evaluations will be required in order to determine how the lithium concentration varies in the circuit. If the variance is too large compared to the concentration for the tracer added then an alternate tracer must be employed.

Another key issue in tracer selection deals with its effect on the cell house where the zinc electro-deposition occuls. It is well documented that even small amounts of certain elements will have a deleterious effect on zinc plating efficiency. To ensure that lithium would not interfere in this process an electrolysis test was carried out with $4 \mathrm{ppm}$ lithium added to the electrolyte. The test results showed that lithium did not effect the plating efficiency. 
The final criterion for tracer selection is that it not be too expensive and that a reliable analytical technique be available. Recently, a technique was developed using an ICP (Inductively Coupled Plasma) machine to analyze lithium in the presence of high iion and zinc concentrations. The results showed that lithium could be analyzed above $20 \mathrm{ppb}$ with a precision of $+/-3.3 \%$ and an accuracy of $92 \%$.

\section{DETERMINATION OF THE EVAPORATION RATE}

\section{Objective}

In order to calculate the exit flow from the pilot reactors, a mass balance calculation around the reactors was carried out. To perform this calculation it was important to quantify the amount of water evaporating from these covered reactors.

\section{Procedure}

- Fill reactor with jarosite filtrate

- Flow approximately $45 \mathrm{~mL} / \mathrm{min}$ of the jarosite filtrate into the reactor

- Heat reactor to $98^{\circ} \mathrm{C}$

- Measure the inlet and the outlet flows

\section{Results}

Inlet flow $=59.87 \mathrm{~g} / \mathrm{min}$

Outlet flow $=57.64,58.07,48.96=54.89 \mathrm{~g} / \mathrm{min}$ average

Evaporation Rate $=59.87-54.89=4.98 \mathrm{~g} / \mathrm{min}+/-4.19(+/-103.2 \%)$

Evaporation Rate used in Mass Balance Calculations: $5.0 \mathrm{~g} / \mathrm{min}$ 


\section{APPENDIX IV}

\section{ZINC FERRITE AND JAROSITE SOLIDS}

\section{JAROSITE SLURRY STABILITY TESTS}

\section{Objective}

Since there is a concern that the jarosite seeds will react with the jarosite solution during storage, it is important to quantify the stability of the prepared jarosite slurry.

\section{Procedure}

- Prepare a mixture of $33 \%$ jarosite slurry by mixing $1.7 \mathrm{~L}$ of jarosite solution with $2.3 \mathrm{~kg}$ of filtered jarosite solids

- The jarosite solution, which is the Thickener 11 over-flow solution from CEZinc, has a density of $1.302 \mathrm{~g} / \mathrm{mL}$ and contains approxirnately $25 \mathrm{~g} / \mathrm{L} \mathrm{H}_{2} \mathrm{SO}_{4}, 85 \mathrm{~g} / \mathrm{L} \mathrm{Zn}$ and $6 \mathrm{~g} / \mathrm{L} \mathrm{Fe}$. The jarosite solids contain $35.5 \%$ moisture and approximately $30 \% \mathrm{Fe}$ and $2.5 \% \mathrm{Zn}$.

- Sample the slurry and filter. Assay filtrate and solids for zinc, and iron and titrate filtrate to obtain the sulphuric acid concentration.

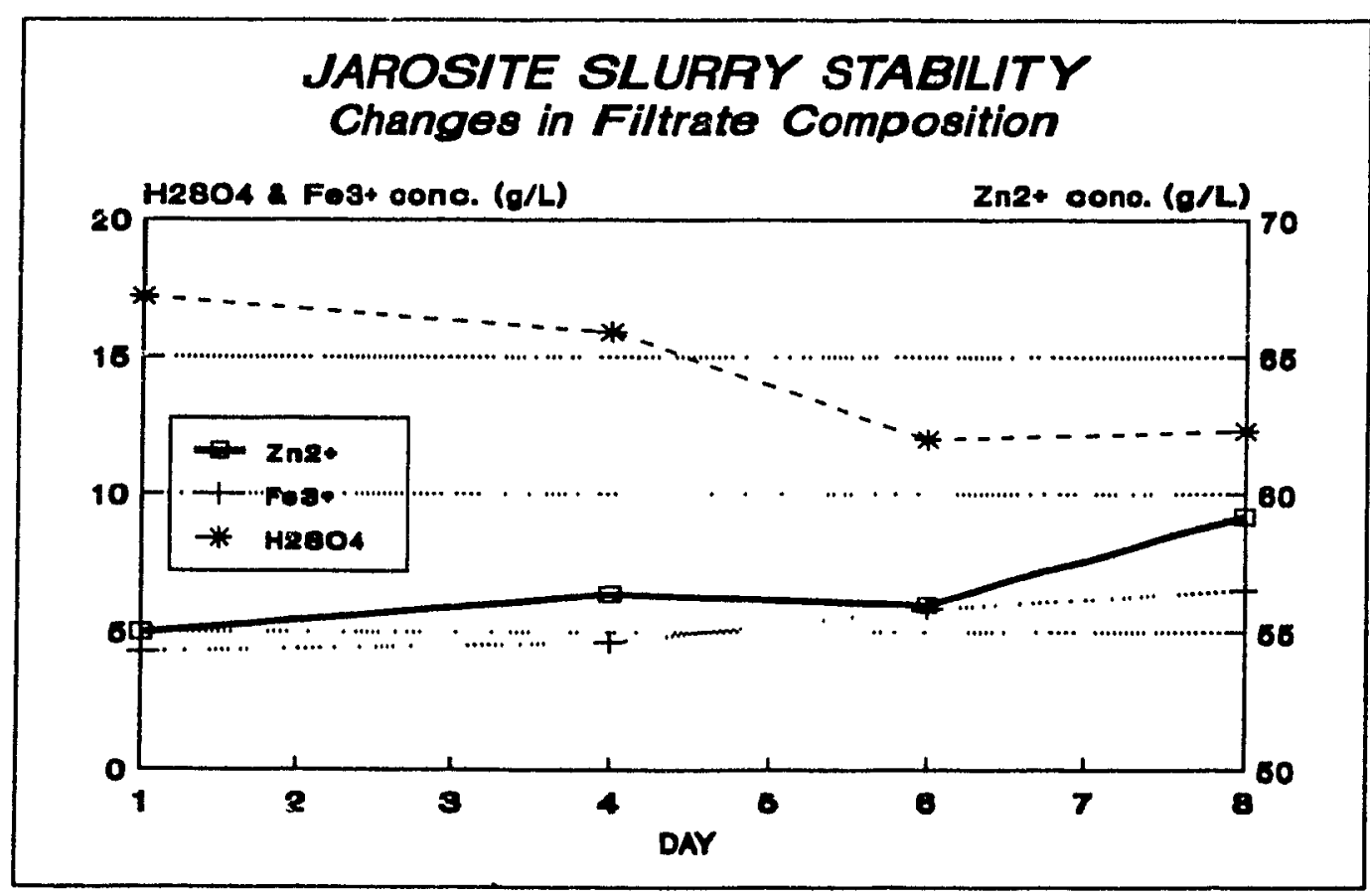




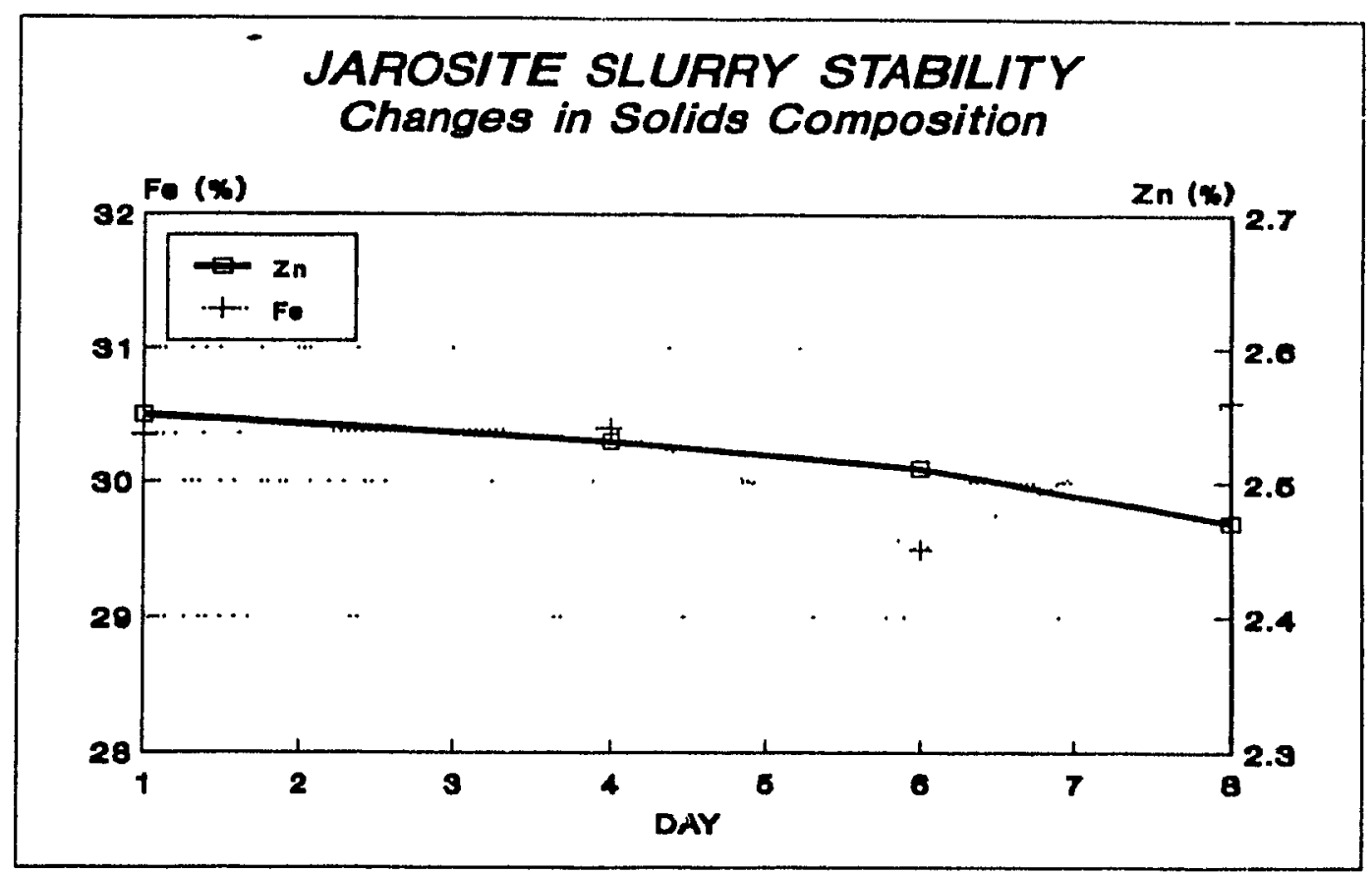

From the previous figures, it was concluded that the jarosite solution will begin to leach the jarosite solids after a period of 5 days. This is shown through the reduction in acid concentration with a corresponding increase in the zinc and iron concentrations in the solution. Furthermore, the reduction in the percent zinc in the solids further confirms that zinc is being leached during storage. No information can be drawn from the percent iron in the solids assays as these data were erratic.

The results from this test have shown that we can prepare the jarosite slurry the day before a pilot experiment but the prepared slurry must be discarded after being stored for over 5 days. Furthermore, we can be assured that the composition of the jarosite slurry does not change during the course of the pilot experiments which have a duration of 24 hours. 


\section{ZINC FERRITE SOLIDS PREPARATION PROCEDURE}

\section{Objective}

Since the zinc ferrite solids from CEZinc contain up to $60 \%$ jarosite seeds, it was necessary to produce our own zinc ferrite solids using calcine solids from CEZinc. The resulting solids will not contain any jarosite seed but can be considered as industrial zinc ferrite since we are using industrial calcine for their preparation.

\section{Procedure}

To produce $15 \mathrm{~kg}$ of $\mathrm{Zn}$ Ferrite solids, it is necessary to leach $50 \mathrm{~kg}$ of calcine. The ratio of zinc ferrite to calcine is approximately $31 \%$ Calcine contains approximately $60 \%$ zinc oxides and $24 \%$ zinc ferrites.

Fill a $250 \mathrm{~L}$ stirred lank reactor with $150 \mathrm{~L}$ of cold water. Reactor should be equipped with some over-head ventilation. Stant impeller

. Add half of the calcine $(25 \mathrm{~kg})$ and slowly pump approximately $12 \mathrm{~L}$ of $96 \%$ sulphuric acid into the reactor. The temperature will begin to rise.

Slowly add remaining calcine and contınue to pump another 10-12 L of acid until the pH is stable between 1.8 to 2.0 (don't forgel to adjust the temperature compensator in the $\mathrm{pH}$ meter). Under these conditions all of the zinc oxides should be leached Since the temperature does rise rapidly, add some cold waler to cool.

Verfily acidity by taking a sample. It should be close $105 \mathrm{~g} / \mathrm{L}$ If the acidity is not high enough $(<5 \mathrm{~g} / \mathrm{L}$ ) then ferric hydroxide formation will occur and these solids are difficult to filter.

Allow reagents to react for 1 hour

Add cold water to fill reactor 106 inches from the top. Turn off agitation.

Let slurry settle for 30 minutes and then remove $50 \mathrm{~L}$ of the supernatant. Replace with cold waler. (This will reduce the concentration of the zinc and iron in solution which are probably close to the saturation point).

Add $5 \mathrm{~L}$ of $0.5 \mathrm{gl}$ Percol 351 flocculent and agitate for 2 minutes.

Reduce agitation and start to filter the slurry through a filter press. Once the press is full wash the solids by passing water through the press.

The filter press should be able to hold all of the solids in the $250 \mathrm{~L}$ reactor.

Remove solids from the press and determine the \% moisture for the batch. 
COMPOUND DETERMINATION

\section{Objective}

The zinc ferrite solids, used in the pilot experiments, were produced in batches as outlined in Appendix V. Since one batch only provided enough solids for one pilot experiment, it was important to determine what solid compounds were present in each batch since it was difficult to prepare each batch in exactly the same way.

\section{Assumptions}

- $100 \mathrm{~g}$ Basis

- Assume: $100 \%$ of the $\mathrm{Zn}$ in the solids is present as $\mathrm{ZnO} \cdot \mathrm{Fe}_{2} \mathrm{O}_{3}$ $100 \%$ of the $\mathrm{Pb}$ in the solids is present as $\mathrm{PbSO}_{4}$

\section{TEST B : Zn Ferrite Batch \#2}

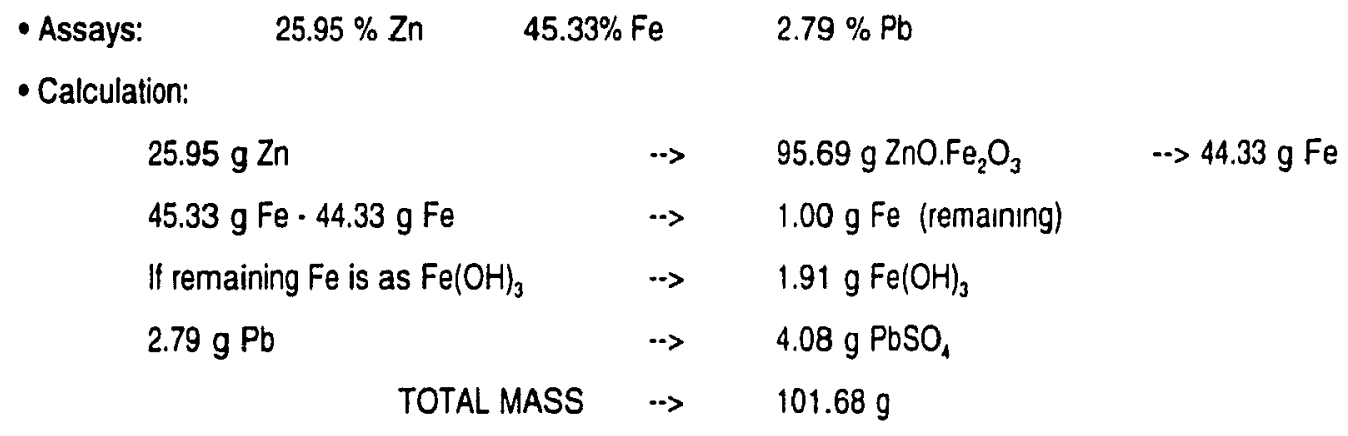

- Composition of Batch \#2:

$$
\begin{array}{cc}
94.1 \% \mathrm{ZnO}_{\mathrm{Fe}} \mathrm{O}_{3} & 4.0 \% \mathrm{PbSO}_{4} \\
1.9 \% \mathrm{Fe}(\mathrm{OH})_{3} & 0.0 \% \text { Other }
\end{array}
$$

\section{TEST C : Zn Ferrite Batch \#3}

- Assays: $\quad 24.97 \% \mathrm{Zn} \quad 45.12 \% \mathrm{Fe} \quad 2.37 \% \mathrm{~Pb}$

- Composition of Batch \#3:

$$
\begin{array}{ll}
91.9 \% \mathrm{ZnO} \mathrm{Fe}_{2} \mathrm{O}_{3} & 35 \% \mathrm{PbSO}_{4} \\
47 \% \mathrm{Fe}(\mathrm{OH})_{3} & 00 \% \text { Other }
\end{array}
$$




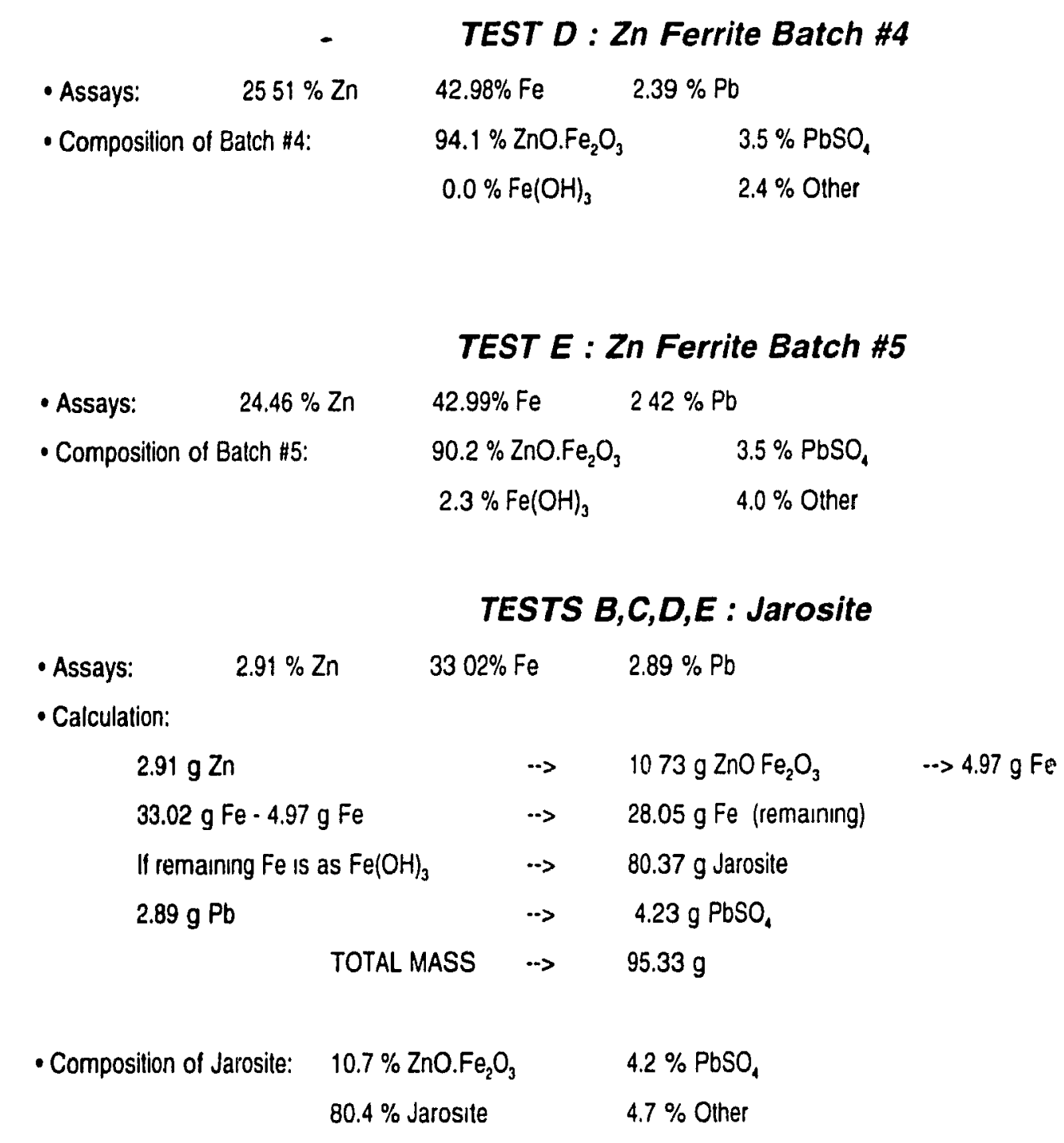

JAROSITE AND ZINC FERRITE PARTICLE SIZE DISTRIBUTIONS

Jarosite Particles

The particle analysis was carried out using a Microtrac instrument. From the figure below, we see that all of the jarosite particles are smaller than 15 microns and are larger than 0.12 microns. The majority of these particles range between 1 to 5 microns. 


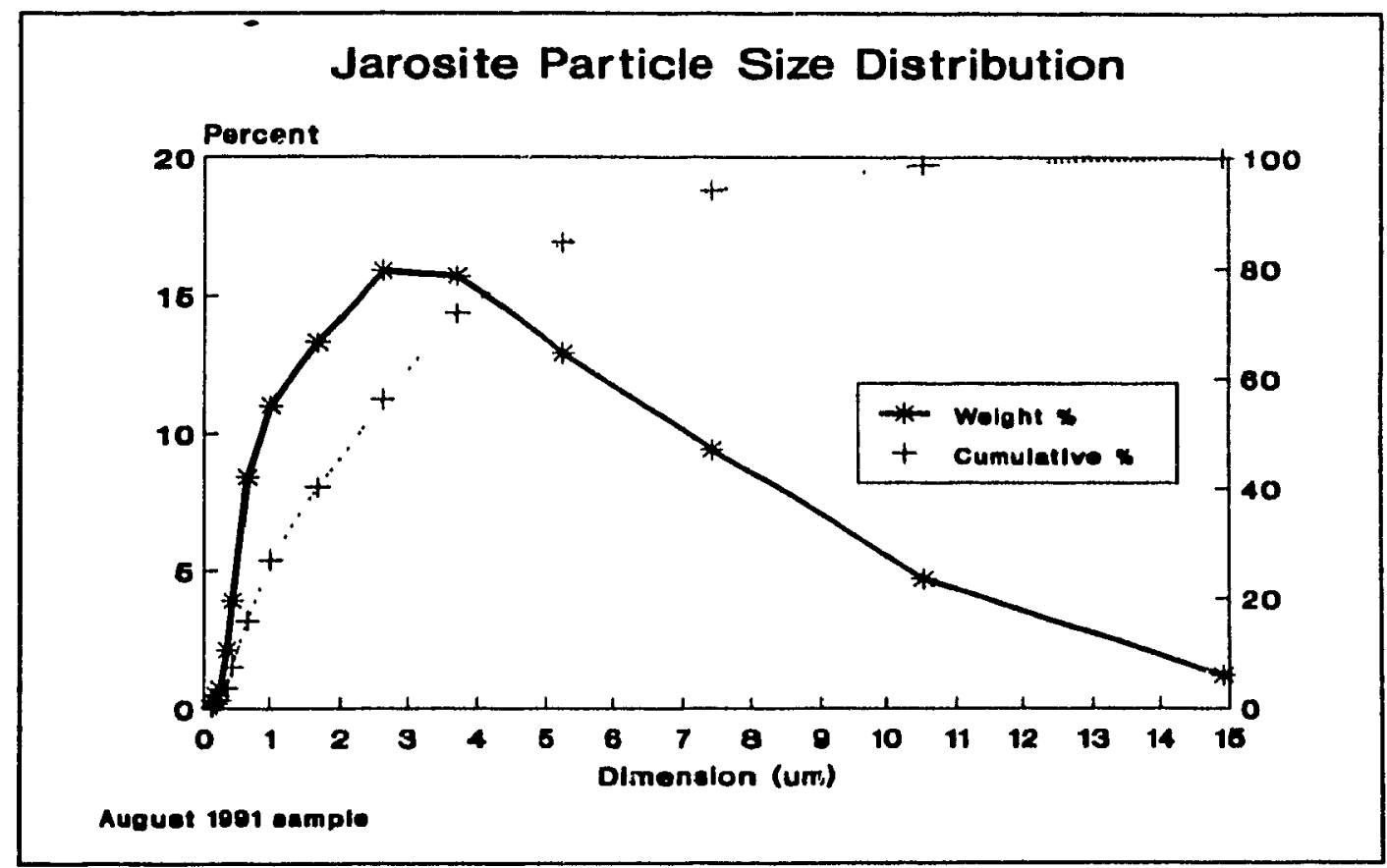

\section{Zinc Ferrite Particles}

It was attempted to determine the particle size distribution of the industrial zinc ferrite particles by wet sieve analysis. This analysis was inconclusive since over $86 \%$ of the particles were smaller than 25 microns (using a 500 mesh sieve). 


\section{APPENDIX V}

\section{ACID TITRATION METHOD}

\section{Preparaiion}

- $\quad$ Pipette $10 \mathrm{~mL}$ of filtrate into a $250 \mathrm{~mL}$ flask

- Add approximately $25 \mathrm{~mL}$ of distilled water and dissolve 2 grams of Potassium lodide crystals $(\mathrm{KI})$ into mixture (don't add too much).

- Add approximately $5 \mathrm{~mL}$ of $20 \%$ sodium thiosulphate $\left(\mathrm{Na}_{2} \mathrm{~S}_{2} \mathrm{O}_{3}\right)$. Stir. Add enough so that an additional drop does not result in a brown streak in the solution. The solution should be clear at this point. (Don't add too much sodium thiosulphate as end-point is difficult to detect)

- $\quad$ Add 2 drops of methylorange indicator $(0.2 \%)$. The solution should turn a red/pink colour.

- Titrate solution using a standardized $20 \%(21.6 \mathrm{~g} / \mathrm{L})$ Sodium Carbonate $\left(\mathrm{Na}_{2} \mathrm{CO}_{3}\right)$ solution until the yellow/orange end-point is reached.

- $\left[\mathrm{H}_{2} \mathrm{SO}_{4}\right] \mathrm{g} / \mathrm{L}=\mathrm{mL}$ of Titrant $\times$ FACTOR

Standardization of $\mathrm{Na}_{2} \mathrm{CO}_{3}$ Titrant with $\mathrm{HCl}$

Attempt to prepare a $0.204 \mathrm{~mol} / \mathrm{L} \mathrm{Na}_{2} \mathrm{CO}_{3}$ titrant $(\mathrm{MW}=105.99 \mathrm{~g} / \mathrm{mol}) \rightarrow>21.6 \mathrm{~g} / \mathrm{L}$

Add $10 \mathrm{~mL}$ of $0.1 \mathrm{~N} \mathrm{HCl}$ and titrate as described above.

Example calculation:

Titrant volume: $2.35,2.20,2.25-->2.26 \mathrm{~mL}$ average

$\left(\mathrm{mL} \mathrm{Na}_{2} \mathrm{CO}_{3}\right) \times\left(\mathrm{N} \mathrm{Na}_{2} \mathrm{CO}_{3}\right)=(\mathrm{mL} \mathrm{HCl}) \times(\mathrm{N} \mathrm{HCl})$

$\mathrm{N} \mathrm{Na} \mathrm{CO}_{3}=(10 \mathrm{~mL} * 0.1 \mathrm{~mol} / \mathrm{L}) / 2.26 \mathrm{~mL}=0.4412 \mathrm{~mol} / \mathrm{L}$

FACTOR $=0.4412 \mathrm{~mol} / \mathrm{L} / 0.204 \mathrm{~mol} / \mathrm{L}=2.16$ 


\section{- APPENDIX VI}

\section{TEST FOR COMPARING THE MEANS OF TWO VARIABLES}

Hypothesis: $\quad \mu_{A} \neq \mu_{B} \quad$ The ensemble mean (expected value) of $A$ is significantly different from the ensemble mean of $B$

Test:

$$
\left|X_{A}-X_{B}\right|>t_{1-\frac{a}{2}} s_{P} \sqrt{\frac{n_{A}+n_{B}}{n_{A} n_{B}}}
$$

If the difference between the sample means is greater than the right hand side of the inequality then the hypothesis is accepted.

Assumption: $\quad \sigma_{A} \cong \sigma_{B} \quad$ and these ensemble variances are both unknown

\section{Sample statistics}

Number of samples in A:

Variable $A$, sample i:

$$
\begin{aligned}
& n_{A} \\
& X_{A t}
\end{aligned}
$$

Sample Mean:

$$
X_{A}=\frac{1}{n_{A}} \sum_{i=1}^{n_{A}} X_{A}
$$

Sample Variance:

$$
s_{A}^{2}=\frac{1}{n_{A}-1} \sum_{i=1}^{n_{A}}\left(X_{A_{1}}-\bar{X}_{A}\right)^{2}
$$

Degrees of Freedom:

$$
v_{A}=n_{A}-1
$$

Pooled Sample Variance:

$$
s_{p}^{2}=\frac{v_{A} s_{A}^{2}+v_{B} s_{B}^{2}}{v_{A}+v_{B}}
$$




\section{Sample Calculation:}

TEST B, TANK 1: Iron Concentration Data

Initial steady-state:

A

Step change steady-state:

$B$

Final steady-state:

C

$$
\begin{array}{llll}
X_{A}=24.86 \mathrm{~g} / \mathrm{L} & n_{A}=5 & V_{A}=4 \\
X_{B}=27.55 \mathrm{~g} / \mathrm{L} & n_{B}=4 & V_{B}=3 \\
X_{C}=25.59 \mathrm{~g} / \mathrm{L} & n_{C}=4 & v_{C}=3 \\
S_{A}{ }^{2}=0.730 & S_{A}=0.850 & \\
S_{B}{ }^{2}=0.686 & S_{B}=0.828 & \\
S_{C}{ }^{2}=0.775 & S_{C}=0.880 &
\end{array}
$$

Hypothesis: $\mu_{A} \neq \mu_{B}$

at $95 \%$ Confidence:

$$
\begin{aligned}
& \alpha=0.05 \\
& v=7 \\
& t_{0975}=2.365
\end{aligned}
$$

$$
s_{p}=0.843
$$$$
n=0.450
$$

Left hand side of equation

$$
=X_{A}-X_{B}
$$$$
=2.69
$$

Right hand side of equation

$$
=\quad 2.365 \times 0.843 \times 0.45^{05}
$$$$
=1.34
$$

Since $2.69>1.34$ the hypothesis is satisfied

Therefore, the initial steady-state is significantly different from the step change steadystate (as expected)

Hypothesis: $\mu_{\mathrm{A}} \neq \mu_{\mathrm{C}}$ at $95 \%$ Confidence:

$$
\begin{aligned}
& \alpha=0.05 \\
& v=7 \\
& t_{0975}=2.365
\end{aligned}
$$

$$
s_{p}=0.866
$$$$
n=0.450
$$

Left hand side of equation

$$
\begin{aligned}
& =X_{A}-X_{C} \\
& =0.73 \\
& =2.365 \times 0.866 \times 0.45^{0.5}=1.37
\end{aligned}
$$

Right hand side of equation

Since $0.73<1.37$ the hypothesis is not satisfied

Therefore, the initial steady-state is not significantly different from the final steady-state (as expected) 


\section{- APPENDIX VII}

\section{CALCULATION OF THE IONIC STRENGTH}

The ionic strength of a solution is defined by the following equation:

$$
I=\frac{1}{2} \sum_{1} C_{i} Z_{1}^{2}
$$

where,

$$
c_{1}=\frac{m_{1}}{1} \quad\left(\frac{\text { mole, per } 1000 \mathrm{~g} \text { salt }}{\text { moles, per } 1000 \mathrm{~g} \text { solvent }}\right)
$$

Species: $\begin{array}{lllll}\mathrm{ZnSO}_{4} & \mathrm{H}_{2} \mathrm{SO}_{4} & \mathrm{Fe}_{2}\left(\mathrm{SO}_{4}\right)_{3} & \mathrm{CuSO}_{4}\end{array}$ $(\mathrm{NH})_{4} \mathrm{SO}_{4} \quad \mathrm{MgSO}_{4} \quad \mathrm{MgSO}_{4}$

lons: $\quad \mathrm{Zn}^{2+} \mathrm{H}^{+} \mathrm{Fe}^{3+} \mathrm{Cu}^{2+} \mathrm{Mn}^{2+} \mathrm{Mg}^{2+} \mathrm{NH}^{+} \mathrm{SO}^{2-}$

\begin{tabular}{|c|c|c|c|c|c|}
\hline & \multicolumn{2}{|c|}{ IONS } & & \multirow[b]{2}{*}{$\underline{Z}^{2}$} \\
\hline & $(g / L)$ & $(\mathrm{mol} / \mathrm{L})$ & $(\mathrm{mol} / \mathrm{L})$ & $\underline{Z}$ & \\
\hline $\mathrm{H}^{+}$ & 1.01 & 1.00 & 0.50 & 1 & 1 \\
\hline $\mathrm{Zn}^{2+}$ & 89.0 & 1.36 & 1.36 & 2 & 4 \\
\hline $\mathrm{Fe}^{3+}$ & 25.0 & 0.45 & 0.68 & 3 & 9 \\
\hline $\mathrm{Cu}^{2+}$ & 1.5 & 0.02 & 0.02 & 2 & 4 \\
\hline $\mathrm{NH}_{4}{ }^{+}$ & 4.0 & 0.22 & 0.11 & 1 & 1 \\
\hline $\mathrm{Mg}^{2+}$ & 6.0 & 0.25 & 0.25 & 2 & 4 \\
\hline \multirow[t]{2}{*}{$\mathrm{Mn}^{2+}$} & 8.0 & 0.15 & 0.15 & 2 & 4 \\
\hline & & $\mathrm{L} \mathrm{SO}_{4}{ }^{2 \cdot}=$ & 3.07 & -2 & 4 \\
\hline
\end{tabular}

Assuming: $\left[\mathrm{H}_{2} \mathrm{SO}_{4}\right]=49 \mathrm{~g} / \mathrm{L} \quad-->\quad\left[\mathrm{H}^{+}\right]=1.01 \mathrm{~g} / \mathrm{L}$

Using above equation: $\quad \because I=12.3$ 


\section{- APPENDIX VIII}

TANK 1 ASSAYS: TESTS B, C, D and E

TEST B

\begin{tabular}{|c|c|c|c|c|c|c|c|c|c|}
\hline \multirow{2}{*}{$\begin{array}{l}\text { TIME } \\
\text { (min) }\end{array}$} & \multicolumn{5}{|c|}{ FILTRATE } & \multicolumn{4}{|c|}{ SOLIDS } \\
\hline & $\begin{array}{c}\mathrm{H} 2 \mathrm{SO}_{4} \\
(\mathrm{~g} \Omega)\end{array}$ & $\begin{array}{l}\text { FeT } \\
\text { (gLL) }\end{array}$ & $\begin{array}{c}2 n \\
(g /)\end{array}$ & $\begin{array}{c}\mathrm{Cu} \\
(\mathrm{g} /)\end{array}$ & $\begin{array}{c}\mathrm{Pb} \\
(\mathrm{mg} / \mathrm{L})\end{array}$ & $\begin{array}{c}\mathrm{FeT} \\
\% \\
\end{array}$ & $\begin{array}{l}\mathrm{Zn} \\
\% \\
\end{array}$ & $\begin{array}{l}\mathrm{Cu} \\
\% \\
\end{array}$ & $\begin{array}{l}\mathrm{Pb} \\
\% \\
\end{array}$ \\
\hline \multicolumn{10}{|c|}{ Initial Steady State } \\
\hline 0 & 49.3 & 26.19 & 93.46 & 088 & 1.00 & 3354 & 925 & 0.16 & 332 \\
\hline 10 & 49.5 & 24.78 & 89.37 & 0.84 & 100 & 32.84 & 9.11 & 0.13 & 3.28 \\
\hline 38 & 48.1 & 24.47 & 86.90 & 081 & 100 & 32.69 & 9.01 & 0.12 & 3.26 \\
\hline 107 & 48.5 & 23.87 & 84.23 & 080 & 100 & 3239 & 8.93 & 0.12 & 3.21 \\
\hline 140 & 48.8 & 24.97 & 90.91 & 0.85 & 1.00 & 32.13 & 8.78 & 0.10 & 3.19 \\
\hline AVERAGE & 48.8 & 24.86 & 88.97 & 0.84 & 1.00 & 32.72 & 9.02 & 0.12 & 3.25 \\
\hline STO & 0.6 & 0.85 & 3.57 & 0.03 & 000 & 0.54 & 0.18 & 0.02 & 0.05 \\
\hline$\%$ STD & 1.2 & 3.4 & 4.0 & 3.8 & 0.0 & 1.6 & 1.9 & 17.2 & 1.6 \\
\hline \multicolumn{10}{|l|}{ Transient } \\
\hline 148 & 49.3 & 23.92 & 86.58 & 0.80 & 100 & 31.96 & 8.84 & 0.11 & 3.23 \\
\hline 156 & 45.4 & 21.53 & 74.52 & 069 & 100 & 31.74 & 8.79 & 0.11 & 324 \\
\hline 167 & 53.5 & 24.03 & 85.17 & 079 & 1.00 & 31.34 & 8.62 & 0.10 & 322 \\
\hline 178 & 53.5 & 23.77 & 83.43 & 079 & 100 & 3157 & 854 & 0.10 & 323 \\
\hline 197 & 52.8 & 23.43 & 80.68 & 0.77 & 100 & 31.01 & 8.44 & 0.10 & 326 \\
\hline 215 & 52.2 & 24.51 & 82.34 & 0.80 & 1.00 & 30.71 & 8.22 & 0.09 & 3.2 .1 \\
\hline 247 & 56.5 & 26.65 & 87.28 & 0.84 & 100 & 30.52 & 7.97 & 0.09 & 3.24 \\
\hline \multicolumn{10}{|c|}{ Step Change Steady Stale } \\
\hline 305 & 59.2 & 26.68 & 86.33 & 0.84 & 100 & 30.70 & 7.85 & 0.09 & 3.27 \\
\hline 388 & 57.9 & 27.23 & 87.66 & 084 & 100 & 30.25 & 7.72 & 009 & 3.25 \\
\hline 476 & 62.3 & 28.64 & 90.86 & 0.88 & 100 & 30.18 & 7.36 & 0.08 & 328 \\
\hline 561 & 60.1 & 27.65 & 86.88 & 086 & 100 & 30.00 & 7.31 & 008 & 3.21 \\
\hline AVERAGE & 59.9 & 27.55 & 87.93 & 0.86 & 100 & 30.28 & 7.56 & 0.08 & 3.26 \\
\hline STD & 1.9 & 0.83 & 2.03 & 002 & 000 & 0.30 & 0.27 & 001 & 0.03 \\
\hline$\%$ STD & 3.1 & 3.0 & 2.3 & 22 & 00 & 1.0 & 3.5 & 9.3 & 0.9 \\
\hline \multicolumn{10}{|l|}{ Transient } \\
\hline 570 & 53.2 & 24.47 & 78.34 & 0.77 & 100 & 30.33 & 7.42 & 0.08 & 3.23 \\
\hline 580 & 55.9 & 26.52 & 85.10 & 083 & 100 & 30.33 & 7.52 & 0.08 & 3.23 \\
\hline 590 & 53.4 & 25.84 & 84.53 & 0.80 & 100 & 29.81 & 740 & 0.08 & 3.20 \\
\hline 600 & 51.5 & 24.53 & 81.52 & 078 & 100 & 35.19 & 8.18 & 0.28 & 3.62 \\
\hline 611 & 53.4 & 26.36 & 88.60 & 083 & 100 & 35.19 & 8.15 & 0.19 & 350 \\
\hline \multicolumn{10}{|c|}{ Final Steady State } \\
\hline 623 & 51.7 & 25.79 & 85.14 & 081 & 100 & 35.21 & 820 & 0.16 & 3.44 \\
\hline 662 & 52.5 & 26.73 & 90.87 & 084 & 100 & 3487 & 8.18 & 0.15 & 3.38 \\
\hline 718 & 52.1 & 25.13 & 85.83 & 080 & 100 & 35.65 & 8.21 & 0.14 & 3.38 \\
\hline 779 & 50.7 & 24.71 & $\therefore 85.32$ & 079 & 100 & 35.22 & 7.84 & 0.14 & 334 \\
\hline AVERAGE & 51.8 & 25.59 & 86.79 & 081 & 100 & 3524 & 8.11 & 015 & 3.38 \\
\hline STD & 0.8 & 0.88 & 2.74 & 002 & 200 & 032 & 0.18 & 0.01 & 0.04 \\
\hline$\%$ STD & 1.5 & 3.4 & 3.2 & 27 & 00 & 0.9 & 2.2 & 5.8 & 12 \\
\hline
\end{tabular}


TEST C

\begin{tabular}{|c|c|c|c|c|c|c|c|c|c|}
\hline \multirow{2}{*}{$\begin{array}{l}\text { TIME } \\
\text { (min) }\end{array}$} & \multicolumn{5}{|c|}{ FILTRATE } & \multicolumn{4}{|c|}{ SOLIDS } \\
\hline & $\begin{array}{c}\mathrm{H}_{2 S O 4} \\
(\mathrm{~g} / \mathrm{LT}\end{array}$ & $\begin{array}{c}\text { FeT } \\
(g / L)\end{array}$ & $\begin{array}{c}\mathrm{Zn} \\
(\mathrm{g} / \mathrm{L})\end{array}$ & $\begin{array}{c}\mathrm{Cu} \\
(\mathrm{g} / \mathrm{L})\end{array}$ & $\begin{array}{c}\mathrm{Pb} \\
(\mathrm{mg} / \mathrm{L})\end{array}$ & $\begin{array}{c}\mathrm{FeT} \\
\%\end{array}$ & $\begin{array}{l}\mathrm{Zn} \\
\%\end{array}$ & $\begin{array}{l}\mathrm{Cu} \\
\%\end{array}$ & $\begin{array}{l}\mathrm{Pb} \\
\%\end{array}$ \\
\hline
\end{tabular}

Initial Steady State

\begin{tabular}{|c|c|c|c|c|c|c|c|c|c|}
\hline 0 & 46.6 & 26.31 & 86.82 & 0.90 & 1.00 & 35.92 & 8.91 & 028 & 3.32 \\
\hline 28 & & 23.07 & 75.97 & 0.78 & 1.00 & 35.02 & 9.05 & 0.19 & 3.28 \\
\hline 95 & 46.4 & 24.25 & 80.99 & 083 & 1.00 & 36.00 & 890 & 0.22 & 3.26 \\
\hline AVERAGE & 46.5 & 2454 & 8126 & 0.84 & 100 & 35.6 & 90 & 0.2 & 3.3 \\
\hline STD & 0.1 & 1.6 & 54 & 0.1 & 0.0 & 05 & 01 & 0.0 & 0.0 \\
\hline$\%$ STD & 0.3 & 6.7 & 67 & 7.1 & 0.0 & 15 & 09 & 190 & 10 \\
\hline
\end{tabular}

Transient

\begin{tabular}{|c|c|c|c|c|c|c|c|c|c||}
\hline 114 & 47.5 & 25.18 & 83.79 & 086 & 1.00 & 3547 & 893 & 0.21 & 321 \\
\hline 124 & 47.1 & 24.71 & 82.54 & 0.85 & 1.00 & 35.78 & 8.57 & 020 & 323 \\
\hline 134 & & 24.16 & 81.23 & 084 & 100 & 35.76 & 8.34 & 0.20 & 324 \\
\hline 144 & 46.1 & 22.55 & 78.33 & 0.82 & 1.00 & 35.68 & 8.16 & 0.20 & 3.23 \\
\hline 158 & & 22.89 & 81.24 & 0.85 & 1.00 & 35.26 & 7.99 & 0.20 & 3.17 \\
\hline 168 & 47.0 & 22.88 & 82.11 & 087 & 100 & 35.05 & 7.85 & 0.19 & 319 \\
\hline 181 & & 21.80 & 8069 & 0.85 & 100 & 35.45 & 7.77 & 019 & 320 \\
\hline 205 & 47.6 & 21.63 & 79.86 & 085 & 100 & 35.54 & 7.65 & 0.19 & 3.15 \\
\hline 235 & & 21.53 & 81.36 & 0.87 & 100 & 35.12 & 7.52 & 019 & 3.14 \\
\hline
\end{tabular}

Step Change Steady State

\begin{tabular}{||c|c|c|c|c|c|c|c|c|c||}
\hline 296 & 46.6 & 20.40 & 76.48 & 0.82 & 100 & 35.22 & 7.37 & 0.19 & 3.13 \\
\hline 364 & & 20.63 & 78.55 & 084 & 100 & 3584 & 735 & 0.18 & 316 \\
\hline 421 & 47.1 & 20.46 & 78.18 & 0.84 & 104 & 35.16 & 7.32 & 0.18 & 3.10 \\
\hline 480 & & 20.30 & 76.02 & 0.82 & 100 & 35.36 & 7.31 & 0.18 & 3.13 \\
\hline AVERAGE & 46.9 & 20.45 & 77.31 & 0.83 & 101 & 35.39 & 7.34 & 0.19 & 3.13 \\
\hline STD & 0.4 & 0.14 & 125 & 002 & 002 & 0.31 & 0.03 & 0.00 & 0.03 \\
\hline$\%$ STD & 0.8 & 0.7 & 1.6 & 18 & 2.2 & 0.9 & 0.4 & 14 & 0.8 \\
\hline
\end{tabular}

Transient

Transient
\begin{tabular}{||c|c|c|c|c|c|c|c|c|c||}
\hline 549 & 48.5 & 22.65 & 81.11 & 0.86 & 100 & 35.54 & 7.48 & 0.19 & 3.18 \\
\hline 558 & & 22.19 & 79.32 & 083 & 100 & 35.38 & 7.71 & 019 & 3.17 \\
\hline 569 & 47.1 & 22.17 & 76.80 & 0.80 & 100 & 35.87 & 7.88 & 0.19 & 320 \\
\hline 578 & & 23.53 & 80.24 & 084 & 100 & 3548 & 790 & 0.21 & 3.23 \\
\hline 588 & 47.8 & 24.05 & 85.91 & 0.89 & 100 & 35.44 & 8.00 & 020 & 323 \\
\hline 604 & & 2422 & 85.99 & 089 & 100 & 35.95 & 823 & 0.20 & 3.28 \\
\hline 622 & 47.0 & 24.12 & 84.25 & 0.87 & 100 & 35.28 & 8.16 & 0.19 & 325 \\
\hline 632 & & 23.93 & 82.03 & 084 & 100 & 35.54 & 8.31 & 0.20 & 3.30 \\
\hline 640 & 46.8 & 24.85 & 84.51 & 087 & 100 & 35.64 & 8.32 & 0.20 & 331 \\
\hline 661 & & 25.01 & 84.23 & 086 & 100 & 36.07 & 8.52 & 020 & 332 \\
\hline 667 & 46.1 & 25.31 & 83.22 & 085 & 100 & 3630 & 886 & 021 & 341 \\
\hline
\end{tabular}

Final Steady State

\begin{tabular}{||c|c|c|c|c|c|c|c|c|c||}
\hline 781 & & 27.63 & 90.42 & 092 & 100 & 36.54 & 9.12 & 021 & 340 \\
\hline 842 & 48.0 & 27.57 & 91.36 & 093 & 100 & 3691 & 9.30 & 021 & 344 \\
\hline 902 & & 27.30 & 91.91 & 094 & 100 & 36.76 & 8.85 & 0.21 & 3.41 \\
\hline AVERAGE & 48.0 & 27.5 & 91.23 & 093 & 100 & 36.7 & 9.1 & 0.2 & 3.4 \\
\hline STD & & 0.2 & .0 .8 & 00 & 00 & 02 & 0.2 & 0.0 & 0.0 \\
\hline$\%$ STD & & 0.6 & 0.8 & 13 & 00 & 05 & 2.5 & 15 & 0.7 \\
\hline
\end{tabular}


TESTD

\begin{tabular}{|c|c|c|c|c|c|c|c|c|c|}
\hline \multirow{2}{*}{$\begin{array}{l}\text { TIME } \\
\text { (min) }\end{array}$} & \multicolumn{5}{|c|}{ FILTRATE } & \multicolumn{4}{|c|}{ SOLIDS } \\
\hline & $\begin{array}{c}\mathrm{H} 2 \mathrm{SO} 4 \\
(\mathrm{~g} L)\end{array}$ & $\begin{array}{l}\mathrm{F}_{\Theta} \mathrm{T} \\
(\mathrm{g} L)\end{array}$ & $\begin{array}{c}\mathrm{Zn} \\
(\mathrm{g} /)\end{array}$ & $\begin{array}{c}\mathrm{Cu} \\
(\mathrm{g} / \mathrm{L})\end{array}$ & $\begin{array}{c}\mathrm{Pb} \\
(\mathrm{mg} / \mathrm{L})\end{array}$ & $\begin{array}{c}\mathrm{FeT} \\
\%\end{array}$ & $\begin{array}{l}\mathrm{Zn} \\
\%\end{array}$ & $\begin{array}{l}\mathrm{Cu} \\
\%\end{array}$ & $\begin{array}{l}\mathrm{Pb} \\
\%\end{array}$ \\
\hline \multicolumn{10}{|c|}{ nitial Steady State } \\
\hline 7 & 43.6 & & 92.34 & 093 & 1.00 & 35.92 & 9.26 & 0.24 & 3.27 \\
\hline 51 & 41.4 & 36.06 & 85.35 & 0.85 & 1.00 & 36.06 & 9.19 & 0.23 & 3.30 \\
\hline 74 & 46.3 & 35.35 & 90.49 & 0.89 & 1.00 & 35.35 & 9.24 & 0.22 & 3.24 \\
\hline AVERAGE & 43.8 & 35.70 & 89.39 & 0.89 & 100 & 35.78 & 9.23 & 0.23 & 3.27 \\
\hline STD & 2.5 & 0.5 & 3.6 & 0.0 & 0.0 & 0.4 & 0.0 & 0.0 & 0.0 \\
\hline$\%$ STD & 5.6 & 1.4 & 4.0 & 4.6 & 0.0 & 1.1 & 0.4 & 4.7 & 1.0 \\
\hline \multicolumn{10}{|l|}{ Transient } \\
\hline 98 & 43.4 & 35.88 & 84.25 & 0.83 & 1.00 & 35.88 & 910 & 0.21 & 3.30 \\
\hline 118 & 51.1 & 36.00 & 87.66 & 0.83 & 1.00 & 36.00 & 9.09 & 0.21 & 3.32 \\
\hline 138 & 54.3 & 35.67 & 86.78 & 0.81 & 1.00 & 35.67 & 8.92 & 021 & 3.35 \\
\hline 158 & 57.5 & 35.40 & 87.56 & 0.80 & 100 & 35.40 & 8.77 & 021 & 3.36 \\
\hline 188 & 58.3 & 35.13 & 85.28 & 0.77 & 100 & 35.13 & 8.71 & 0.21 & 3.37 \\
\hline 238 & 57.1 & 35.33 & 82.29 & 073 & 100 & 35.33 & 8.60 & 0.20 & 3.40 \\
\hline \multicolumn{10}{|c|}{ Step Change Steady State } \\
\hline 320 & 63.1 & 35.58 & 87.67 & 0.77 & 100 & 35.58 & 8.48 & 0.20 & 3.42 \\
\hline 419 & 65.6 & 34.96 & 89.21 & 0.78 & 1.00 & 34.96 & 8.21 & 0.20 & 3.43 \\
\hline 496 & 59.7 & 35.42 & 83.16 & 073 & 1.00 & 35.42 & 8.46 & 0.20 & 3.41 \\
\hline AVERAGE & 62.8 & 35.32 & 86.68 & 0.76 & 1.00 & 35.32 & 8.38 & 0.20 & 3.42 \\
\hline STD & 3.0 & 0.3 & 3.1 & 0.0 & 0.0 & 0.3 & 0.2 & 00 & 0.0 \\
\hline$\%$ STD & 4.7 & 0.9 & 3.6 & 40 & 0.0 & 0.9 & 1.8 & 1.2 & 0.4 \\
\hline
\end{tabular}

Transient

\begin{tabular}{|l|l|l|l|l|l||l|l|l|l|}
\hline 517 & 63.1 & 35.23 & 88.01 & 0.77 & 2.11 & 35.23 & 8.42 & 0.20 & 3.42 \\
\hline 520 & 62.7 & 34.94 & 85.95 & 0.75 & 1.00 & 34.94 & 8.37 & 0.20 & 3.42 \\
\hline 530 & 57.9 & 34.72 & 84.44 & 0.74 & 149 & 34.72 & 8.33 & 0.20 & 3.40 \\
\hline 539 & 58.7 & 33.93 & 89.21 & 079 & 1.00 & 33.93 & 8.28 & 0.20 & 3.39 \\
\hline 550 & 55.5 & 34.43 & 87.59 & 0.78 & 1.00 & 34.43 & 8.36 & 0.20 & 3.41 \\
\hline 560 & 51.5 & 34.21 & 82.63 & 074 & 242 & 34.21 & 8.35 & 0.20 & 3.40 \\
\hline 570 & 53.1 & 34.26 & 86.29 & 0.78 & 1.00 & 34.26 & 8.36 & 0.20 & 3.41 \\
\hline 582 & 52.1 & 34.15 & 87.11 & 079 & 1.00 & 34.15 & 8.37 & 0.21 & 3.40 \\
\hline
\end{tabular}

Final Steady State

\begin{tabular}{|c|c|c|c|c|c|c|c|c|c|}
\hline 620 & 515 & 34.63 & 85.36 & 083 & 100 & 34.63 & 8.68 & 0.21 & 3.40 \\
\hline 643 & 50.7 & 34.35 & 87.92 & 086 & 100 & 34.35 & 8.67 & 0.20 & 3.40 \\
\hline 740 & 48.3 & 34.50 & 86.55 & 085 & 100 & 34.50 & 8.87 & 0.21 & 3.42 \\
\hline 845 & 50.3 & 34.78 & 89.20 & 089 & 100 & 34.78 & 8.69 & 0.20 & 3.39 \\
\hline 913 & 50.3 & 34.26 & 90.04 & 090 & 100 & 34.26 & 8.55 & 0.21 & 3.37 \\
\hline AVERAGE & 50.2 & 34.50 & 87.81 & 087 & 100 & 3450 & 8.69 & 0.21 & 3.40 \\
\hline STD & 1.2 & 0.2 & 1.9 & 00 & 00 & 0.2 & 0.1 & 0.0 & 0.0 \\
\hline \% STD & 2.3 & 0.6 & 2.2 & 3.3 & 0.0 & 0.6 & 1.3 & 1.0 & 0.5 \\
\hline
\end{tabular}


TEST E

\begin{tabular}{|c|c|c|c|c|c|c|c|c|c|}
\hline \multirow{2}{*}{$\begin{array}{l}\text { TIME } \\
\text { (min) }\end{array}$} & \multicolumn{5}{|c|}{ FILTRATE } & \multicolumn{4}{|c|}{ SOLIDS } \\
\hline & $\begin{array}{l}\mathrm{H} 2 \mathrm{SO}_{4} \\
(\mathrm{~g} / \mathrm{)})\end{array}$ & $\begin{array}{l}\mathrm{FeT} \\
(g / L)\end{array}$ & $\begin{array}{c}\mathrm{Zn} \\
(\mathrm{g} /)\end{array}$ & $\begin{array}{c}\mathrm{Cu} \\
(\mathrm{g} / \mathrm{L})\end{array}$ & $\begin{array}{c}\mathrm{Pb} \\
(\mathrm{mg} / \mathrm{L})\end{array}$ & $\begin{array}{l}\mathrm{FeT} \\
\%\end{array}$ & $\begin{array}{l}\mathrm{Zn} \\
\%\end{array}$ & $\begin{array}{l}\mathrm{Cu} \\
\%\end{array}$ & $\begin{array}{l}\mathrm{Pb} \\
\%\end{array}$ \\
\hline \multicolumn{10}{|c|}{ Initial Steady State } \\
\hline 22 & 50.0 & 24.58 & 87.24 & 0.86 & 1.00 & 35.45 & 8.55 & 031 & 3.15 \\
\hline 43 & 48.0 & 23.51 & 83.32 & 0.82 & 1.07 & 35.33 & 8.70 & 0.31 & 3.15 \\
\hline 73 & 45.9 & 22.81 & 80.68 & 079 & 1.00 & 35.32 & 8.46 & 0.31 & 3.16 \\
\hline AVERAGB & 48.0 & 23.64 & 83.75 & 082 & 1.02 & 3537 & 8.57 & 0.31 & 3.15 \\
\hline STD & 2.1 & 0.9 & 3.3 & 0.0 & 0.0 & 0.07 & 0.12 & 0.00 & 0.01 \\
\hline$\%$ STD & 4.3 & 3.8 & 3.9 & 4.2 & 4.1 & 02 & 1.4 & 0.0 & 02 \\
\hline \multicolumn{10}{|l|}{ Transient } \\
\hline 115 & 47.3 & 23.00 & 80.92 & 0.80 & 1.00 & 33.12 & 8.77 & 0.22 & 3.26 \\
\hline 125 & 46.5 & 21.99 & 78.81 & 0.77 & 1.84 & 33.41 & 9.10 & 0.22 & 3.25 \\
\hline 135 & 46.5 & 23.10 & 82.48 & 0.81 & 1.10 & 33.42 & 9.32 & 0.22 & 3.22 \\
\hline 155 & 41.9 & 21.30 & 76.80 & 0.75 & 1.00 & 33.63 & 9.59 & 0.23 & 3.22 \\
\hline 175 & 47.5 & 24.68 & 88.87 & 0.88 & 1.00 & 33.33 & 9.76 & 0.23 & 3.22 \\
\hline 207 & 44.6 & 23.35 & 8447 & 084 & 1.00 & 3346 & 10.02 & 023 & 3.19 \\
\hline \multicolumn{10}{|c|}{ Step Change Steady State } \\
\hline 324 & 42.5 & 23.72 & 85.97 & 0.85 & 1.00 & 33.66 & 10.07 & 0.24 & 3.19 \\
\hline 363 & & 25.41 & 91.74 & 0.91 & 1.00 & 33.97 & 10.34 & 0.24 & 3.24 \\
\hline 428 & 43.2 & 24.71 & 88.88 & 0.88 & 1.00 & 33.83 & 10.46 & 024 & 3.20 \\
\hline 453 & & 23.94 & 87.52 & 0.87 & 1.00 & 33.72 & 10.51 & 0.24 & 3.18 \\
\hline AVERAGE & 42.9 & 24.44 & 8853 & 0.88 & 1.00 & 33.8 & 10.3 & 0.2 & 3.2 \\
\hline STD & 0.5 & 0.8 & 2.4 & 0.0 & 0.0 & 0.1 & 0.2 & 0.0 & 0.0 \\
\hline$\%$ STD & 1.2 & 3.2 & 2.8 & 2.8 & 0.0 & 0.4 & 1.9 & 1.6 & 0.8 \\
\hline \multicolumn{10}{|l|}{ Transient } \\
\hline 536 & 43.6 & 25.42 & 91.50 & 0.91 & 1.00 & 3354 & 10.50 & 0.25 & 3.18 \\
\hline 545 & & 25.72 & 9030 & 090 & 1.00 & 34.40 & 10.49 & 0.24 & 3.24 \\
\hline 556 & 45.8 & 25.63 & 90.21 & 090 & 1.00 & 3390 & 10.16 & 0.23 & 321 \\
\hline 576 & & 24.82 & 85.38 & 0.85 & 1.00 & 33.34 & 9.68 & 023 & 3.24 \\
\hline 597 & 46.4 & 25.57 & 87.25 & 087 & 1.00 & 33.34 & 929 & 0.22 & 3.30 \\
\hline 629 & & 23.75 & 82.07 & 0.81 & 1.00 & 33.16 & 8.86 & 0.22 & 3.30 \\
\hline 675 & 48.9 & 24.08 & 82.73 & 082 & 1.94 & 32.77 & 8.36 & 0.21 & 3.31 \\
\hline \multicolumn{10}{|c|}{ Final Steady State } \\
\hline 751 & & 26.04 & 9143 & 0.90 & 1.00 & 32.70 & 8.27 & 0.20 & 3.36 \\
\hline 800 & 53.7 & 25.33 & 88.68 & 0.88 & 1.00 & 32.76 & 8.15 & 0.20 & 3.33 \\
\hline 862 & & 25.79 & 88.78 & 0.88 & 1.00 & 32.90 & 8.14 & 0.20 & $3.3 \%$ \\
\hline 922 & 52.7 & 25.15 & 8636 & 085 & 1.00 & 32.71 & 8.14 & 0.20 & 3.34 \\
\hline AVERAGE & 53.2 & 25.58 & 88.81 & 088 & 1.60 & 32.8 & 8.2 & 0.2 & 3.3 \\
\hline STD & 0.7 & 0.4 & 2.1 & 0.0 & 00 & 0.1 & 0.1 & 0.0 & 0.0 \\
\hline$\%$ STD & 1.3 & 1.6 & 2.3 & 2.3 & 0.0 & 0.3 & 0.8 & 0.8 & 0.5 \\
\hline
\end{tabular}

